\title{
Database on Performance of Neutron Irradiated FeCrAl Alloys
}

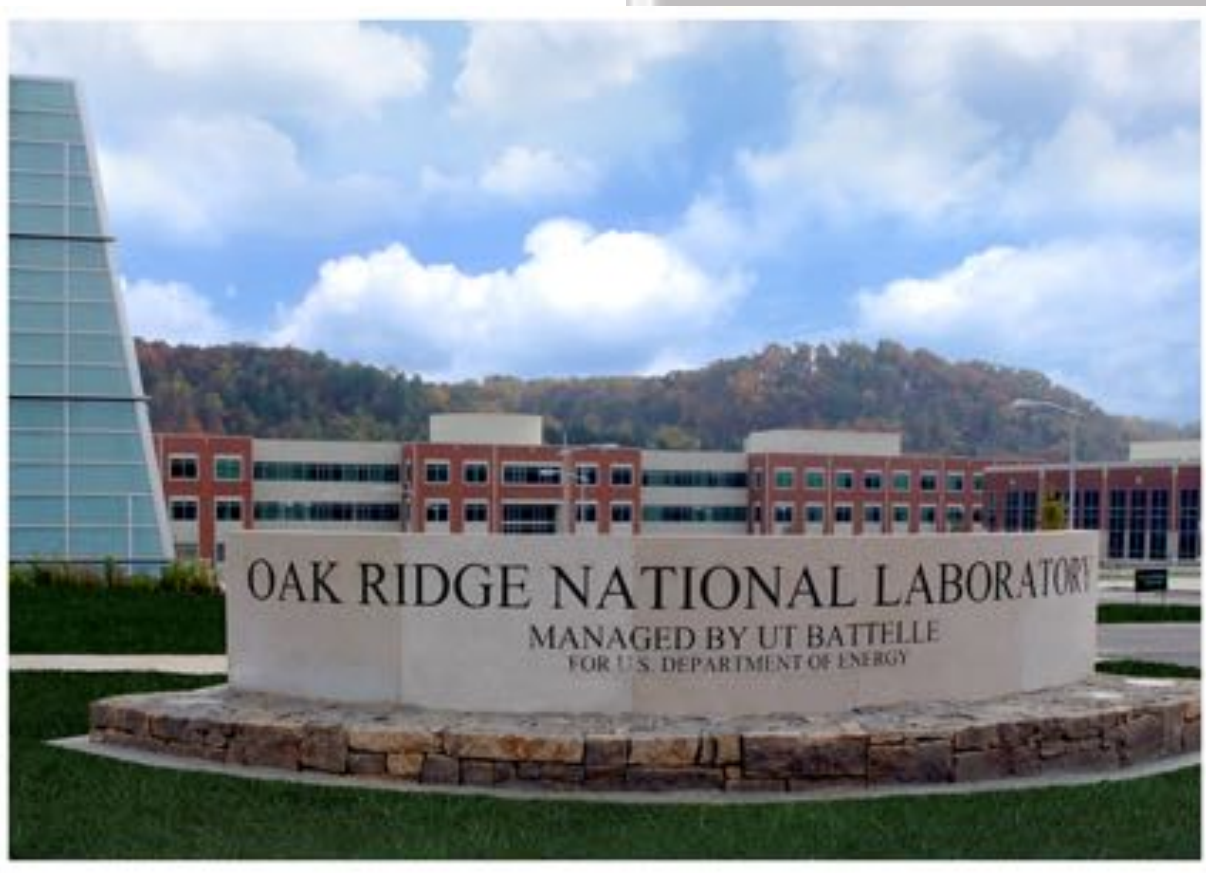

Approved for public release. Distribution is unlimited.
Kevin G. Field Samuel A. Briggs Philip D. Edmondson Jack C. Haley Richard H. Howard Xunxiang $\mathrm{Hu}$ Kenneth C. Littrell Chad M. Parish Yukinori Yamamoto

July 29, 2016 


\section{DOCUMENT AVAILABILITY}

Reports produced after January 1, 1996, are generally available free via US Department of Energy (DOE) SciTech Connect.

Website http://www.osti.gov/scitech/

Reports produced before January 1, 1996, may be purchased by members of the public from the following source:

National Technical Information Service

5285 Port Royal Road

Springfield, VA 22161

Telephone 703-605-6000 (1-800-553-6847)

TDD 703-487-4639

Fax 703-605-6900

E-mail info@ntis.gov

Website http://www.ntis.gov/help/ordermethods.aspx

Reports are available to DOE employees, DOE contractors, Energy Technology Data Exchange representatives, and International Nuclear Information System representatives from the following source:

Office of Scientific and Technical Information

PO Box 62

Oak Ridge, TN 37831

Telephone 865-576-8401

Fax 865-576-5728

E-mail reports@osti.gov

Website http://www.osti.gov/contact.html

This report was prepared as an account of work sponsored by an agency of the United States Government. Neither the United States Government nor any agency thereof, nor any of their employees, makes any warranty, express or implied, or assumes any legal liability or responsibility for the accuracy, completeness, or usefulness of any information, apparatus, product, or process disclosed, or represents that its use would not infringe privately owned rights. Reference herein to any specific commercial product, process, or service by trade name, trademark, manufacturer, or otherwise, does not necessarily constitute or imply its endorsement, recommendation, or favoring by the United States Government or any agency thereof. The views and opinions of authors expressed herein do not necessarily state or reflect those of the United States Government or any agency thereof. 
Fuel Cycle Research and Development (FCRD)

\section{Database on Performance of Neutron Irradiated FeCrAl Alloys}

Kevin G. Field, Samuel A. Briggs, Philip D. Edmondson, Jack C. Haley, Richard H. Howard, Xunxiang Hu, Kenneth C. Littrell, Chad M. Parish, and Yukinori Yamamoto

Date Published: July 29, 2016

Prepared by

OAK RIDGE NATIONAL LABORATORY

Oak Ridge, TN 37831-6283

managed by

UT-BATTELLE, LLC

for the

US DEPARTMENT OF ENERGY

under contract DE-AC05-00OR22725 



\section{CONTENTS}

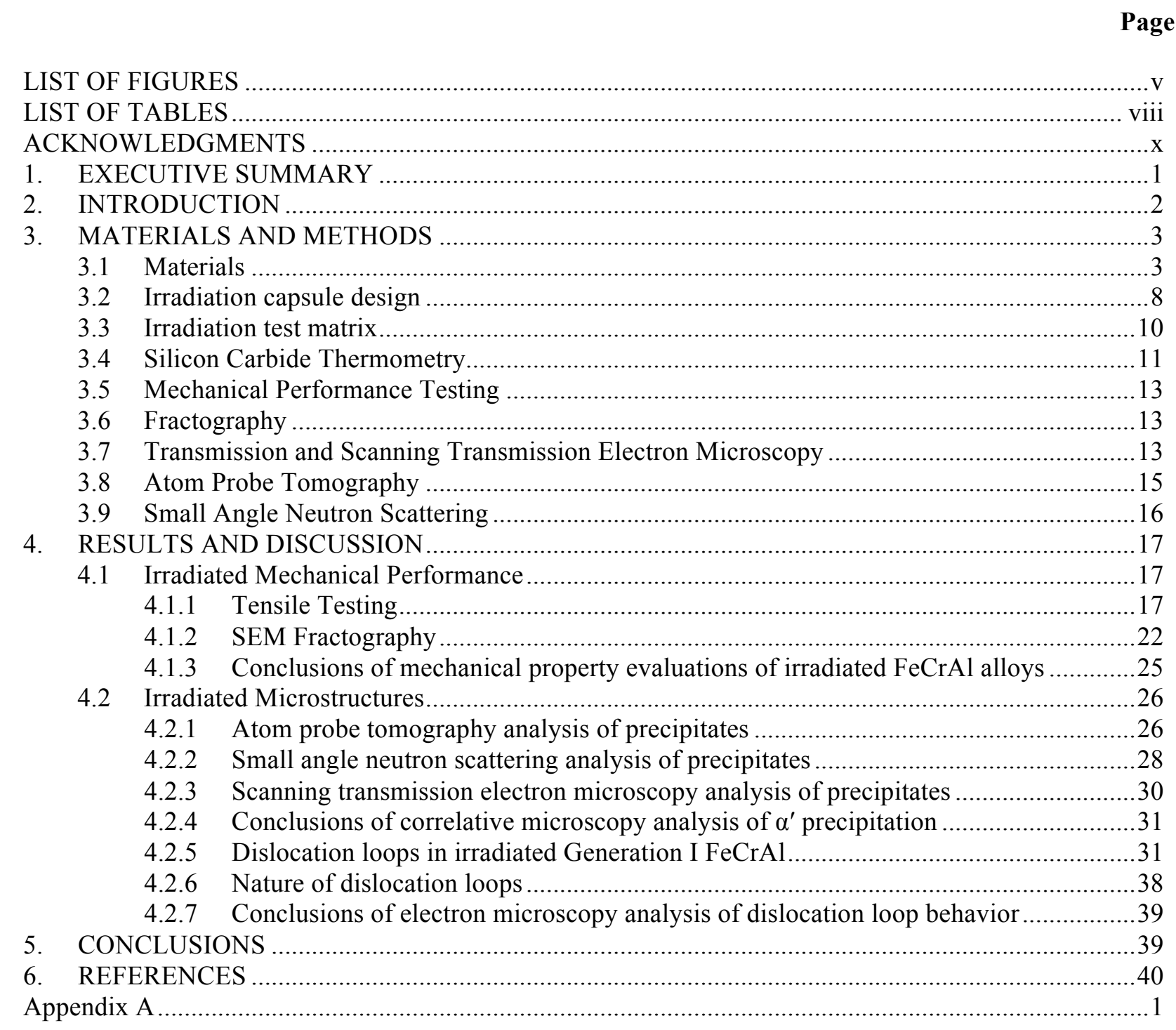





\section{LIST OF FIGURES}

Figure 1: Optical micrographs of candidate Generation I FeCrAl alloys for irradiation testing; (a) F1C5AY (b) B125Y, (c) B154Y-2, and (d) B183Y-2. Rolling direction is left to right in all images.

Figure 2: On-zone bright field STEM micrograph of line dislocation networking in B183Y-2 in the as-received condition. Line dislocation density is $1.0 \pm 0.5 \times 10^{14} \mathrm{~m}^{-2}$.

Figure 3: Optical micrographs of candidate Generation II FeCrAl alloys for irradiation testing; (a) C06M (b) C35M, (c) C36M, (d) C37M, and (e) C35MN. Rolling direction is left to right in all images.

Figure 4: Simplified schematic of the SS-J2 tensile specimen geometry for HFIR irradiations.

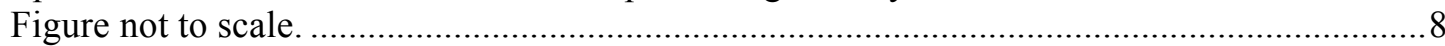

Figure 5: Schematic of irradiation targets loaded with 36 SS-J2 tensile specimens. .................................

Figure 6: Predicted specimen temperature contours for a $330^{\circ} \mathrm{C}$ irradiation in HFIR. ............................ 9

Figure 7: Plots showing representative stress-strain curves for the Generation I Fe-12Cr-4.4.AL (B125Y) alloy irradiated up to $13.8 \mathrm{dpa}$ and tested at a) room temperature $\left(24^{\circ} \mathrm{C}\right)$ and b) target irradiation temperature $\left(320^{\circ} \mathrm{C}\right)$.

Figure 8: Plots showing representative stress-strain curves for the Generation I FeCrAl alloys of varying composition irradiated at a-b) $1.8 \mathrm{dpa}$ at $382^{\circ} \mathrm{C}$ and c-d) $13.8 \mathrm{dpa}$ at $341^{\circ} \mathrm{C}$ tested $\mathrm{a} \& \mathrm{c})$ at room temperature $\left(24^{\circ} \mathrm{C}\right)$ and $\left.\mathrm{b} \& \mathrm{~d}\right)$ target irradiation temperature $\left(320^{\circ} \mathrm{C}\right)$.

Figure 9: Summary of Generation I and commercial $\mathrm{FeCrAl}$ alloys tensile response as a function of dose (dpa) for tensile tests performed at room temperature. Green polygon represents local polynomial regression fitting with $95 \%$ confidence to the Generation I FeCrAl alloys. YS: Yield Strength, UTS: Ultimate Tensile Strength, UE: Uniform Elongation, TE: Total Elongation.

Figure 10: Summary of Generation I and APMT commercial FeCrAl alloys tensile response as a function of dose (dpa) for tensile tests performed at target irradiation temperature $\left(320^{\circ} \mathrm{C}\right)$. Green polygon represents local polynomial regression fitting with $95 \%$ confidence to the Generation I FeCrAl alloys. YS: Yield Strength, UTS: Ultimate Tensile Strength, UE: Uniform Elongation, TE: Total Elongation.

Figure 11: Plots showing representative stress-strain curves for the Generation II FeCrAl alloys, a) Generation II FeCrAl alloys of varying composition irradiated to $1.8 \mathrm{dpa}$ at $364^{\circ} \mathrm{C}$ and b) $\mathrm{C} 35 \mathrm{M}$ (constant composition) irradiated to $1.8 / 9 \mathrm{dpa}$ at varying temperatures. All tensile tests performed at room temperature $\left(24^{\circ} \mathrm{C}\right)$.

Figure 12: Scanning electron micrographs showing the fracture surfaces after tensile testing at room temperature $\left(24^{\circ} \mathrm{C}\right)$. a-c) Fe-10Cr-4.8Al (F1C5AY), d-f) Fe-18Cr-2.9Al (B183Y-2), and g-i) APMT. a,d,g) alloys in the as-received condition; b,e,h) alloys irradiated to 1.8 dpa at $382^{\circ} \mathrm{C}$; and $\mathrm{c}, \mathrm{f}, \mathrm{i}$ ) alloys irradiated to $13.8 \mathrm{dpa}$ at $341^{\circ} \mathrm{C}$.

Figure 13: Scanning electron micrographs showing the fracture surfaces after tensile testing at target irradiation temperature $\left(320^{\circ} \mathrm{C}\right)$. a-c) Fe-10Cr-4.8Al (F1C5AY), d-f) Fe-18Cr2.9Al (B183Y-2), and g-i) APMT. a,d,g) alloys in the as-received condition; b,e,h) alloys irradiated to $1.8 \mathrm{dpa}$ at $382^{\circ} \mathrm{C}$; and c,f,i) alloys irradiated to $13.8 \mathrm{dpa}$ at $341^{\circ} \mathrm{C}$.

Figure 14: Reduction of area (RA) of selected Generation I and APMT FeCrAl alloys as a function of dose dose (dpa) for tensile tests performed at a) room temperature $\left(24^{\circ} \mathrm{C}\right)$ and b) target irradiation temperature $\left(320^{\circ} \mathrm{C}\right)$.

Figure 15: Scanning electron micrographs showing the fracture surfaces after tensile testing at room temperature $\left(24^{\circ} \mathrm{C}\right)$. a\&d) $1.9 \mathrm{dpa}$ at $200^{\circ} \mathrm{C}$ nominal irradiation temperature, b\&e) 1.8 dpa at $361^{\circ} \mathrm{C}$, and c\&f) $1.9 \mathrm{dpa}$ at $550^{\circ} \mathrm{C}$ nominal irradiation temperature; a-c) low magnification and d-f) high magnification. 
Figure 16: Representative atom probe reconstructions demonstrating precipitate morphology dependence on $\mathrm{FeCrAl}$ alloy composition. Precipitates as identified by the maximum separation method [47,48] are individually colored. Black atoms represent 2 at.\% of detected matrix $\mathrm{Fe}$ atoms.

Figure 17: Representative atom probe reconstructions demonstrating precipitate morphology dependence on irradiation dose for B183Y-2. Precipitates as identified by the maximum separation method $[47,48]$ are individually colored. Black atoms represent 2 at.\% of detected.

Figure 18: Plots of SANS scattering intensities for (a) the Generation I FeCrAl alloys irradiated to 7 dpa at $320^{\circ} \mathrm{C}$, and (b) the different irradiation conditions of B183Y-2.

Figure 19: Comparison of observed coarsening trends with those predicted by the LSW model. Reasonable fits to the SANS data is achieved, with the plot shown in (a) demonstrating $\mathrm{R} \propto \mathrm{t} 1 / 3$ and (b) demonstrating $\mathrm{N} \alpha^{\prime} \propto \mathrm{t}-1$.

Figure 20: (a) STEM-ADF image, [110] on-zone. (b) STEM/EDS map for Cr-Ka X-rays. (c) Color overlay of ADF and EDS maps. All images from B183Y-2, $7.0 \mathrm{dpa}, 320{ }^{\circ} \mathrm{C}$ .30

Figure 21: Dislocation structure in irradiated (a) Fe-10Cr-4.8Al, (b) Fe-12Cr-4.4Al, (c) Fe-15Cr3.9Al, and (d) Fe-18Cr-2.9Al. STEM-ABF tilted to the [100] zone axis used to image dislocation structures. $\boldsymbol{a 2 1 1 1}$ dislocation loops appear as ellipses parallel to the [011], and $\boldsymbol{a 1 0 0}$ dislocation loops appear edge-on and parallel to the [002] direction.

Figure 22: Dislocation structure in irradiated (a) Fe-10Cr-4.8Al, (b) Fe-12Cr-4.4Al, (c) Fe-15Cr3.9Al, and (d) Fe-18Cr-2.9Al. STEM-ABF tilted to the [100] zone axis used to image dislocation structures. $\boldsymbol{a 2 1 1 1}$ dislocation loops appear as ellipses parallel to the [011], and $\boldsymbol{a 1 0 0}$ dislocation loops appear edge-on and parallel to the [002] direction.

Reproduced from Ref. [17].

Figure 23: Summary of Generation I dislocation loop populations as a function of $\mathrm{Cr}$ content (in wt.\%) after irradiation to a\&c) $0.3-0.8 \mathrm{dpa}$ between the temperatures of $334-355^{\circ} \mathrm{C}$ and b\&d) $1.8 \mathrm{dpa}$ at $382^{\circ} \mathrm{C}$. Number densities are shown in $\mathrm{a} \& \mathrm{~b}$ while average diameter are shown in c\&d.

Figure 24: Dislocation loop distribution as of function of distance from a grain boundary in the K720 sample irradiated to $1.8 \mathrm{dpa}$ at $382^{\circ} \mathrm{C}$. (a) BF-STEM image, (b) ADF-STEM image, (c) indexed loop map showing different loop types; black circles are black dot damage, red ellipses are $\boldsymbol{a 2 1 1 1}$ loops, blue circles are in-plane $\boldsymbol{a 1 0 0}$ loops, and blue ellipses are edge-on $\boldsymbol{a 1 0 0}$ loops. Thickness of sample is $74.5 \pm 5.2 \mathrm{~nm}$.

Figure 25: Comparison of size and number density of imaged defects in the warm rolled B125Y-2 model alloy to the defects observed in the annealed K720 sample irradiated to the same condition.

Figure 26: Kinematical two-beam bright field images of an $\boldsymbol{a 2 1 1 1}$ dislocation loop imaged in varying foil tilts to determine the defect nature: a) titled to $+020, b)$ tilted to the $01-1$, and c) titled to the 011 to determine the loops Burgers vector. d) titled to the 020 near the [100] zone axis and to e) the 020 near the [30-1] zone axis confirms the loop's Burgers vector. e) tilted to the $0-20$ to determine inside-outside contrast formation. 



\section{LIST OF TABLES}

Table 1: Summary of FeCrAl alloy compositions in weight percent (wt.\%). ........................................

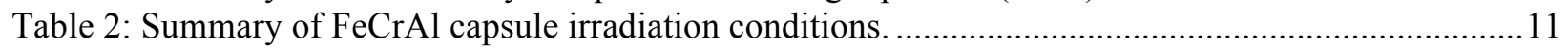

Table 3: Results of dilatometric analysis of SiC thermometry bars contained within irradiated

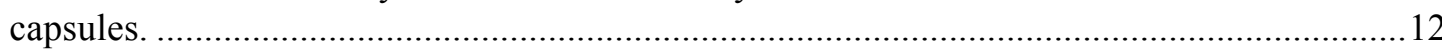

Table 4: Summary of results for APT analysis of precipitation in Generation I FeCrAl alloys. Compositions are given in at.\%.....

Table 5: Summary of results of SANS analysis for precipitation in Generation I FeCrAl alloys for all dose and composition conditions studied.

Table 6: Summary of results of STEM-BF analysis for dislocation loops in Generation I FeCrAl alloys for all dose and composition conditions studied..... 



\section{ACKNOWLEDGMENTS}

Research was sponsored by the DOE's Office of Nuclear Energy, Advanced Fuel Campaign of the Fuel Cycle R\&D Program. Neutron irradiation of FeCrAl alloys at ORNL's HFIR user facility was sponsored by the Scientific User Facilities Division, Office of Basic Energy Sciences, DOE. Atom probe tomography was conducted at the Center for Nanophase Materials Science, which is a DOE office of Science User Facility; and the MaCS Laboratory at the Center for Advanced Energy Studies at Idaho National Laboratory. This work was supported by the US Department of Energy, Office of Nuclear Energy under DOE Idaho Operations Office Contract DE-AC07-051D14517 as part of a Nuclear Science User Facilities experiment. Funding for SAB was provided by the DOE Office of Nuclear Energy's Nuclear Energy University Programs. 


\section{EXECUTIVE SUMMARY}

The present report summarizes and discusses the database on radiation tolerance for Generation I, Generation II, and commercial FeCrAl alloys. This database has been built upon mechanical testing and microstructural characterization on selected alloys irradiated within the High Flux Isotope Reactor (HFIR) at Oak Ridge National Laboratory (ORNL) up to doses of 13.8 dpa at temperatures ranging from $200^{\circ} \mathrm{C}$ to $550^{\circ} \mathrm{C}$. The structure and performance of these irradiated alloys were characterized using advanced microstructural characterization techniques and mechanical testing. The primary objective of developing this database is to enhance the rapid development of a mechanistic understanding on the radiation tolerance of FeCrAl alloys thereby enabling informed decisions on the optimization of composition and microstructure of $\mathrm{FeCrAl}$ alloys for application as an accident tolerant fuel (ATF) cladding. This report is structured to provide a brief summary of critical results related to the database on radiation tolerance of $\mathrm{FeCrAl}$ alloys.

Section 2 provides a brief overview of the motivation for this work and an introduction to the $\mathrm{FeCrAl}$ alloy class as a nuclear technology. FeCrAl alloys are an attractive class for an ATF cladding due to its high temperature steam oxidation up to $1450^{\circ} \mathrm{C}$, thereby increasing overall safety margins by limiting the heat and hydrogen production during high temperature steam exposures [2-4]. Continuing research and development efforts are focused on optimizing this alloy class for radiation tolerance.

Section 3 introduces the materials and methods to develop the database on radiation tolerance. To date, 13 different alloys have been irradiated in the HFIR with subsets of this alloy set undergoing extensive post-irradiation examination (PIE) efforts. PIE efforts have included tensile testing of sub-sized sheet type tensile specimens, atom probe tomography, scanning transmission electron microscopy, and small angle neutron scattering. When possible, state-ofthe-art techniques and processes have been applied to these PIE efforts.

Section 4.1 summarizes the results on the mechanical testing of the irradiated FeCrAl alloys. In general, at temperatures between $320-400^{\circ} \mathrm{C}$, the investigated $\mathrm{FeCrAl}$ alloys exhibited typical radiation-induced hardening and embrittlement. The severity of this response was found to have dependencies on composition, initial microstructure, radiation dose, and radiation temperature. Hence, the process of radiation-induced hardening is complex for $\mathrm{FeCrAl}$ alloys.

Section 4.2.1-4.2.7 present the results on determining the hardening and embrittling microstructural features on irradiated FeCrAl. Extensive PIE efforts have shown that hardening is an interplay between the precipitation of the Cr-rich $\alpha^{\prime}$ phase, the loss of pre-existing line dislocations, and the formation of dislocation loops and small defect clusters. Many factors were determined to influence the ratio, or the balance, of these defects in the irradiated FeCrAl alloys. Such intricate nature of the defect formations in the irradiated FeCrAl alloys is the under pinning force for the complex mechanical behavior summarized in Section 4.1.

As reported in the conclusions, Section 5, the overarching point of view within this report is the radiation tolerance of $\mathrm{FeCrAl}$ is complicated, with many mechanisms and factors to be considered at once. 


\section{INTRODUCTION}

The nuclear accident that occurred at the Fukushima Daiichi nuclear power plant in 2011 resulted in an increased interest in accident tolerant fuel (ATF) cladding, structural materials, and fuel forms for light water reactor (LWR) systems. Most of the proposed redesigns focus on replacement of the currently utilized $\mathrm{Zr}$-based components with a material with improved high temperature steam oxidation resistance while maintaining the $\mathrm{UO}_{2}$ ceramic fuel form $[1,2]$. Of these replacement cladding materials, FeCrAl-based alloys with minor $\mathrm{Y}$ additions have shown promise as a near-term deployment solution that increases safety margins by forming an $\mathrm{Al}_{2} \mathrm{O}_{3}$ oxide scale in steam environments up to $1450{ }^{\circ} \mathrm{C}$ while limiting the heat and hydrogen production that can exacerbate accident conditions $[3,4]$. Furthermore, FeCrAl properties can be fine-tuned via minor alloying additions and oxide-dispersion strengthening to retain superior high temperature strength compared to Zr-based alloys, allowing for enhanced margins during design basis accident scenarios.

Primary research and development efforts at Oak Ridge National Laboratory (ORNL) are focused on optimization of the FeCrAl alloy composition and microstructure with the goal of developing a well-rounded, nuclear-grade, candidate $\mathrm{FeCrAl}$ alloy that is ready for deployment. The candidate material should maintain high temperature steam oxidation resistance in both pressurized water reactor (PWR) and boiling water reactor (BWR) environments while retaining adequate performance during both normal operation and accident scenarios. As such, a balance must be achieved between materials properties including high temperature mechanical strength, oxidation resistance, formability, thermal stability, creep strength, and radiation tolerance.

Assessing the radiation tolerance of candidate $\mathrm{FeCrAl}$ materials is important to properly gauge the materials performance over the course of its service lifetime. The unique microstructural and microchemical features induced by radiation damage can adversely affect several of the aforementioned properties leading to degradation of materials performance and potentially premature failure. In order to understand microstructural evolution and the resulting change in properties with neutron radiation exposure, an ongoing irradiation campaign coupled with comprehensive post-irradiation examination (PIE) analysis has been developed. This report focuses on the continuing evaluation of irradiation performance for FeCrAl model and engineering alloys with an emphasis on developing a microstructural and mechanical response database. This database can then be used to form a mechanistic understanding of radiationinduced hardening and embrittlement in this material system.

ORNL's FeCrAl alloys development approach is organized into distinct phases in order to facilitate a step-wise, informed alloy design process. Phase I was based around exploratory studies of the Fe-Cr-Al design space and focused primarily on assessment of how various aspects of alloy performance were affected by major alloying element composition. The alloys utilized for these investigations were simple FeCrAl-Y model alloys and are typically regarded as Generation I FeCrAl alloys within reporting [3,5-16]. These Phase I alloys have demonstrated that higher $\mathrm{Cr}$ and $\mathrm{Al}$ contents are generally more desirable for maximizing corrosion and/or oxidation resistance but too much of either can limit alloy applications; excessive $\mathrm{Cr}$ additions increase the formation of embrittling Cr-rich $\alpha^{\prime}$ precipitates [17-19], while high Al content results in failure during the seamless tube extrusion process required for LWR cladding 
fabrication [20]. Weldability was shown to have little dependence on composition when using controlled fusion welding techniques [21]. PIE efforts on Phase I materials have demonstrated that irradiation accelerates the formation of $\alpha^{\prime}$ phase precipitates in addition to forming dislocation loop structures, which both contribute to radiation-induced hardening that increases in severity with dose, though the impact of irradiation temperature was not evaluated [17].

Phase II alloy (or Generation II/engineering alloy) compositions were down-selected based on results of Phase I/Generation I FeCrAl alloys evaluations and are based on a Fe-13Cr-4.5Al$0.05 \mathrm{Y}$ material [3]. Computational thermodynamics models were utilized to guide minor alloying additions in order to enhance material strength while maintaining adequate high temperature oxidation resistance and good fabricability for thin-walled tube extrusion by commercial manufacturers. Summaries of the Generation II ATF FeCrAl alloys down-selection and design process can be found in previously published reports [3,5-16]. These engineering alloys are currently undergoing irradiation in the High Flux Isotope Reactor (HFIR) at ORNL, with a subset of low-fluence specimens recently becoming available for analysis. In addition to investigating the influence of minor alloying element additions on the microstructure and properties investigated in the Generation I alloys, the Phase II irradiation campaign also seeks to determine how irradiation temperature can affect radiation response in the FeCrAl alloy class. Preliminary mechanical testing results are included in this report, with more in-depth microstructural analysis planned in the near future.

The objective of this report is to summarize the completed results on the irradiated Generation I model alloys and selected commercial $\mathrm{FeCrAl}$ alloys while also providing an update regarding irradiation and PIE progress on Generation II engineering alloys with the aim of assembling a database on $\mathrm{FeCrAl}$ alloy performance for radiation environments. It specifically addresses the composition and fluence dependencies of $\mathrm{FeCrAl}$ microstructure and mechanical properties exposed to LWR-relevant conditions with the goal of developing a mechanistic understanding of structure/property relationships governing radiation response through a detailed database of radiation performance. The presented evaluation makes use of mechanical tests of sub-sized tensile specimens coupled with advanced and complementary microstructural characterization tools including atom probe tomography (APT), small angle neutron scattering (SANS), and scanning transmission electron microscopy (STEM).

\section{MATERIALS AND METHODS}

\subsection{Materials}

The alloys that have undergone neutron irradiation and radiation tolerance screening include Generation I, Generation II, and commercial FeCrAl alloys. Generation I alloys are ORNL developed model $\mathrm{FeCrAl}$ alloys with $\mathrm{Y}$ additions used to screen primary composition effects $(\mathrm{Cr}$ and $\mathrm{Al}$ ) on radiation tolerance, as well as other key performance aspects such as welding [21], oxidation [4,9,22], burst behavior [23], and corrosion [24]. Generation I alloys are otherwise referenced as B-series alloys or model alloys in previous reports [3,5-16]. Generation II alloys are ORNL developed FeCrAl alloys with Y additions that also include additional minor alloying elements such as $\mathrm{Mo}, \mathrm{Nb}, \mathrm{Si}$, and/or C. Minor alloy additions and further refinement in thermomechanical processing for Generation II alloys means generally a higher strength alloy at 
elevated temperatures compared to Generation I alloys with identical or similar $\mathrm{Cr}$ and/or $\mathrm{Al}$ contents [3]. Generation II alloys are also commonly referred to as $\mathrm{C}$-series alloys or engineering grade alloys in previous reports. All Generation I and Generation II materials are sheet-product; no rod or tube product of ORNL derived material was used in this study. Additionally, an ORNL developed oxide dispersion strengthened (ODS) with elevated oxygen contents was used. This alloy is designated as $125 \mathrm{YF}$ [25]. Finally, two commercial alloys have been selected for study: Alkrothal 720 (K720) sheet-product and Kanthal APMT rod-product. These two alloys represent commercial variants of wrought and powder metallurgy produced FeCrAl alloys, respectively. Table 1 summarizes the chemical composition of each alloy determined by inductively coupled plasma and combustion techniques.

Table 1: Summary of FeCrAl alloy compositions in weight percent (wt.\%).

\begin{tabular}{|l|c|c|c|c|c|c|c|c|c|c|c|}
\hline \multirow{3}{*}{ Alloy } & \multicolumn{9}{|c|}{ Composition (wt \%) } \\
\cline { 2 - 13 } & Fe & $\mathbf{C r}$ & $\mathbf{A l}$ & $\mathbf{Y}$ & $\mathbf{C}$ & $\mathbf{S}$ & $\mathbf{O}$ & $\mathbf{N}$ & $\mathbf{P}$ & Si & Mo \\
\hline F1C5AY & 85.15 & 10.01 & 4.78 & 0.038 & 0.005 & 0.0010 & 0.0013 & 0.0003 & 0.006 & $<0.01$ & $<0.01$ \\
\hline B125Y & 83.56 & 11.96 & 4.42 & 0.027 & 0.005 & 0.0013 & 0.0017 & 0.0009 & 0.0 & 0.01 & $<0.01$ \\
\hline B154Y-2 & 80.99 & 15.03 & 3.92 & 0.035 & 0.005 & 0.0004 & 0.0025 & 0.0007 & $<0.002$ & 0.01 & $<0.01$ \\
\hline B183Y-2 & 79.52 & 17.51 & 2.93 & 0.017 & 0.005 & 0.0006 & 0.0015 & 0.0011 & $<0.002$ & $<0.01$ & $<0.01$ \\
\hline C06M & 81.80 & 10.03 & 6.00 & 0.010 & 0.003 & 0.0012 & 0.0016 & 0.0004 & 0.003 & 0.180 & 1.96 \\
\hline C35M & 79.43 & 13.06 & 5.31 & 0.053 & 0.001 & $<0.0003$ & 0.0012 & 0.0003 & 0.007 & 0.130 & 2.00 \\
\hline C35MN & 78.70 & 13.00 & 5.11 & 0.044 & 0.005 & 0.0003 & 0.0014 & 0.0002 & $<0.002$ & 0.180 & 1.99 \\
\hline C36M & 78.8 & 12.98 & 6.00 & 0.040 & 0.003 & $<0.0003$ & 0.0016 & 0.0002 & $<0.002$ & 0.180 & 1.98 \\
\hline C37M & 77.49 & 13.01 & 7.22 & 0.081 & 0.001 & $<0.0003$ & 0.0026 & 0.0002 & 0.004 & 0.190 & 1.99 \\
\hline 125YF $^{125.9}$ & 11.67 & 4.73 & 0.19 & 0.020 & 0.0030 & .192 & 0.0202 & NR & 0.010 & 0.01 \\
\hline APMT & 69.01 & 21.64 & 4.93 & 0.120 & 0.03 & $<0.001$ & 0.494 & 0.0504 & 0.01 & $<0.001$ & 2.77 \\
\hline K720 & 81.36 & 12.95 & 4.21 & 0.0 & 0.034 & 0.0015 & 0.0018 & 0.0074 & 0.008 & 0.3 & $<0.01$ \\
\hline
\end{tabular}

${ }^{1}$ Addtional elements: Co: 0.02, Cu: 0.04, Hf: 0.16, Mn: 0.1, Nb: 0.02, Ni: 0.12, Ti: 0.02, V: 0.04, Zr: 0.1, all in wt \%

${ }^{2}$ Addtional elements: Co: 0.02, Cu: 0.01, Mn: 0.44, Ni: 0.12, Ti: 0.44, V: 0.03, Zr: 0.06, all in wt \%

Generation I alloys were fabricated by arc-melting pure element feedstock and pre-alloyed Al-Y in a back-filled argon gas atmosphere to form button ingots. Ingots were flipped and melted several times to reduce inhomogeneity within the ingots. Finished ingots were drop-cast into a bar shaped water-cooled copper mold under argon cover gas. Cast ingots were homogenized at $1200^{\circ} \mathrm{C}$ for more than two hours and then hot-forged at $1200^{\circ} \mathrm{C}$. To maintain a small grain size, the homogenized and forged ingots were hot-rolled at $700^{\circ} \mathrm{C}$ with more than $90 \%$ total thickness reduction. Hot-rolled product was then annealed at $700^{\circ} \mathrm{C}$ followed by air cooling and then a $10 \%$ thickness reduction was applied using cold rolling. The cold rolling process was used to simulate the cold-shaping processing route for seamless fuel cladding tube production and hence maintain a dislocation density and sink density similar to that of finalized commercial FeCrAl cladding tube. The result is a fully ferritic microstructure with 20-30 $\mu \mathrm{m}$ grain size, as shown in Figure 1, and a line dislocation density of $6.3 \pm 1.0 \times 10^{13} \mathrm{~m}^{-2}$ to $1.5 \pm 0.7 \times 10^{14} \mathrm{~m}^{-2}$. The line dislocations were organized in a pronounced cell structure in all Generation I alloys used in this investigation. Figure 2 shows a representative micrograph of the dislocation line networks in these alloys. 
a)

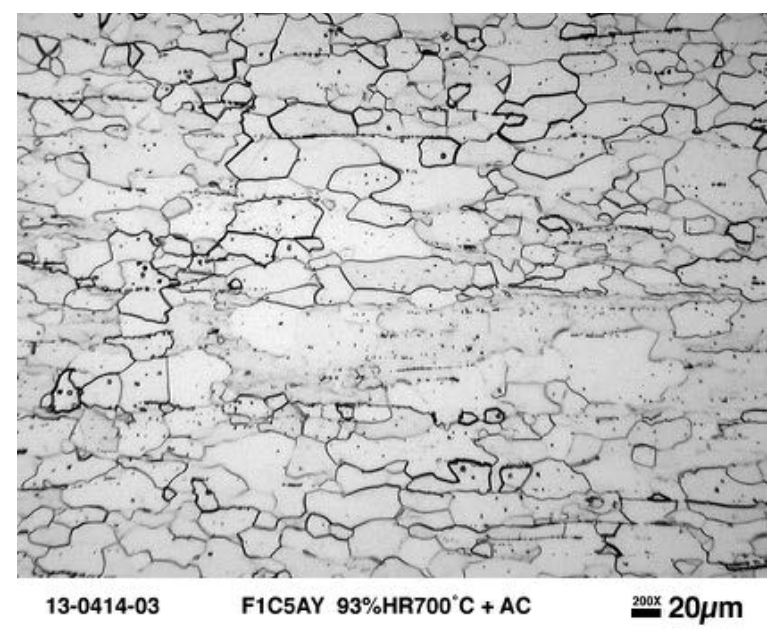

c)

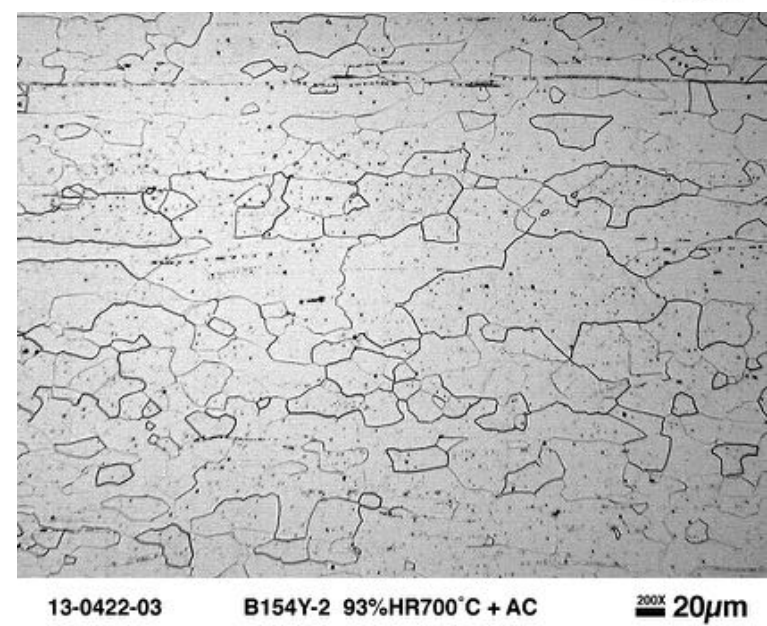

b)

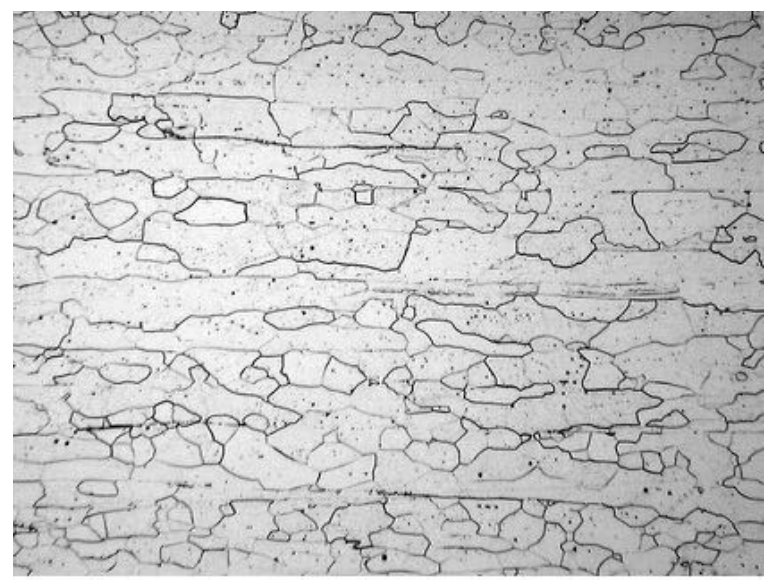

d)

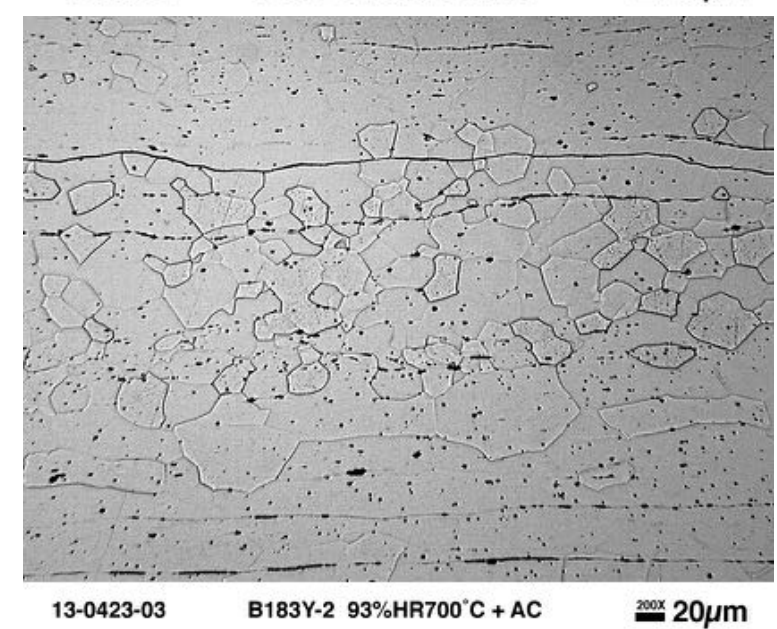

Figure 1: Optical micrographs of candidate Generation I FeCrAl alloys for irradiation testing; (a) F1C5AY (b) B125Y, (c) B154Y-2, and (d) B183Y-2. Rolling direction is left to right in all images.

Generation II alloy ingots were fabricated at a commercial vendor using vacuum induction melting (VIM). The VIM ingots were $\sim 18 \mathrm{~kg}$ and formed an $81 \mathrm{~mm}$ x $300 \mathrm{~mm}$ cylinder. VIM ingots were first homogenized at $1200^{\circ} \mathrm{C}$ in an argon atmosphere for $4 \mathrm{~h}$. Ingots were then sectioned to form smaller pieces and then these pieces were hot forged at $800^{\circ} \mathrm{C}$ with $50 \%$ total thickness reduction to form primary plate product. The plates were hot-rolled at $800^{\circ} \mathrm{C}$ with an additional $40 \%$ reduction and then annealed at $800^{\circ} \mathrm{C}$ in laboratory air for $1 \mathrm{~h}$. The hot-rolled plates were than warm-rolled at $300^{\circ} \mathrm{C}$ with an $80-90 \%$ total thickness reduction. A final anneal at $650^{\circ} \mathrm{C}$ for $1 \mathrm{~h}$ in air completed the thermomechanical processing of the Generation II alloys. All Generation II alloys showed a fully-ferritic microstructure, Figure 3. Figure 3 shows the alloys exhibited elongated grains along the rolling direction with dispersions of partially recrystallized grains on the order of $5 \mu \mathrm{m}$. These elongated grain structures are the result of the hot-rolling process. To date, electron microscopy has not been completed to determine the line dislocation density in the Generation II alloys. As these alloys exist in a partially deformed state, it is expected that a reasonable density of line dislocations in a loose network exists but remains to be determined. 


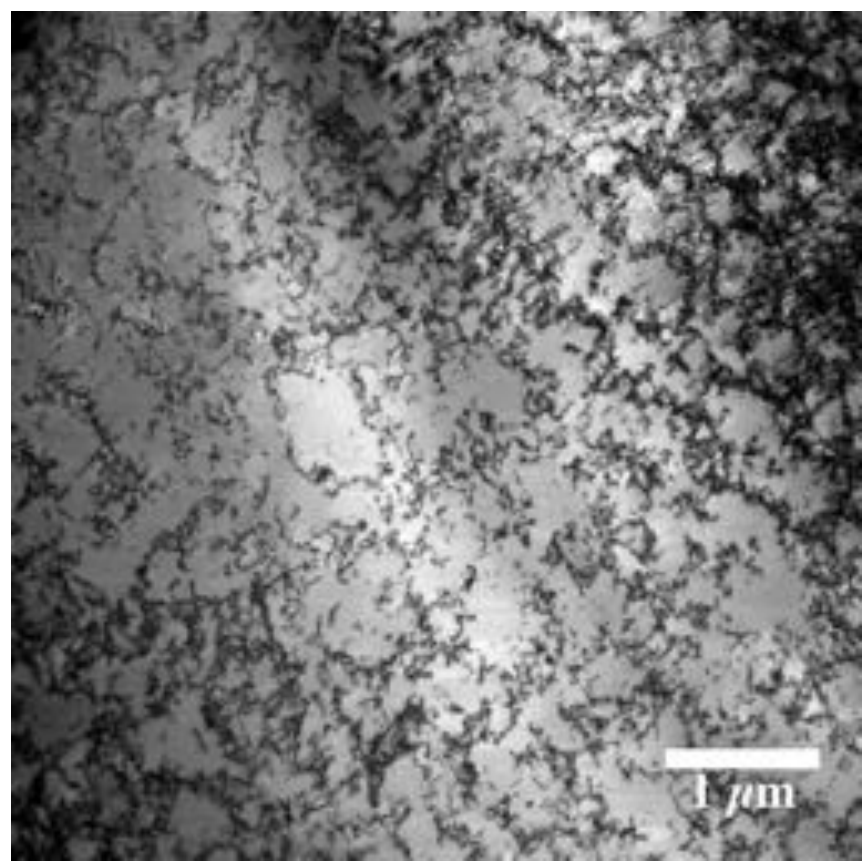

Figure 2: On-zone bright field STEM micrograph of line dislocation networking in B183Y-2 in the as-received condition. Line dislocation density is $1.0 \pm 0.5 \times 10^{14} \mathrm{~m}^{-2}$. 
a)

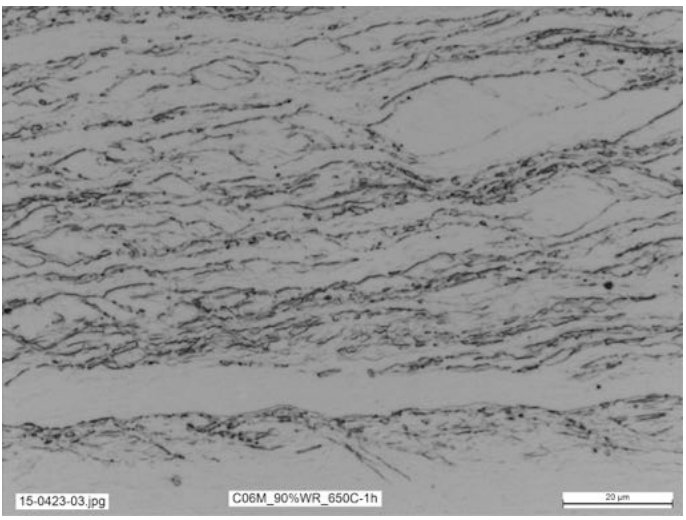

c)

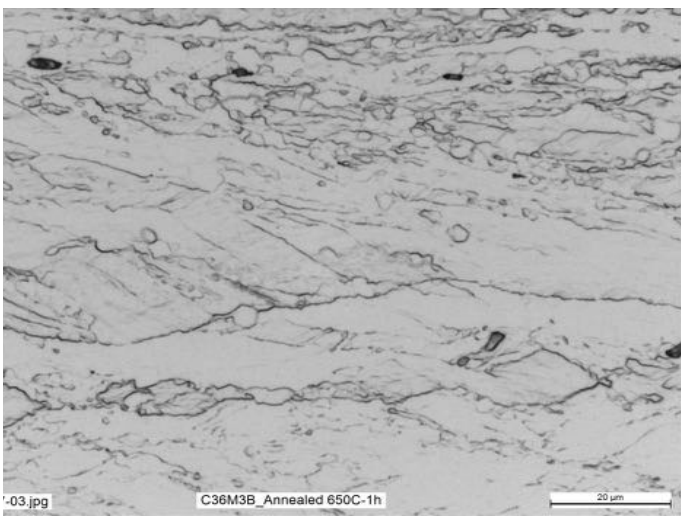

e)

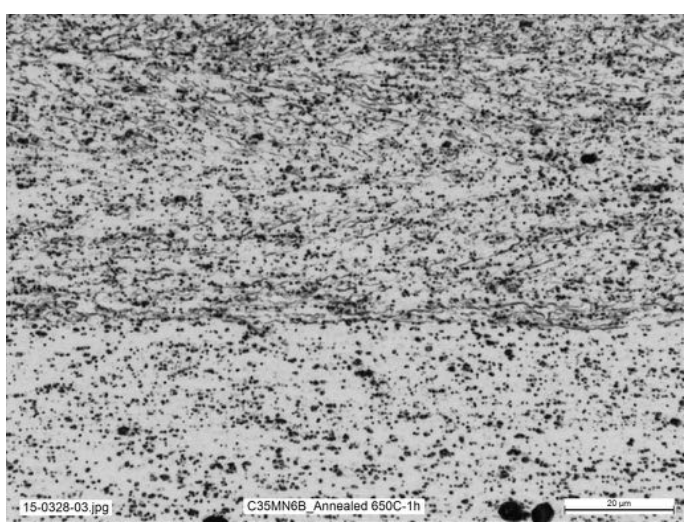

b)

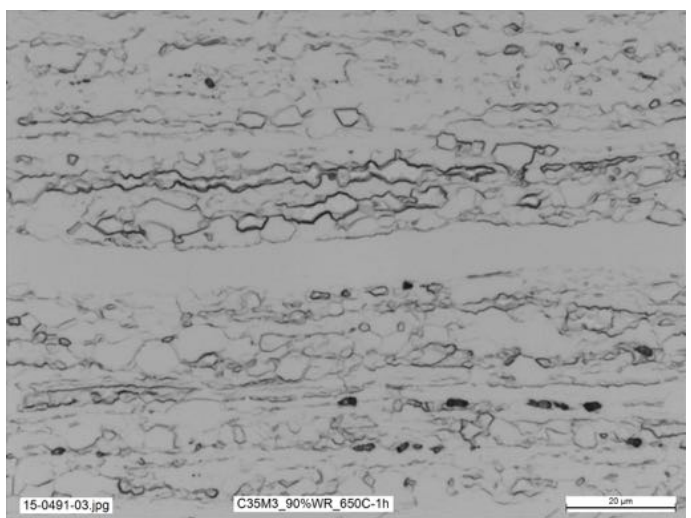

d)

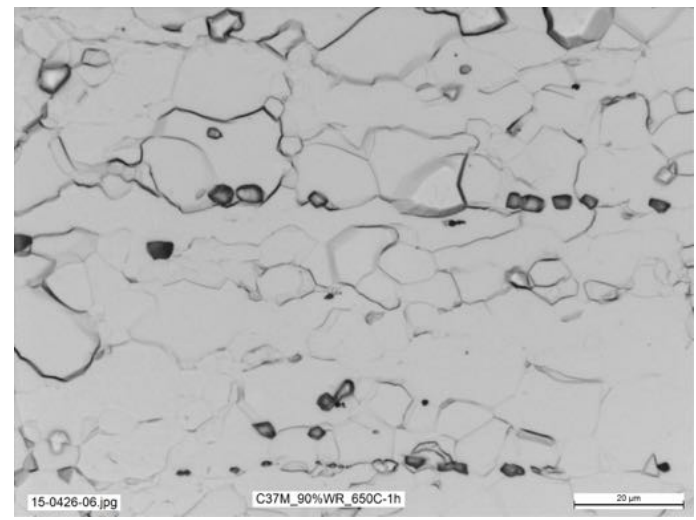

Figure 3: Optical micrographs of candidate Generation II FeCrAl alloys for irradiation testing; (a) C06M (b) C35M, (c) C36M, (d) C37M, and (e) C35MN. Rolling direction is left to right in all images. 


\subsection{Irradiation capsule design}

All irradiation capsules were designed for use in ORNL's High Flux Isotope Reactor (HFIR) in the central flux trap of the reactor. HFIR is a beryllium-reflected, pressurized, light-water-cooled and moderated flux-trap-type reactor operating at a power level of $85 \mathrm{MWt}$. The center flux trap of the reactor houses a bundle of irradiation capsule holder positions that offer neutron fluxes on the order of $2-11 \times 10^{14} \mathrm{n} / \mathrm{cm}^{2} \mathrm{~s}(\mathrm{E}>0.1 \mathrm{MeV})$. Typical reactor cycle lengths are 24 days with a rapid power up and shutdown. For FeCrAl alloys, dpa per cycles are on the order of 1.5-2.0 $\mathrm{dpa}$ /cycle depending on final composition and location within the reactor core. For irradiations necessitating lower damage (dpa) a hydraulic tube facility can be used. The reactor's operating temperature resides near $65^{\circ} \mathrm{C}$ meaning that temperatures above this can be achieved by controlling the heat transfer between the irradiation target internals and the reactor coolant. This is done by controlling the fill gas inside the target internals and the radial gap between the specimen holder and the outer housing.

Here, a similar capsule design was used for each irradiation condition. The capsules, also commonly referred to as "rabbits," can accommodate SS-J type specimens by using steel chevrons to support the gauge region of the tensile specimens. The SS-J type specimen configuration is shown in Figure 4. This tensile specimen geometry has seen wide spread use in HFIR irradiations since first being introduced by Japanese researchers in the 1990s [26]. Originally, the specimen geometry had pin holes in each tensile head to facilitate tensile testing but in the past decade most irradiation programs have shifted towards eliminating these features in favor of shoulder loading. The elimination of tensile holes has the added benefit of providing sufficient material in the head of the tensile specimen for microhardness testing, electron microscopy sample preparation, and even miniaturized bend bar specimens. The sheet type configuration also allows for easy stacking and effective heat transfer across these stacked faces.

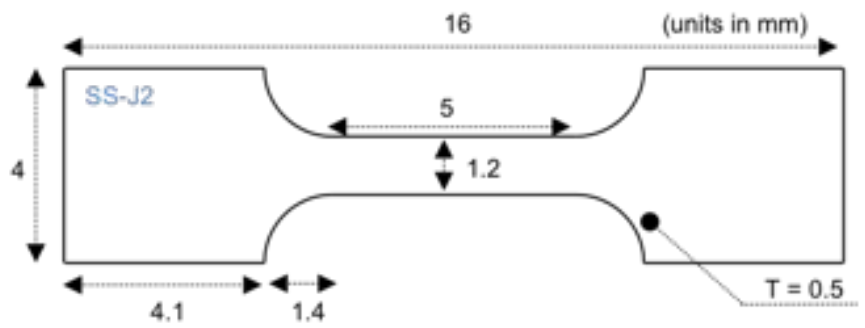

Figure 4: Simplified schematic of the SS-J2 tensile specimen geometry for HFIR irradiations. Figure not to scale.

The SS-J type is routinely produced in three thicknesses: $0.25 \mathrm{~mm}, 0.50 \mathrm{~mm}$ and $0.75 \mathrm{~mm}$. It should be noted that Byun et al. [27] and Gussev et al. [26] evaluated the effect of the thickness to width $(\mathrm{T} / \mathrm{W})$ ratio on the tensile properties and showed the $\mathrm{T} / \mathrm{W}$ ratio plays a significant effect in the total elongation values of SS-J type specimens. Here, the $0.50 \mathrm{~mm}$ thickness was selected for use in the HFIR irradiations as it provided the highest number of specimens within each irradiation capsule while providing the median value of total elongation values between the three thickness variants. Given this, due to the sub-sized nature of these specimens the total elongations values have not reached saturation according to Byun et al. meaning the reported values are conservative compared to more standardized tensile geometries. 
Use of the SS-J type specimen with a thickness of $0.5 \mathrm{~mm}$ (designated SS-J2) allows for three SS-J2 specimens to be stacked into each of the four quadrants of the square cutout in the subassemblies of the irradiation rabbits. Three sub-assemblies are accommodated in a single irradiation rabbit resulting in a total of 12 SS-J2 specimens per sub-assembly or a total of 36 specimens per rabbit at maximum. The sub-assembly design aids in both assembly of the rabbits prior to irradiation and in the disassembly process in a hot cell facility. Each assembly has raised standoff features to center the holder assembly within the outer containment housing. Grafoil is used to separate the holder sub-assemblies from the cool bottom of the housing. Figure 5 provides a 3D schematic of the general irradiation capsule design.

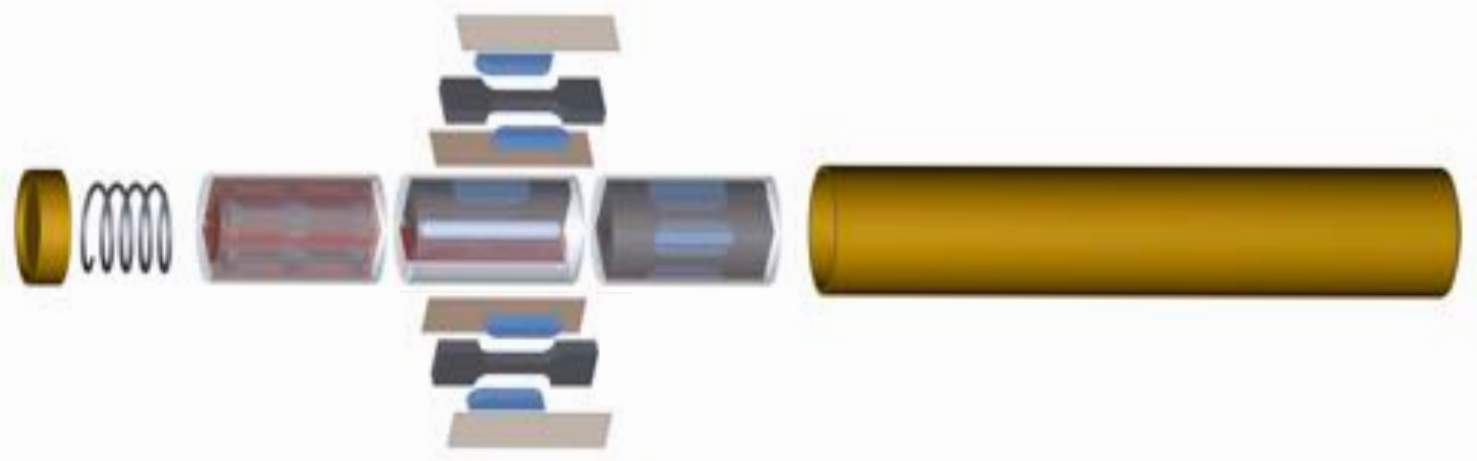

Figure 5: Schematic of irradiation targets loaded with 36 SS-J2 tensile specimens.

Determination of the predicted rabbit operating temperature is completed using an ANSYS finite element analysis design. A three-dimensional model of the capsule allows for detailed insight into thermal gradients within the design. A single tensile configuration located at the rabbit centerline is used to optimize the thermal design of the rabbits. Boundary conditions such as heating rates and convective heat transfer rates are HFIR specific and assumed to be constant. An example of the 3D thermal model and corresponding gradients are shown in Figure 6. Material selection of the rabbits is based on the designed operational temperature of individual rabbits. Typically, for low temperature irradiations $<450^{\circ} \mathrm{C}, \mathrm{Al} 6061-\mathrm{T} 6$ is used while elevated temperature tests use molybdenum-derived components.

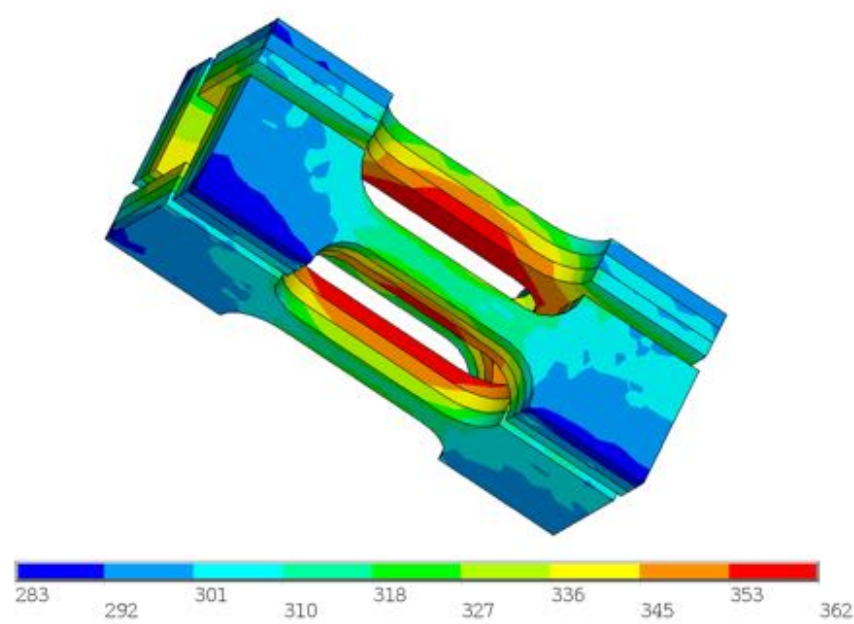

Figure 6: Predicted specimen temperature contours for a $330^{\circ} \mathrm{C}$ irradiation in HFIR. 
The irradiation capsule design does not accommodate online measurement of key experimental values including neutron flux and temperature. For neutron flux, the capsule axial average of the neutron flux $(\mathrm{E}>0.1 \mathrm{MeV})$ was used as the nominal neutron flux during the experiment. Depending on location of the rabbit within the flux trap of the HFIR, axial gradients on neutron flux could be as high as $20 \%$, but these effects are not explicitly addressed here in these simple materials screening experiments. For irradiation temperature, although active monitoring such as thermocouples are not provided in the capsule design, the use of passive SiC thermometry is implemented. These $\mathrm{SiC}$ samples reside in both varying radial and axial positions within the rabbit, Figure 5, and allow for the determination of a nominal irradiation temperature and verification of the thermal model(s) [28]. Limitations of passive SiC thermometry is discussed in Section 3.4.

\subsection{Irradiation test matrix}

Two major neutron irradiation programs have been completed to date: the FCAY and FCAT series of irradiations. A summary of the test matrices from these programs are provided in Table 2. The FCAY series of irradiations, which stand for the Fe-Cr-Al-Y series, were the first to be completed. The primary function of the FCAY irradiations were to assess the radiation tolerance of Generation I and the selected commercial FeCrAl alloys at prototypical LWR irradiation temperatures from beginning-of-life to end-of-life. Emphasis was placed on understanding both the low dose ( $<2 \mathrm{dpa})$ and high dose ( $>10 \mathrm{dpa})$ behavior of the FeCrAl alloys and whether any compositional effects existed. To accomplish this, five irradiation targets were designed and built. The two lowest doses ( 0.3 and $0.8 \mathrm{dpa}-$ FCAY -01 and FCAY02 respectively) used the hydraulic tube facility within HFIR while all other FCAY capsules used static irradiations positions. The target temperature for the irradiations were $320^{\circ} \mathrm{C}$. All thirty-six positions within each rabbit were used and filled with candidate $\mathrm{FeCrAl}$ alloys ranging in $\mathrm{Cr}$ composition from 10-22 wt.\% and Al composition from 2.9-5 wt.\%. The Generation I alloys used were selected as a subset of Generation I alloys for study as the alloys represented the leanest $\mathrm{Cr}$ composition for a given $\mathrm{Al}$ content that exhibited oxidation resistance in the presence of steam at $1200^{\circ} \mathrm{C}$. Hence, the FCAY series of irradiation capsules represent the preliminary database on radiation tolerance of $\mathrm{FeCrAl}$ alloys.

The FCAT series of irradiations, which stands for the Fe-Cr-Al-Tensile series, proceeded the FCAY irradiations. The goal of the FCAT series of irradiations is/was to not only understand the role of composition but also to understand the effects of irradiation temperature and damage dose on Generation II FeCrAl alloys. Damage dose levels were selected to mirror the mid and high dose levels of irradiation ( $\sim 2 \mathrm{dpa}, \sim 7 \mathrm{dpa}$, and $\sim 14 \mathrm{dpa}$ ) of the FCAY series allowing for direct relation between the two irradiations programs. Three different irradiation temperatures were selected: $200^{\circ} \mathrm{C}, 330^{\circ} \mathrm{C}$, and $550^{\circ} \mathrm{C}$. The temperatures were selected to reflect different regimes where different radiation-induced microstructures dominate: a dislocation loop dominated regime at $200^{\circ} \mathrm{C}$, a mixed dislocation loop and precipitation dominated regime at $330^{\circ} \mathrm{C}$, and softening or limited dislocation loop dominated regime at and above $550^{\circ} \mathrm{C}$ [29]. The Generation II alloys were selected as they represented prime candidates for commercial deployment but also probes the effects of both $\mathrm{Cr}$ and $\mathrm{Al}$ as represented in Table 1. 
Table 2: Summary of FeCrAl capsule irradiation conditions.

\begin{tabular}{|c|c|c|c|c|c|c|}
\hline Capsule ID & $\begin{array}{l}\text { Exposure } \\
\text { Time } \\
\text { (hrs) }\end{array}$ & 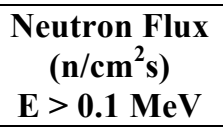 & 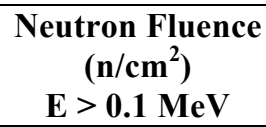 & $\begin{array}{c}\text { Dose Rate } \\
\text { (dpa/s) }\end{array}$ & $\begin{array}{l}\text { Dose } \\
\text { (dpa) }\end{array}$ & $\begin{array}{c}\text { Irradiation } \\
\text { Temperature } \\
\left({ }^{\circ} \mathbf{C}\right)\end{array}$ \\
\hline FCAY-01 & 120 & $8.54 \times 10^{14}$ & $3.69 \times 10^{20}$ & $7.7 \times 10^{-7}$ & 0.3 & $334.5 \pm 0.6$ \\
\hline FCAY-02 & 301 & $8.54 \times 10^{14}$ & $9.25 \times 10^{20}$ & $7.7 \times 10^{-7}$ & 0.8 & $355.1 \pm 3.4$ \\
\hline FCAY-03 & 614 & $8.84 \times 10^{14}$ & $1.95 \times 10^{21}$ & $8.1 \times 10^{-7}$ & 1.8 & $381.9 \pm 5.4$ \\
\hline FCAY-04 & 2456 & $8.74 \times 10^{14}$ & $7.73 \times 10^{21}$ & $7.9 \times 10^{-7}$ & 7.0 & $319.9 \pm 12.7$ \\
\hline FCAY-05 & 4914 & $8.74 \times 10^{14}$ & $1.55 \times 10^{22}$ & $7.8 \times 10^{-7}$ & 13.8 & $340.5 \pm 25.7$ \\
\hline
\end{tabular}

\begin{tabular}{|c|c|c|c|c|c|c|}
\hline FCAT-01 & 548 & $1.10 \times 10^{15}$ & $2.17 \times 10^{21}$ & $9.8 \times 10^{-7}$ & 1.9 & $200^{*}$ \\
\hline FCAT-02 & 548 & $1.04 \times 10^{15}$ & $2.05 \times 10^{21}$ & $9.3 \times 10^{-7}$ & 1.8 & $363.6 \pm 23.1$ \\
\hline FCAT-03 & 548 & $1.10 \times 10^{15}$ & $2.17 \times 10^{21}$ & $9.8 \times 10^{-7}$ & 1.9 & $550^{*}$ \\
\hline FCAT-04 & $2304^{*}$ & $1.10 \times 10^{15}$ & $8.68 \times 10^{21} *$ & $9.8 \times 10^{-7} *$ & $7.6^{*}$ & $200^{*}$ \\
\hline FCAT-05 & $2304^{*}$ & $1.04 \times 10^{15}$ & $8.20 \times 10^{21} *$ & $9.3 \times 10^{-7} *$ & $7.2^{*}$ & $330^{*}$ \\
\hline FCAT-06 & $2304^{*}$ & $1.10 \times 10^{15}$ & $8.68 \times 10^{21} *$ & $9.8 \times 10^{-7} *$ & $7.6^{*}$ & $550^{*}$ \\
\hline FCAT-07 & $4608^{*}$ & $1.10 \times 10^{15}$ & $1.74 \times 10^{22} *$ & $9.8 \times 10^{-7} *$ & $15.2^{*}$ & $200^{*}$ \\
\hline FCAT-08 & $4608^{*}$ & $1.04 \times 10^{15}$ & $1.64 \times 10^{22} *$ & $9.3 \times 10^{-7} *$ & $14.4^{*}$ & $330^{*}$ \\
\hline FCAT-09 & $4608^{*}$ & $1.10 \times 10^{15}$ & $1.74 \times 10^{22 *}$ & $9.8 \times 10^{-7} *$ & $15.2^{*}$ & $550^{*}$ \\
\hline
\end{tabular}

*Target values represented, nominal values are currently being determined

\subsection{Silicon Carbide Thermometry}

As discussed in the prior sections, all irradiation capsules were non-instrumented. Passive SiC thermometry was used to assess the nominal irradiation temperature in each capsule. SiC has been routinely used for such assessments [28,30]. It should be noted that $\mathrm{SiC}$ temperature monitors have several limitations. Under irradiation, $\mathrm{SiC}$ undergoes a lattice expansion which can be subsequently annealed out when the post-irradiation annealing temperature exceeds the irradiation temperature. This effect can be effectively captured using dilatometric analysis.

$\mathrm{SiC}$ is sensitive to the irradiation temperature and errors can be introduced when temperature fluctuations exist. For example, if the irradiation temperature rises during the end of an irradiation the early onset defects in the $\mathrm{SiC}$ will be effectively annealed out resulting in the nominal temperature determined using dilatometric analysis to be skewed towards higher irradiation temperatures instead of a time averaged value. Similar effects occur when temperatures fluctuate to lower temperatures, where if the temperature continuously decreases then the annealing curve has a shallower slope and shows initial annealing beginning at the lowest temperature. For this, $\mathrm{SiC}$ monitors have been quoted to have errors between $12^{\circ} \mathrm{C}$ and $100^{\circ} \mathrm{C}[30]$.

Here, dilatometric analysis of the passive $\mathrm{SiC}$ thermometry was conducted up to a maximum temperature of $600^{\circ} \mathrm{C}$ at a constant ramp rate of $1{ }^{\circ} \mathrm{C} / \mathrm{min}$ and a cooling rate of $2.5^{\circ} \mathrm{C} / \mathrm{min}$ using a Netzsch 402 CD dilameter. The temperature derivatives of the corrected expansion values outputted by the Netzsch $402 \mathrm{CD}$ dilatometer was used to determine the instantaneous coefficient of thermal expansion $(\alpha)$. The $\alpha$ value is used as an input into the custom in-house algorithm developed by Campbell et al. [28].

As shown in Figure 5, each irradiation capsule contained $12 \mathrm{SiC}$ thermometry bar specimens -4 each in upper, central, and lower positions within the capsule. Irradiation temperatures for 
capsules from the first HFIR irradiation cycle (FCAY-01, FCAY-02 and FCAY-3) were determined by performing the dilatometric analysis on three surviving $\mathrm{SiC}$ bars and averaging the calculated median temperatures, with error reported as the standard deviation of these values. No value was placed on the axial location of the specimens. Temperatures for subsequent FCAY capsules were calculated by averaging median temperatures for $6 \mathrm{SiC}$ specimens -2 each from the upper, central and lower positions, thus providing additional insight into the axial temperature variation in the capsule. The same techniques will be used for the FCAT capsules but the analysis remains ongoing to date. Results from this dilatometric analysis are summarized in Table 3. Irradiation temperatures in Table 2 are from the average median temperatures reported in Table 3.

Table 3: Results of dilatometric analysis of SiC thermometry bars contained within irradiated capsules.

\begin{tabular}{|c|c|c|c|c|c|}
\hline Capsule & Specimen & Minimum & Median & Maximum & $\begin{array}{c}\text { Average } \\
\text { Median }\end{array}$ \\
\hline \multirow[t]{2}{*}{ ID } & ID & Temperature & Temperature & Temperature & Temperature \\
\hline & & $\left({ }^{\circ} \mathrm{C}\right)$ & $\left({ }^{\circ} \mathrm{C}\right)$ & $\left({ }^{\circ} \mathrm{C}\right)$ & $\left({ }^{\circ} \mathrm{C}\right)$ \\
\hline \multirow{3}{*}{ FCAY-01 } & 85 & 265.2 & 334.0 & 357.1 & \multirow{3}{*}{$334.5 \pm 0.6$} \\
\hline & 90 & 308.0 & 335.2 & 358.6 & \\
\hline & 91 & 308.3 & 334.4 & 365.0 & \\
\hline \multirow{3}{*}{ FCAY-02 } & 20 & 321.6 & 355.1 & 380.0 & \multirow{3}{*}{$355.1 \pm 3.4$} \\
\hline & 21 & 325.9 & 358.5 & 381.0 & \\
\hline & 22 & 343.1 & 351.7 & 372.4 & \\
\hline \multirow{3}{*}{ FCAY-03 } & 31 & 357.2 & 381.8 & 406.5 & \multirow{3}{*}{$381.9 \pm 5.4$} \\
\hline & 74 & 361.8 & 387.4 & 409.5 & \\
\hline & 77 & 366.7 & 376.6 & 402.5 & \\
\hline \multirow{7}{*}{ FCAY-04 } & 46 TOP & 308.1 & 319.3 & 351.1 & \multirow{2}{*}{$309.4 \pm 14.0$} \\
\hline & 47 TOP & 286.4 & 299.5 & 333.7 & \\
\hline & $38 \mathrm{MID}$ & 306.5 & 322.9 & 357.8 & \multirow{2}{*}{$329.8 \pm 9.8$} \\
\hline & $41 \mathrm{MID}$ & 325.7 & 336.7 & 365.2 & \\
\hline & $42 \mathrm{BOT}$ & 312.4 & 313.6 & 357 & \multirow{2}{*}{$320.5 \pm 9.8$} \\
\hline & $43 \mathrm{BOT}$ & 294.7 & 327.4 & 347.1 & \\
\hline & Average & \multicolumn{4}{|c|}{$319.9 \pm 12.7$} \\
\hline \multirow{7}{*}{ FCAY-05 } & 51 TOP & 382.8 & 376.4 & 395.3 & \multirow{2}{*}{$368.2 \pm 11.6$} \\
\hline & 60 TOP & 340.7 & 360 & 385.1 & \\
\hline & $50 \mathrm{MID}$ & 315.5 & 341.4 & 364.4 & \multirow{2}{*}{$351.5 \pm 14.3$} \\
\hline & 55 MID & 323.7 & 361.6 & 383.4 & \\
\hline & $52 \mathrm{BOT}$ & 278.0 & 313.0 & 343.8 & \multirow{2}{*}{$311.9 \pm 1.6$} \\
\hline & $58 \mathrm{BOT}$ & 273.1 & 310.7 & 341.6 & \\
\hline & Average & \multicolumn{4}{|c|}{$343.9 \pm 27.2$} \\
\hline & & & & & \multirow{3}{*}{$370.6 \pm 17.6$} \\
\hline \multirow{7}{*}{ FCAT-02 } & 14 TOP & 346.2 & 358.1 & 372.5 & \\
\hline & 16 TOP & 359.9 & 383 & 405.7 & \\
\hline & $18 \mathrm{MID}$ & 336.4 & 345.2 & 368.2 & \multirow{2}{*}{$364.9 \pm 27.9$} \\
\hline & $20 \mathrm{MID}$ & 394.1 & 384.6 & 402.1 & \\
\hline & $22 \mathrm{BOT}$ & 337.9 & 329.5 & 342.4 & \multirow{2}{*}{$355.5 \pm 36.7$} \\
\hline & $24 \mathrm{BOT}$ & 369.9 & 381.4 & 403.1 & \\
\hline & Average & \multicolumn{4}{|c|}{$363.6 \pm 23.1$} \\
\hline
\end{tabular}




\subsection{Mechanical Performance Testing}

To date, all mechanical performance testing on neutron irradiated $\mathrm{FeCrAl}$ alloys has been completed on sheet-type sub-sized (non-ASTM standard) SS-J2 (thickness $=0.5 \mathrm{~mm}$ ) tensile specimens. Unless otherwise specified, testing has been completed using an Instron universal test machine housed in the Irradiated Materials Examination and Testing (IMET) hot cell facility at ORNL. Testing on the Instron was completed using shoulder loading with a crosshead speed of $0.0055 \mathrm{~mm} / \mathrm{s}$ resulting in a nominal strain rate of $\sim 10^{-3} \mathrm{~s}^{-1}$. No contact or non-contact extensometery was completed at the time of the test. All specimens had gauge lengths near 5 $\mathrm{mm}$, no direct measurement of gauge lengths was completed. It is expected this assumption has little impact on the strain measurements of the sample $(<1 \%)$. Engineering strain was determined from the digitally recorded crosshead separation. Engineering stress was determined based on the load and the measured thickness and width of the gauge region prior to irradiation. Note, this calculation therefore assumes negligible linear or volumetric swelling in the specimens during/after irradiation. Tensile tests were performed at room temperature $\left(24^{\circ} \mathrm{C}\right)$ in air or at $320^{\circ} \mathrm{C}$ in vacuum. In most cases, only one tensile test was completed per test temperature and irradiation condition. For cases where multiple tests were completed, the mechanical performance data is quoted as the mean of the tests with the error reported as one standard deviation of the mean.

\subsection{Fractography}

Fractography was performed on fracture tensile specimens after tensile testing using an in-cell, remotely operated JEOL JSM-6010LA scanning electron microscope (SEM) housed at the IMET hot cell facility at ORNL. When available, non-irradiated specimens were investigated using the same equipment and techniques. The JEOL SEM was operated at $5 \mathrm{kV}$ with a $10 \mathrm{~mm}$ working distance and a spot size of 50 (calibrated units not provided by vendor). Broken tensile halves were loaded into a specialized holder to allow the fracture surface normal to be orientated parallel to the SEM electron beam. When available, both halves of the fracture surface were imaged. Note, at times one tensile halve was not available as it was either being used for microstructural examination in other radiological facilities or it was lost during in-cell specimen handling. A non-calibrated universal serial bus (USB) optical microscope was placed in-cell for qualitative, general imaging and general impression of grain relief and necking of Generation II neutron irradiated $\mathrm{FeCrAl}$ alloys.

\subsection{Transmission and Scanning Transmission Electron Microscopy}

All electron microscopy samples were prepared using focused ion beam (FIB) techniques. In the case of irradiated specimens, FIB was completed on one half of a broken tensile head that was metallographically prepared prior to FIB work. All FIB work was completed within the nondeformed head area of the fractured tensile specimens. Electron transparent thin foils were prepared from these regions using standardized techniques on a FEI Quanta 3D 200i dual-beam FIB or a FEI Versa dual-beam FIB with a field emission gun (FEG). All FIB produced samples were cleaned using first a $5 \mathrm{kv}$ low energy rastered ion beam followed by a final $2 \mathrm{kV}$ rastered ion beam polish. This step was crucial to reducing, or in most cases, completely eliminated any FIB-induced artifacts into the specimens. 
A JEOL JEM-2100F field emission gun scanning transmission electron microscope (FEG(S)TEM) or Philips CM200 FEB-(S)TEM was used for imaging dislocation loop and line morphologies. General imaging was completed using on-zone STEM imaging on the [100] zone axis by means of simultaneous bright field (BF) and annular dark field (ADF) detectors. On-zone STEM imaging enables all expected dislocation loop variants in neutron irradiated Fe-based body centered cubic (BCC) materials to be imaged in a single micrograph, greatly increasing collection efficiency while minimizing contrast interpretations. For more information regarding this technique the reader is referred to several other works and those within $[17,31,32]$. Determination of loop type (i.e. vacancy or interstitial type) was completed using kinematical bright-field imaging around the [100] zone axis.

In several cases, large field-of-views (FOVs) were used to assess the non-irradiated and irradiated microstructures. Large FOVs were established by stitching individual images to maintain the high-resolution qualities of the high magnification (and hence small FOVs) images. When stitching, care was taken to minimize any artifacts in the final image which might affect the final quantifications. Initially, automated software analysis of the stitched images based on Hough transform algorithms were used to determine the size, shape, and location of each observed defect in regards to its location near a grain boundary. Unfortunately, at the time of this study, these algorithms were not robust enough to explicitly differentiate between edge-on $a\langle 100\rangle$ loops, tilted $a / 2\langle 111\rangle$ loops, and in-plane $a\langle 100\rangle$ loops when the foils were imaged in the [100] orientation. Hence, all quantification presented within was completed using hand counting techniques. The "fit ellipse" routine was used in ImageJ $[33,34]$ to record each defects spatial position ( $\mathrm{x}$ and $\mathrm{y}$ ), the major and minor axis (i.e. diameter), and angle of the major axis to the origin of the image. Defect type, e.g. Burgers vector, was determined based on the morphology maps provided by Yao et al. [35] for the [100] zone axis.

In general, conventional TEM techniques are not useful for analysis of $\alpha^{\prime}$ precipitates as the precipitating phase is semi-coherent with the $\alpha$-Fe matrix and does not produce any diffraction contrast [36]. As such, observations of these Cr-rich precipitates requires the use of chemically sensitive techniques, such as STEM coupled with energy dispersive X-ray spectroscopy (STEM/EDS). While APT and SANS are more robust techniques for performing a rigorous quantitative analysis of precipitate morphology and chemistry, STEM/EDS is useful for correlating precipitate structures with other microstructural features not easily captured using the former techniques, such as dislocation loops. For this purpose, STEM/EDS chemical maps were acquired simultaneously with the STEM-BF, STEM-ADF or STEM-HAADF images using a 2 $\mathrm{nA}$ probe to determine how precipitate morphology is affected by the presence of these structures.

Specimen thickness was determined either using convergent beam electron diffraction (CBED) or energy filtered transmission electron microscopy (EFTEM). CBED thickness was completed under two-beam conditions with the (130) diffraction spot strongly excited. EFTEM measurements were completed using a collection semi-angle of $6.36 \mathrm{mrad}$ and a calculated mean free path of $117.3 \mathrm{~nm}$ based on the alloy and microscopy system used. In the case where multiple specimens or regions of interest (ROIs) were investigated, defect densities were determined from the plots of the slope of areal density versus the ROIs thickness to correct for near-surface FIBinduced artifacts and/or loss of glissile defects to the foil surface [37-39]. 


\subsection{Atom Probe Tomography}

Fractured tensile specimens from Section 3.5 were mechanically polished using standard metallography techniques prior to FIB sample preparation. All atom probe tomography samples were prepared using FIB, no electropolished samples were used. Atom probe needle samples were prepared from the non-deformed head area of the fractured tensile specimens using a FEI Quanta 3D 200i dual-beam FIB. Primary needle sharpening was completed using a $30 \mathrm{kV}$ Ga ion beam with final sharpening being completed using a $5 \mathrm{kV}$ polishing beam to minimize $\mathrm{Ga}$ implantation in the final analyzed volume. Finalized specimens were quickly transferred from the FIB into the atom probe to minimize sample degradation.

Due to the time and cost intensive nature of the APT technique, only a subset of all irradiated specimens has been tested to date. These include four Generation I FeCrAl alloys neutron irradiated to $7 \mathrm{dpa}$ and the $\mathrm{Fe}-18 \mathrm{Cr}-3 \mathrm{Al}$ Generation I alloy in the unirradiated, $0.8 \mathrm{dpa}$, and 1.8 dpa conditions. At least two needles (specimens) were ran and analyzed per alloy irradiation condition and only datasets containing at least 10 million ions were used for final analysis and quantification.

All specimens were analyzed using a Cameca local electrode atom probe (LEAP) 4000X HR housed at either the Center for Nanophase Materials Sciences (CNMS) at ORNL, or at the Center for Advanced Energy Studies (CAES) at Idaho National Laboratory. The LEAPs were operated in the laser-pulsed mode at a base specimen temperature of $50 \mathrm{~K}$, pulse repetition rate of 200 $\mathrm{kHz}$ and a laser energy of $50 \mathrm{pJ}$. Detection rates were maintained near $0.5 \%$. Primary data reconstruction and analysis was completed using the Cameca Integrated Visualization \& Analysis Software (IVAS 3.6.8).

LEAP was primarily used to find and quantify $\alpha^{\prime}$ precipitation in the irradiated specimens. Preliminary quantification of $\alpha^{\prime}$ precipitation was analyzed using the maximum-separation cluster-finding algorithms packaged within the IVAS software. Details on the input parameters and sensitivity of the analysis can be found elsewhere [40]. Using these algorithms, with careful selection of input parameters, the size, number density, and compositions of the $\alpha^{\prime}$ precipitates and irradiated matrix can be determined. The radius of the $\alpha^{\prime}$ precipitates were calculated using the spherical equivalent radius [41,42] with an assumed atom probe detection efficiency of 0.36 and an assumed atomic density of 84.3 atom $\mathrm{nm}^{-3}$ for both the matrix and $\alpha^{\prime}$ precipitates.

One challenge with analyzing neutron irradiated specimens using atom probe tomography is the presence of non-natural isotopic abundances. For peak decomposition techniques where the ratios of isotopes are used to determine the peak overlaps values, such as the peak overlap of ${ }^{27} \mathrm{Al}^{1+},{ }^{54} \mathrm{Cr}^{2+}$, and ${ }^{54} \mathrm{Fe}^{2+}$ at 27 daltons (Da) in the time-of-flight (TOF) spectrum, the IVAS software package uses pre-built algorithms assuming natural isotopic abundances. To account for the neutron activated volumes analyzed here, the expected isotopic abundances for $\mathrm{Al}, \mathrm{Cr}$, and Fe isotopes were calculated using the ORIGEN-2.2 isotope generation and depletion code based on the decay-corrected data based on the irradiation times and date of APT analysis. Based on these corrected isotopic abundances the peak overlap at 27 Da was manually computed outside of the IVAS software package. Additionally, $\mathrm{Cr}$ was found to decay from ${ }^{51} \mathrm{Cr}$ to ${ }^{51} \mathrm{~V}\left(\mathrm{t}_{1 / 2}=27.7\right.$ days) resulting in slightly reduced $\mathrm{Cr}$ ions found within the analyzed volumes. This effect was 
especially apparent in $\mathrm{Cr}$ enriched volumes such as the $\alpha^{\prime}$ precipitates as $\mathrm{V}$ clustering was also observed, but this effect accounted for less than 0.1 at.\% and hence can be determined as insignificant for final compositions calculated and reported in later Sections.

APT data is sensitive to trajectory aberration effects especially when analyzing regions with large variations in evaporations fields. Here, it is assumed the $\alpha^{\prime}$ precipitates are a low-field volume $\left(\mathrm{F}_{\mathrm{Cr}}=29 \mathrm{~V} / \mathrm{nm}\right)$ embedded in a high field $\alpha-\mathrm{Fe}$ matrix $\left(\mathrm{F}_{\mathrm{Fe}}=33 \mathrm{~V} / \mathrm{nm}\right)$ [43]. The result is analysis of the analyzed APT volumes show increased density within the Cr-rich $\alpha^{\prime}$ precipitates, a non-physical artifact that leads to artificial enrichment of Fe in the $\alpha^{\prime}$ precipitates. This effect was corrected for using the techniques detailed by Briggs et al. [40].

\subsection{Small Angle Neutron Scattering}

APT, as briefly discussed, is a time and cost intensive process to get highly quantitative and repeatable data. To extend the database on $\alpha^{\prime}$ precipitation in irradiated FeCrAl alloys, small angle neutron scattering (SANS) was also employed to determine the size, number density, and volume fraction of $\alpha^{\prime}$ precipitates in the irradiated volumes. All SANS measurements were completed on the CG-2 general-purpose SANS beamline (GP-SANS) at ORNL's HFIR [44]. Three detector distances were used for data collection: two utilizing $0.472 \mathrm{~nm}$ neutrons at distances of $1.079 \mathrm{~m}$ and $7.779 \mathrm{~m}$ and one using $1.2 \mathrm{~nm}$ neutrons at a distance of $19.279 \mathrm{~m}$. In order to maximize the accessible range of momentum transfer, $\mathrm{Q}$, the detector was laterally offset by $0.4 \mathrm{~m}$ in each measurement. In total, measurements spanned a $\mathrm{Q}$ range of $0.01<\mathrm{Q}<10$ $\mathrm{nm}^{-1}$. The data was converted to the $\mathrm{cm}^{-1}$ scale by correcting the medium length data for thickness and transmission before normalizing to the attenuated direct beam. The data from the other two detector lengths was then scaled to match the medium-length data to generate the full, combined curves. All data was collected at room temperature. Multiple scattering corrections were deemed negligible.

Fits to the experimental data assume $\alpha^{\prime}$ clusters to be monodisperse spheres interacting with an exclusion volume and take the function form [6]:

$$
\frac{d \sigma(q)}{d \Omega}=n \Delta \rho^{2} \mathrm{~V}^{2} P(q, r) S(q)=I_{0} P(q, r) S(q)
$$

where $n$ is the number density of particles, $\Delta \rho$ is the difference in the scattering contrast between the precipitate phase and the matrix, $\mathrm{V}$ is the volume of the precipitates, $P(q, r)$ is the particle form factor, and $S(q)$ is the structure factor describing scattering interference between particles. The form factor must satisfy $P(q=0, r)=1$, while $S(q)$ approaches 1 for large $q$. These boundary conditions give unique solutions for radius $(r)$ and the leading coefficient, $I_{0}$, from which $n$ and $\mathrm{V}$ can then be determined based on the assumption that precipitate volumes are spherical.

The scattering contrast, $\Delta \rho$, from Equation 1, and thus the subsequent quantification, is sensitive to the assumed compositions of both the matrix and precipitate phases. Fortunately, the chemical data resulting from atom probe analysis allows for the determination of the expected contrast with a high degree of certainty. However, due to the larger scope of the SANS investigation, not every SANS data point is coupled with APT composition data and thus some assumptions must 
still be applied in the quantification of the SANS results. APT data from the 7 dpa specimens provides a baseline value for cluster and matrix composition. In addition, matrix and cluster composition trends with dose have been observed in the Fe(18)CrAl APT data. By assuming composition changes on the same scale in the alloys for which dose dependence of composition has not been explicitly assessed using APT techniques, scattering contrast can be approximated in order to provide at least a semi-quantitative analysis of precipitate morphology. In considering the $\mathrm{Fe}(18) \mathrm{CrAl}$ APT results, the magnitude of the net SANS scattering contrast is observed to decrease by 1.9 and $17.1 \%$ when comparing the $7 \mathrm{dpa}$ compositions to the 1.8 and $0.8 \mathrm{dpa}$ compositions, respectively. These same percent changes were applied in order to calculate approximate values of the scattering contrast for the 1.8 and $0.8 \mathrm{dpa}$ conditions of each alloy based on the available atom probe composition data from the $7 \mathrm{dpa}$ specimens.

\section{RESULTS AND DISCUSSION}

\subsection{Irradiated Mechanical Performance}

The radiation-induced hardening and embrittlement in the Generation I, Generation II and commercial $\mathrm{FeCrAl}$ alloys was determined using uniaxial tensile testing followed by scanning electron microscopy (SEM) of the fracture surfaces. Tensile tests in the as-received and irradiated case were all performed using the same tensile frame and post-testing analysis software. SEM-based fractography was used as it allows for a reasonable assessment of the reduction of area (RA) which in turns provides the best estimate for retained deformability in the absence of true stress-strain analysis techniques. This technique allows for determination of retrained deformability even in high dose specimens ( $>2 \mathrm{dpa}$ ) as true curves require extensometry techniques such as digital image correlation (DIC) which is prohibitively expensive to deploy within a hot cell environment for this study. Additionally, reduction of area can also be correlated to the upper shelf energy (USE) in irradiated steels and Fe-based alloys [45].

\subsubsection{Tensile Testing}

The tensile properties at room temperature and at nominal target irradiation temperature $\left(320^{\circ} \mathrm{C}\right)$ of the Generation I and commercial FeCrAl alloys have been determined to a maximum dose of $13.8 \mathrm{dpa}$. The high temperature tensile tests $\left(320^{\circ} \mathrm{C}\right)$ have not been performed on the K720 alloy to date. A complete summary of the measured tensile properties on all alloys investigated is provided in Appendix A.

Representative engineering stress-strain curves up to 13.8 dpa for the Generation I B125Y-2 alloy (Fe-12Cr-4.4Al), provided in Figure 7, show typical hardening responses for ferritic alloys after irradiation, near LWR operating temperatures. With increasing dose (dpa), the curves show increases in yield strength which is correlated to a loss of ductility and reductions of work hardening capacity. Figure 7a shows this response during room temperature testing while Figure $7 \mathrm{~b}$ shows the response at high temperature tensile testing $\left(320^{\circ} \mathrm{C}\right)$. Room temperature tests typically showed higher yield strengths and lower ductility although at higher doses ( $>2 \mathrm{dpa})$ no work hardening is observed regardless of tensile test temperature. 
The trends shown in the representative curves in Figure 7 for the B125Y alloy are consistent for all Generation I alloys investigated as presented in Figure 8. Figure 8a and Figure 8b shows representative engineering stress-strain curves for all Generation I alloys irradiated to $1.8 \mathrm{dpa}$ at $382^{\circ} \mathrm{C}$ tested at room temperature and at target irradiation temperature, respectively while Figure $8 \mathrm{c}$ and Figure $8 \mathrm{~d}$ shows curves for Generation I alloys irradiated to $13.8 \mathrm{dpa}$ at $320^{\circ} \mathrm{C}$ and tested at room temperature and at target irradiation temperature, respectively. Figure $8 \mathrm{a}$ and Figure $8 \mathrm{~b}$ shows increasing the $\mathrm{Cr}$ concentration from $10 \mathrm{wt} \% \%$ to $18 \mathrm{wt} . \%$ results in an increased yield strength in the material, regardless of tensile test temperature. The ductility change in the alloys irradiated below 2 dpa is shown to be more complex, with the $12 \mathrm{wt} . \% \mathrm{Cr}$ alloy showing lower total elongation and uniform elongation than the $15 \mathrm{wt} . \% \mathrm{Cr}$ alloy irradiated to $1.8 \mathrm{dpa}$, while the higher test temperature shows nearly identical ductility responses for alloys with $\mathrm{Cr}$

concentrations of $10-15 \mathrm{wt} . \%$. For either case (room temperature or $320^{\circ} \mathrm{C}$ tensile test), the 18 wt.\% Cr Generation I FeCrAl variant shows the highest degree of radiation-induced hardening and embrittlement as indicated by it largest increase in yield strength and greatest decrease in both uniform elongation and total elongation. Given this, when irradiated to higher dpa, Figure $8 \mathrm{c}$ and Figure 8d, the composition dependencies observed at low dose no longer exist. All alloys show nearly zero uniform elongation and nearly identical total elongations if data scattering is taken into consideration. Hence, the composition dependencies discussed by Field et al. [17], appear to be a predominantly low dose phenomena.

a)

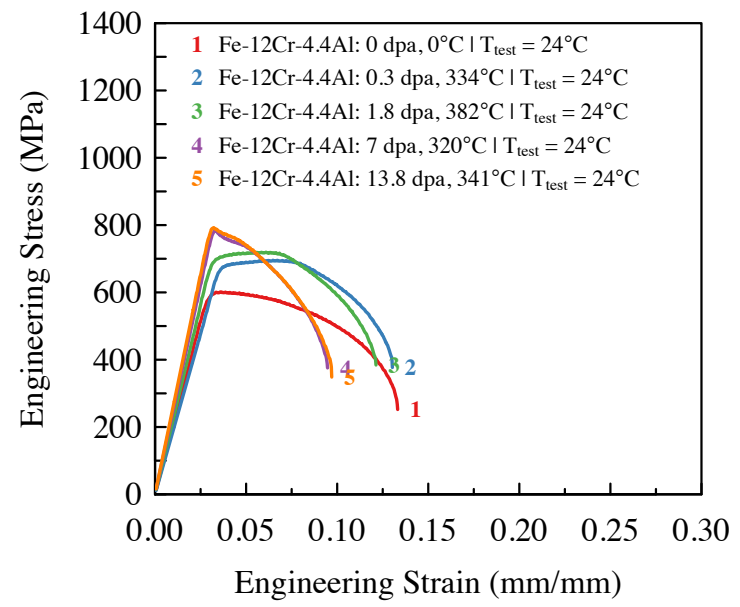

b)

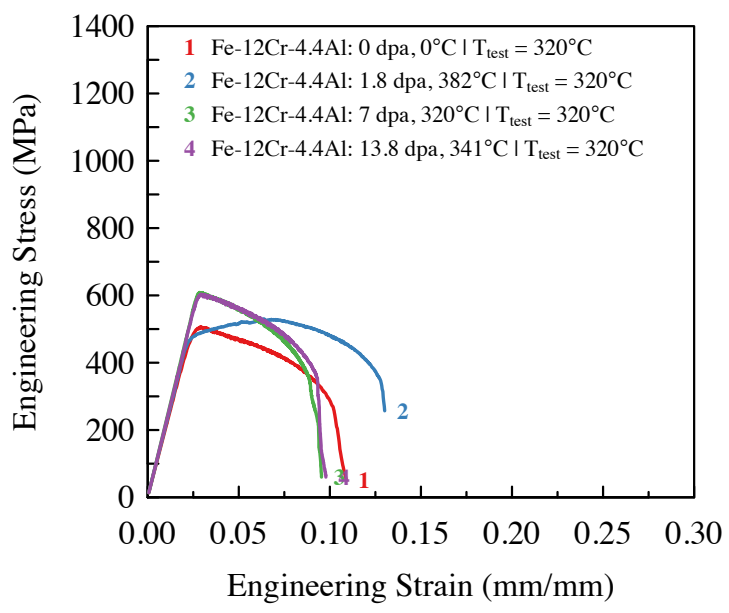

Figure 7: Plots showing representative stress-strain curves for the Generation I Fe-12Cr-4.4.AL (B125Y) alloy irradiated up to $13.8 \mathrm{dpa}$ and tested at a) room temperature $\left(24^{\circ} \mathrm{C}\right)$ and $\left.\mathrm{b}\right)$ target irradiation temperature $\left(320^{\circ} \mathrm{C}\right)$.

Several distinct trends can then be derived from Figure 7 and Figure 8, as given in Figure 9 and Figure 10. Generation I FeCrAl alloys have saturated mechanical properties at $>7 \mathrm{dpa}$, where all alloys exhibited a loss of uniform elongation and saturation of total elongation at nearly $10 \%$. In the saturation regime, yield strengths approached $\sim 800 \mathrm{MPa}$ when tested at room temperature and $\sim 600 \mathrm{MPa}$ when tested at $320^{\circ} \mathrm{C}$. The only outlier from this response is the B183Y-2 alloy (Fe-18Cr-2.9Al alloy) as it failed in a brittle manner at $13.8 \mathrm{dpa}$ when tensile tested at room temperature, Figure 9. The "hump" observed in the ductility parameters in Figure 9 and Figure 10 have been attributed to the annealing of line dislocations introduced during the thermal mechanical processing of the alloys prior to irradiation [17]. 
a)

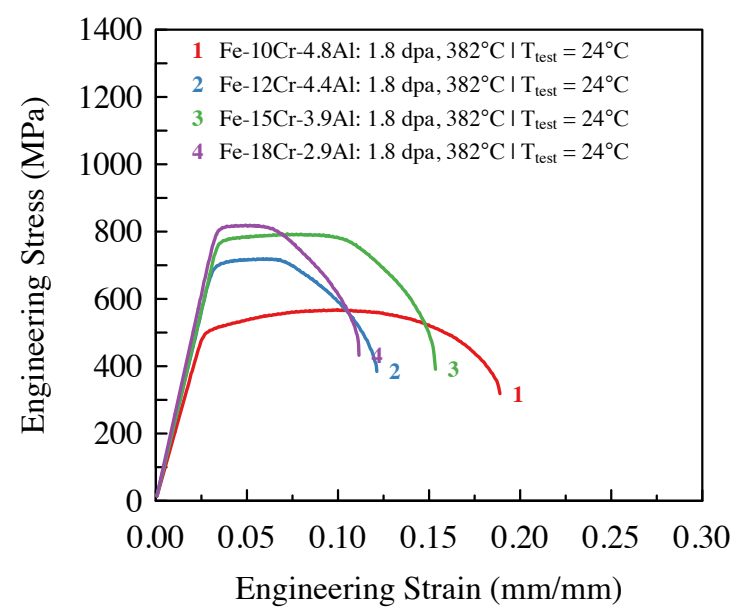

c)

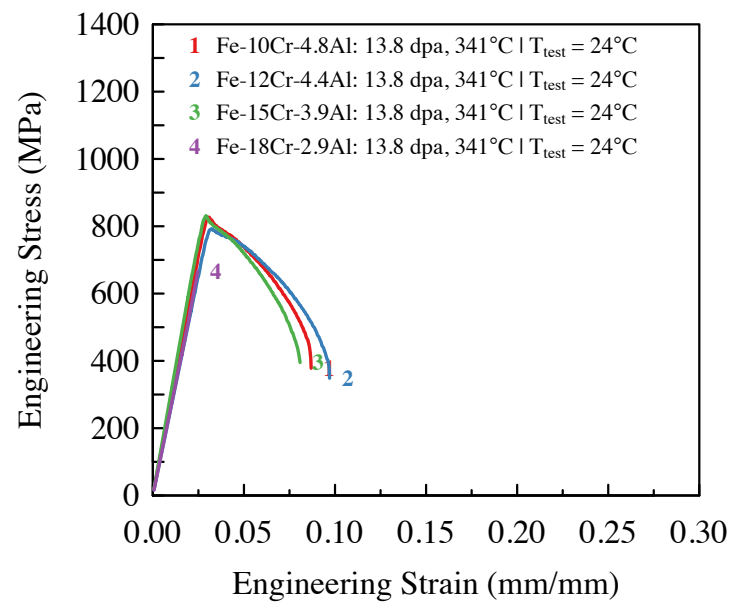

b)

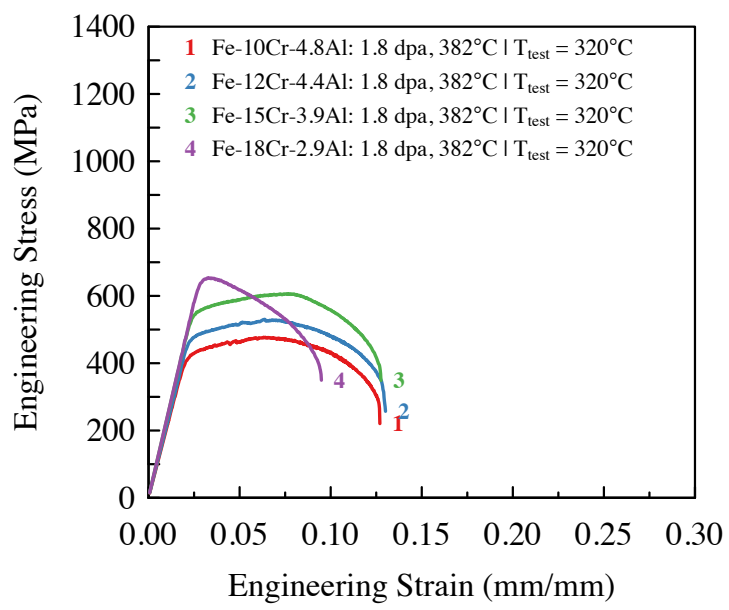

d)

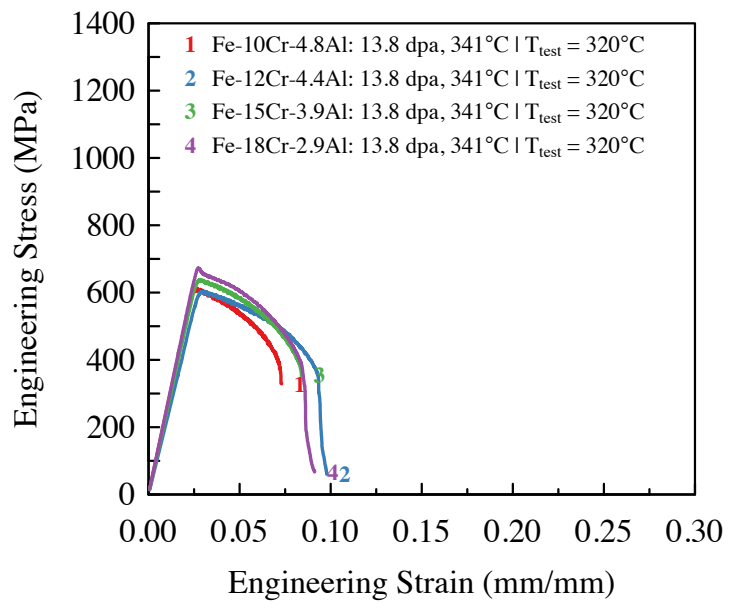

Figure 8: Plots showing representative stress-strain curves for the Generation I FeCrAl alloys of varying composition irradiated at a-b) $1.8 \mathrm{dpa}$ at $382^{\circ} \mathrm{C}$ and c-d) $13.8 \mathrm{dpa}$ at $341^{\circ} \mathrm{C}$ tested a\&c) at room temperature $\left(24^{\circ} \mathrm{C}\right)$ and $\left.b \& d\right)$ target irradiation temperature $\left(320^{\circ} \mathrm{C}\right)$.

Figure 9 and Figure 10 also show the tensile response of the commercial alloys irradiated during the FCAY irradiation program. The APMT commercial FeCrAl alloy is of particular interest as it showed brittle failure above irradiation doses of $1.8 \mathrm{dpa}$ when tested at room temperature, as indicated by the loss of uniform and total elongation, but shows ductile behavior when tensile tested at $320^{\circ} \mathrm{C}$, Figure 10 . The APMT alloy also exhibited the highest degree of radiationinduced hardening when tested at $320^{\circ} \mathrm{C}$. 

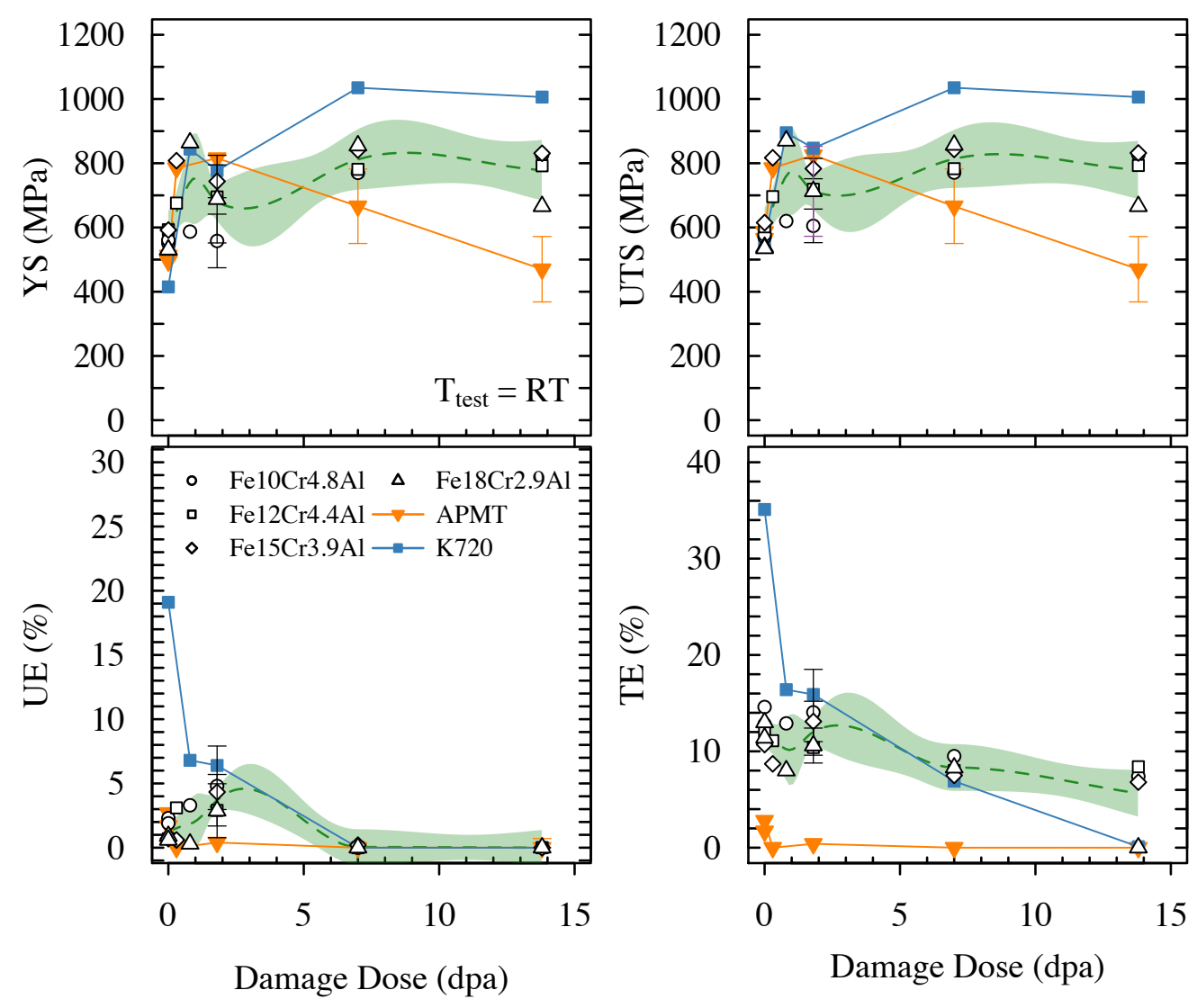

Figure 9: Summary of Generation I and commercial FeCrAl alloys tensile response as a function of dose (dpa) for tensile tests performed at room temperature. Green polygon represents local polynomial regression fitting with $95 \%$ confidence to the Generation I FeCrAl alloys. YS: Yield Strength, UTS: Ultimate Tensile Strength, UE: Uniform Elongation, TE: Total Elongation.

As noted, only room temperature tensile testing has been completed on the $\mathrm{K} 720 \mathrm{FeCrAl}$ alloy. This alloy is a well annealed alloy prior to irradiation with statistically insignificant fraction of line dislocations present prior to irradiation. The alloy shows significant degradation of ductility with increasing dose resulting in a complete loss of uniform and total elongation when irradiated to $13.8 \mathrm{dpa}$ at $320^{\circ} \mathrm{C}$. This is in contrast to the cold worked Generation I FeCrAl alloys with similar primary alloying concentration which had a pronounced dislocation networking as discussed in Section 3.1.

Several factors could be contributing to the poor radiation tolerance in the K720 including increased dislocation loop formation due to the lack of effective defect sinks as indicated by the different dislocation densities between the K720 alloy and the Generation I alloys and/or that tramp elements such as Si that are not present in the Generation I alloys are enriching at the grain boundary in the K720 alloy due to radiation-induced segregation leading to embrittlement of the grain boundaries at high dose. Further investigations are needed to confirm the mechanistic differences in the tensile responses between the Generation I FeCrAl alloys and the commercial K720 alloy. 

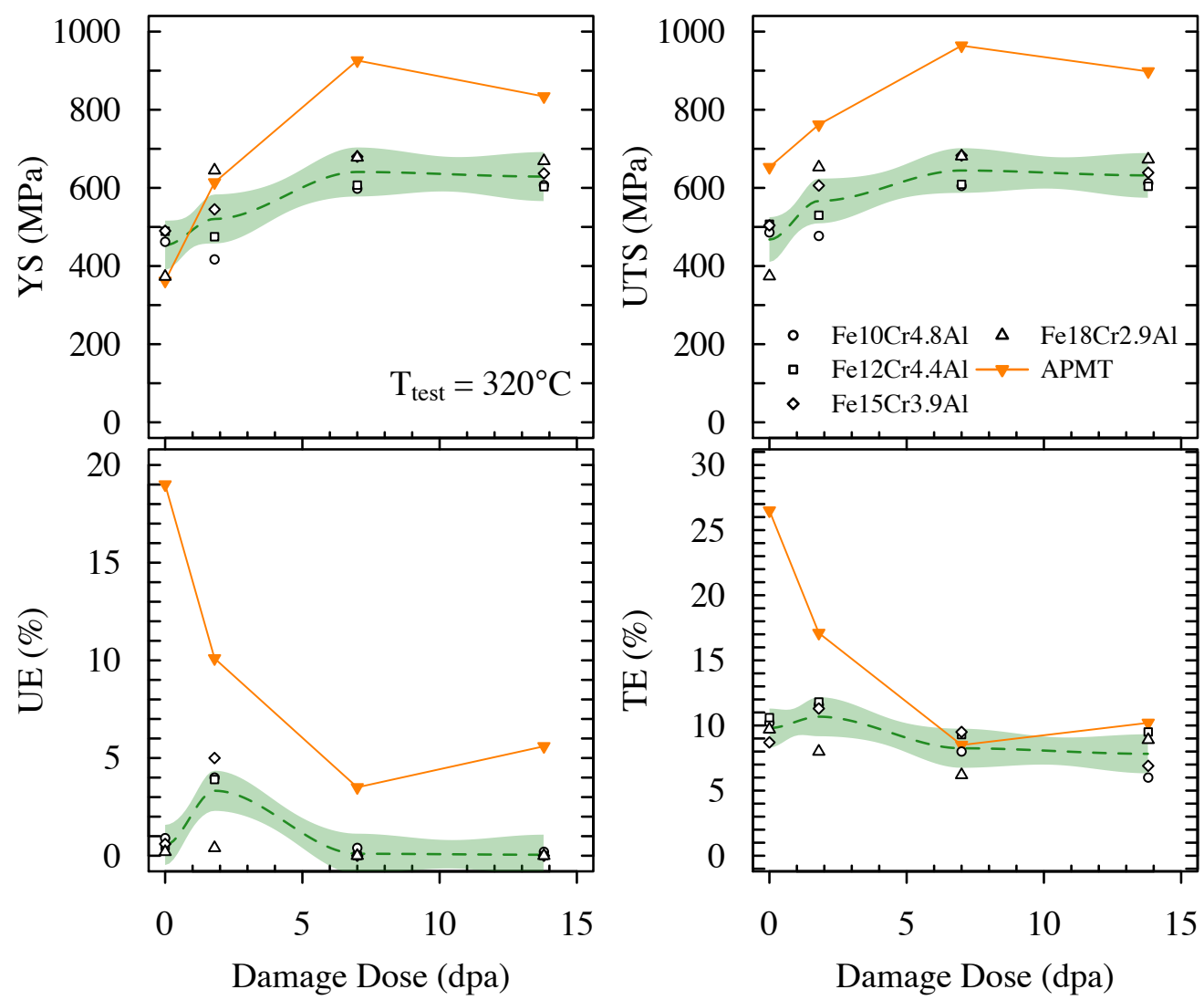

Figure 10: Summary of Generation I and APMT commercial FeCrAl alloys tensile response as a function of dose (dpa) for tensile tests performed at target irradiation temperature $\left(320^{\circ} \mathrm{C}\right)$. Green polygon represents local polynomial regression fitting with $95 \%$ confidence to the Generation I FeCrAl alloys. YS: Yield Strength, UTS: Ultimate Tensile Strength, UE: Uniform Elongation, TE: Total Elongation.

Preliminary tensile testing has been completed on the Generation II alloys irradiation to 1.8-1.9 dpa at $200^{\circ} \mathrm{C}, 330^{\circ} \mathrm{C}$, and $550^{\circ} \mathrm{C}$. All temperatures are target irradiation temperatures although preliminary $\mathrm{SiC}$ thermometry measurements indicates the $330^{\circ} \mathrm{C}$ irradiation is actually closer to $364^{\circ} \mathrm{C}$, Table 3 , but analysis of irradiation temperatures are still on going. Figure 11a shows representative engineering stress-strain curves for C06M, C35M, C36M, and C37M Generation II alloys irradiated to $1.8 \mathrm{dpa}$ at $364^{\circ} \mathrm{C}$, while Figure $11 \mathrm{~b}$ shows representative curves for the $\mathrm{C} 35 \mathrm{M}$ alloy irradiated to varying temperatures. The strong composition dependences observed in the Generation I alloys irradiated to similar dose and temperature do not appear for the Generation II alloys. Generally, all alloys performed similar with yield strengths near 900-1000 $\mathrm{MPa}$, a retention of some degree of work hardenability, uniform elongation, and total elongation. No strong Al effect was observed between the C35M, C36M, and C37M alloys.

Irradiation temperature had a strong effect on the tensile properties of the $\mathrm{C} 35 \mathrm{M}$ alloy, as expected based on literature of $\mathrm{Cr}$-rich, Fe-based ferritic alloys. Irradiation to low temperatures $\left(\sim 200^{\circ} \mathrm{C}\right)$ showed strong radiation-induced hardening with a complete loss of uniform elongation and total elongations below the $10 \%$ saturation value observed in the Generation I alloys. Irradiation to high temperature $\left(\sim 550^{\circ} \mathrm{C}\right)$ showed radiation-induced softening, with increased 
ductility and reduction in the yield strength compared to the as-received properties (not shown). Further investigation on the irradaition temperature effects on the tensile response of Generation II FeCrAl alloys will be completed after a complete irradiation temperature analysis of the FCAT-01, FCAT-02, and FCAT-03 irradiation capsules have been completed.

a)

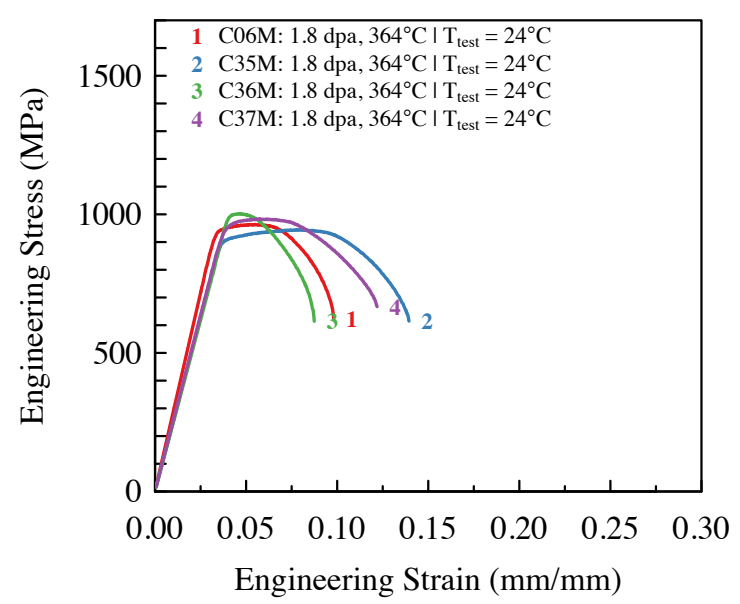

b)

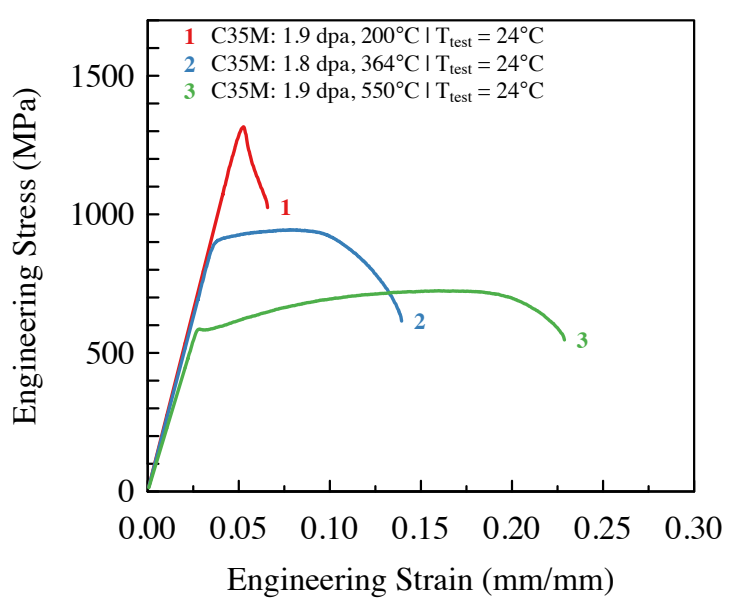

Figure 11: Plots showing representative stress-strain curves for the Generation II FeCrAl alloys, a) Generation II FeCrAl alloys of varying composition irradiated to $1.8 \mathrm{dpa}$ at $364^{\circ} \mathrm{C}$ and b) $\mathrm{C35M}$ (constant composition) irradiated to $1.8 / 9$ dpa at varying temperatures. All tensile tests performed at room temperature $\left(24^{\circ} \mathrm{C}\right)$.

\subsubsection{SEM Fractography}

All SEM-based fractography was completed within the hot cell and hence only a sub-set of specimens were investigated. Figure 12 shows typical SEM fractographs associated with room temperature tensile tests performed on the irradiated Generation I F1C5AY and B183Y-2 alloy and the commercial APMT alloy. Figure 13 shows typical SEM fractographs associated with $320^{\circ} \mathrm{C}$ tensile tests performed on the irradiated Generation I F1C5AY and B183Y-2 alloy and the commercial APMT alloy. The low $\mathrm{Cr}$ (Fe-10Cr-4.8Al, F1C5AY) alloy showed typical cup and cone ductile fracture when tested both at room temperature and at $320^{\circ} \mathrm{C}$, regardless of irradiation condition. The ductile fracture mode showed reasonable necking indicating the fracture was not highly localized. The high Cr (Fe-18Cr-2.9A1, B183Y-2) showed nearly identical responses to the low $\mathrm{Cr}$ Generation I variant when tensile tested at $320^{\circ} \mathrm{C}$, Figure 13 , but showed brittle, transgranular cleavage fracture when irradiated to $13.8 \mathrm{dpa}$ at $320^{\circ} \mathrm{C}$ and tensile tested at room temperature, Figure 12f. The brittle behavior in the $18 \mathrm{wt} . \% \mathrm{Cr}$ Generation I alloy is a behavior similar to that of the APMT alloy when tested at room temperature, Figure $12 \mathrm{~g}-\mathrm{i}$. The APMT alloy showed brittle, transgranular cleavage, even in the as-received state when tested at room temperature. This could be indicative of a poor heat of APMT obtained for this study. Given this, the APMT alloy did show reasonably non-localized deformation and ductile behavior even when irradiated to high dose $(13.8 \mathrm{dpa})$ and tensile tested at $320^{\circ} \mathrm{C}$, Figure $13 \mathrm{i}$. 
Generation I Fe-10Cr-4.8Al (F1C5AY):

a)

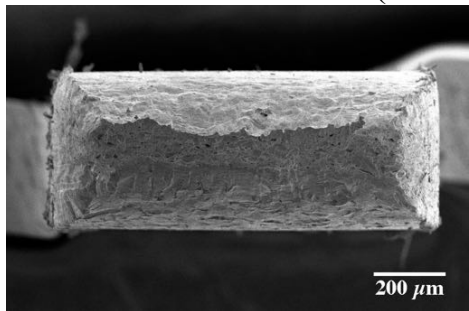

Generation I Fe-18Cr-2.9 Al (B183Y-2):

d)

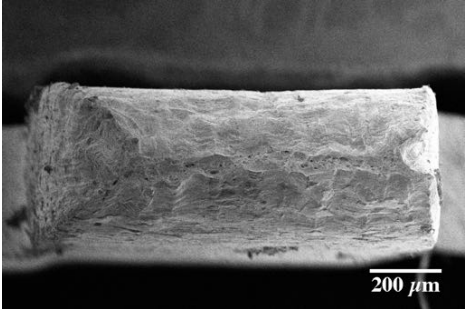

Commercial APMT FeCrAl:

g)

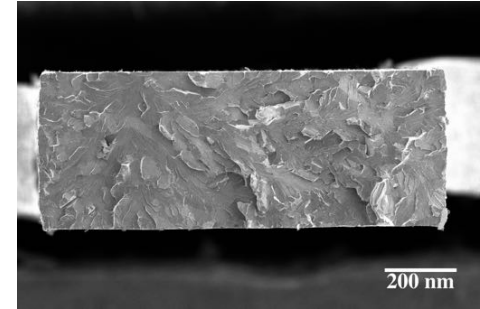

b)

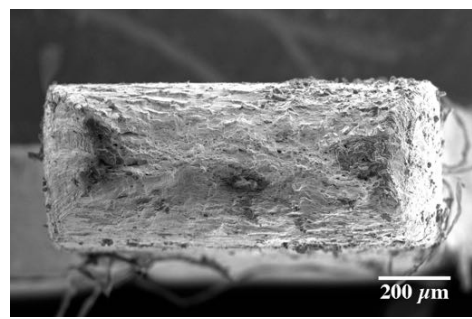

e)

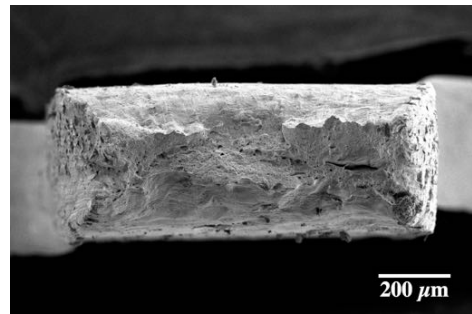

h)

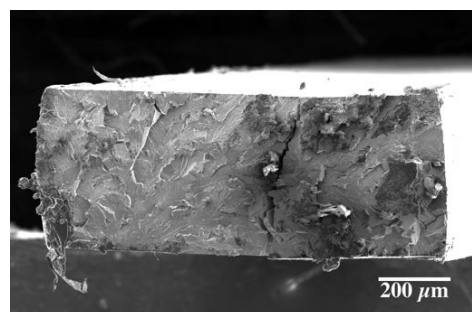

c)

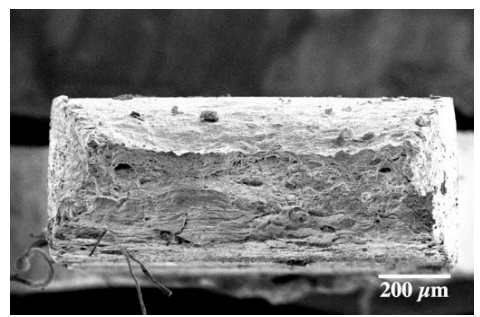

f)

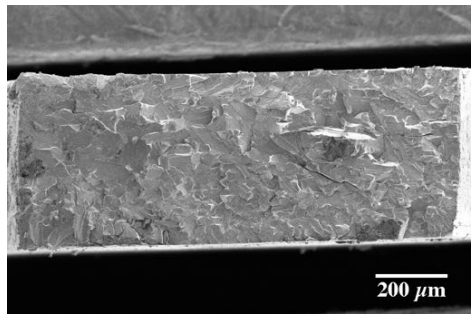

i)

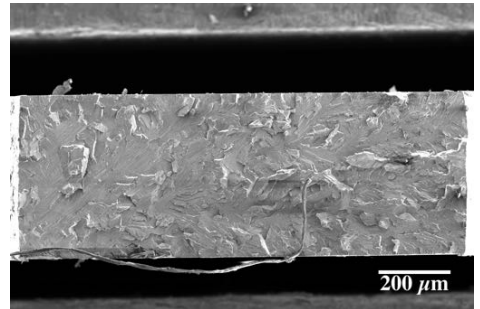

Figure 12: SEM micrographs showing the fracture surfaces after tensile testing at room temperature $\left(24^{\circ} \mathrm{C}\right)$, a-c) Fe-10Cr-4.8Al (F1C5AY), d-f) Fe-18Cr-2.9Al (B183Y-2), and g-i) APMT. $a, d, g)$ alloys in the as-received condition; $b, e, h)$ alloys irradiated to $1.8 \mathrm{dpa}$ at $382^{\circ} \mathrm{C}$; and $\left.\mathrm{c}, \mathrm{f}, \mathrm{i}\right)$ alloys irradiated to 13.8 dpa at $341^{\circ} \mathrm{C}$.

Reduction of area was measured on the specimens in Figure 12 and Figure 13, using a technique similar to that presented by Brachet et al. [45]. Figure 14 summarizes the resulting quantification of reduction of area for the irradiated alloys. Figure 14 indicates good reduction of area values $(>30 \%)$ for all alloys tested at elevated test temperatures, Figure 14b, even to doses above $7 \mathrm{dpa}$. This indicates that even though most FeCrAl alloys show a reduction in uniform elongation after irradiation, that at elevated temperatures the alloys still retain a reasonable degree of deformability. Given this, at room temperature the $18 \mathrm{wt} \% \mathrm{Cr}$ Generation I variant showed no reduction of area, indicative of the brittle fracture shown in Figure 12f, a response also observed for all APMT specimens tested at room temperature regardless of irradiation dose. The observed tensile responses and fracture responses indicates that lower $\mathrm{Cr}$ variants of $\mathrm{FeCrAl}$ alloys have higher radiation tolerance when low temperature mechanical properties are of a concern. 
Generation I Fe-10Cr-4.8Al (F1C5AY):

a)

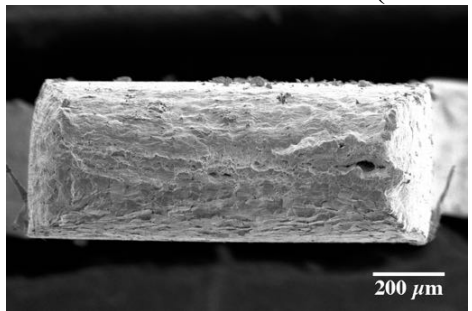

Generation I Fe-18Cr-2.9 Al (B183Y-2):

d)

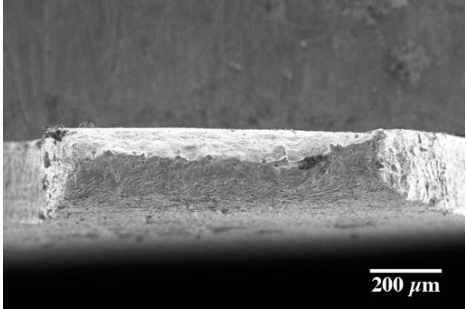

Commercial APMT FeCrAl:

g)

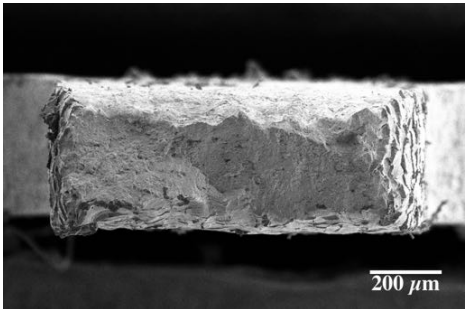

b)

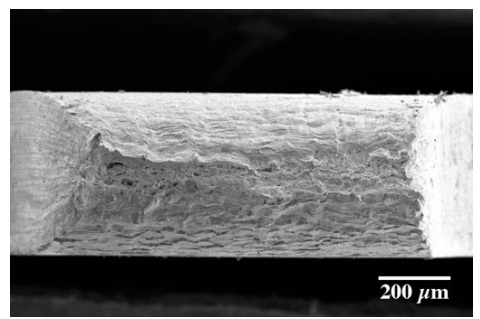

e)

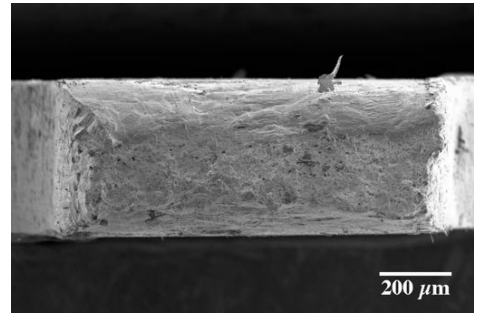

h)

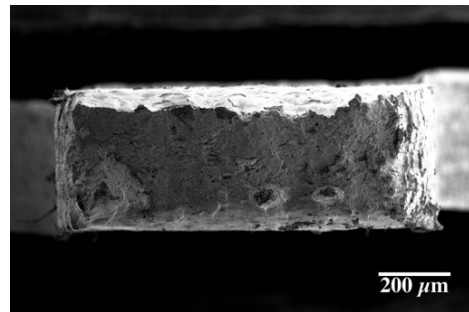

c)

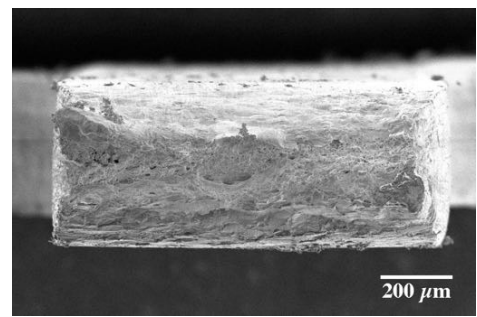

f)

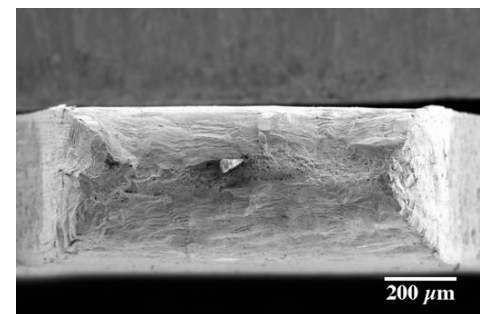

i)

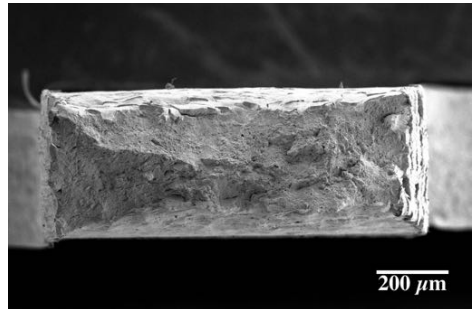

Figure 13: SEM micrographs showing the fracture surfaces after tensile testing at target irradiation temperature $\left(320^{\circ} \mathrm{C}\right)$. a-c) Fe-10Cr-4.8Al (F1C5AY), d-f) Fe-18Cr-2.9Al (B183Y-2), and g-i) APMT. a,d,g) alloys in the as-received condition; b,e,h) alloys irradiated to $1.8 \mathrm{dpa}$ at $382^{\circ} \mathrm{C}$; and c,f,i) alloys irradiated to $13.8 \mathrm{dpa}$ at $341^{\circ} \mathrm{C}$.

a)

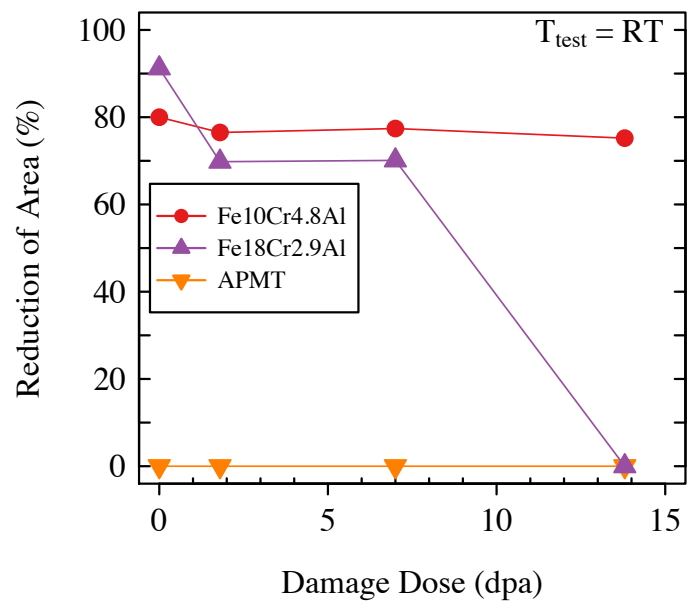

b)

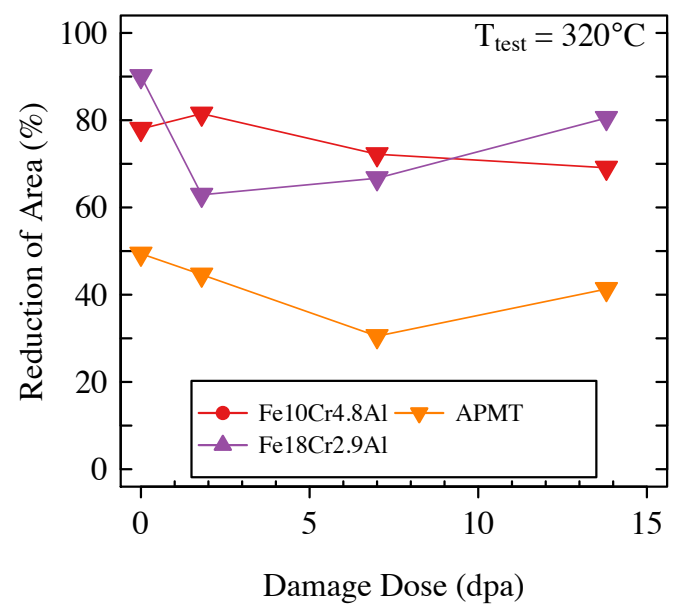

Figure 14: Reduction of area (RA) of selected Generation I and APMT FeCrAl alloys as a function of dose (dpa) for tensile tests performed at a) room temperature $\left(24^{\circ} \mathrm{C}\right)$ and b) target irradiation temperature $\left(320^{\circ} \mathrm{C}\right)$. 
SEM-based fractography has also been performed on the tensile specimens in Figure 11b, Figure 15. The fractographs show typical ductile behavior even at low (nominal $200^{\circ} \mathrm{C}$ ) irradiation temperatures when irradiated to doses below $2 \mathrm{dpa}$. Given this, it appears the reduction of area is significantly reduced during low temperature irradiations but measurement and final analysis of these values are currently pending.

Generation II C35M

a)

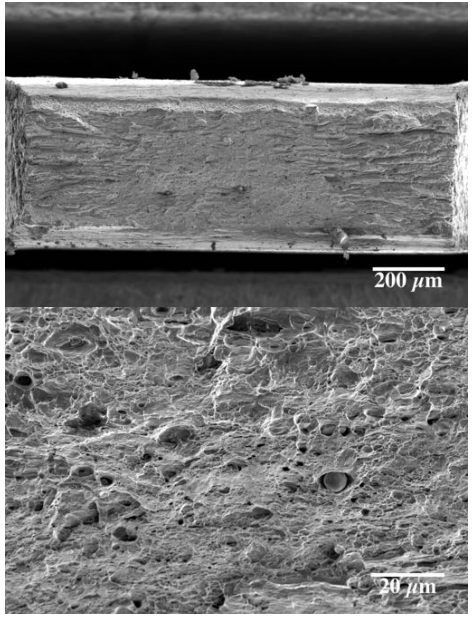

b)

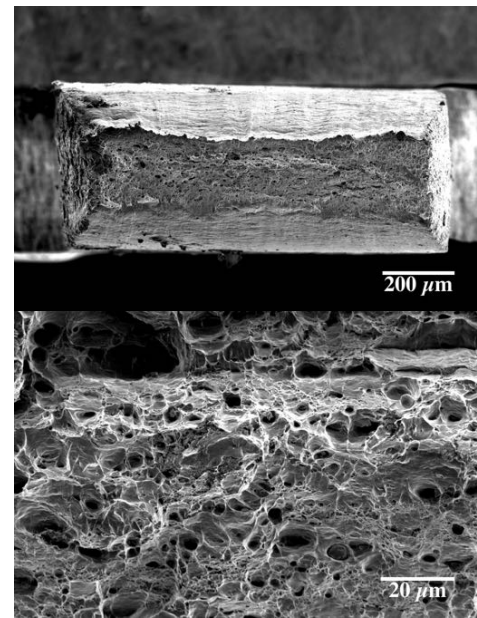

c)

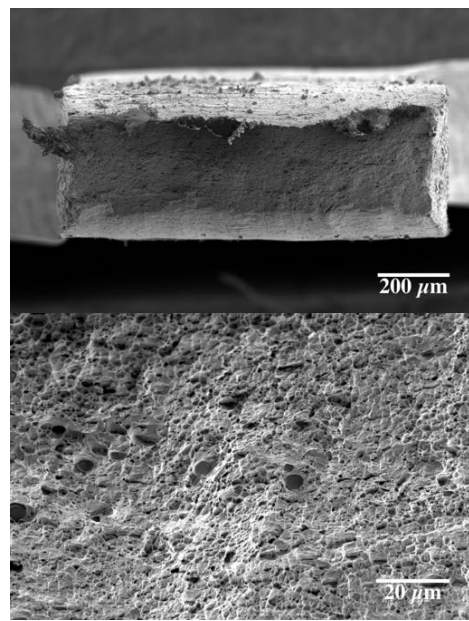

Figure 15: SEM micrographs showing the fracture surfaces after tensile testing at room temperature $\left(24^{\circ} \mathrm{C}\right)$. a\&d) $1.9 \mathrm{dpa}$ at $200^{\circ} \mathrm{C}$ nominal irradiation temperature, b\&e) $1.8 \mathrm{dpa}$ at $361^{\circ} \mathrm{C}$, and c\&f) $1.9 \mathrm{dpa}$ at $550^{\circ} \mathrm{C}$ nominal irradiation temperature; a-c) low magnification and d-f) high magnification.

\subsubsection{Conclusions of mechanical property evaluations of irradiated FeCrAl alloys}

The combined mechanical testing and fracture surface analysis allows for a comprehensive analysis of the mechanical response of irradiated $\mathrm{FeCrAl}$ alloys. To date, composition, irradiation dose, irradiated temperature, and starting microstructure trends/phenomena have been observed.

Based on the presented analysis, the following conclusions can be made:

- Generally, irradiated FeCrAl alloys exhibit classical radiation-induced hardening and embrittlement behavior of Fe-based ferritic alloys including increased yield strength and reduction in ductility with increasing radiation dose (dpa).

- Radiation-induced hardening and embrittlement severity scales with alloy Cr content in Generation I FeCrAl alloys when irradiated to doses below 7 dpa and near typical LWR irradiation temperatures. Composition dependencies are less pronounced as the alloys approach saturation in mechanical properties at and above $7 \mathrm{dpa}$. Given this, high $\mathrm{Cr}$ content $\mathrm{FeCrAl}$ alloys are more susceptible to brittle fracture in the saturation regime of irradiation dose compared to low $\mathrm{Cr}(<15 \mathrm{wt} . \% \mathrm{Cr})$ variants. 
- $\mathrm{Cr}$ and $\mathrm{Al}$ content in Generation II FeCrAl alloys have a less pronounced effect on the change in mechanical properties when irradiated to less than 2 dpa near typical LWR irradiation temperatures.

- Ductile fractures show typical cup-cone fractographs while brittle fractures appear to be transgranular cleavage fracture. Observation of mixed-mode (ductile and brittle) fracture was limited.

- Irradiation temperature, with dose constant, tends to exasperate the irradiation hardening and embrittlement response and at temperatures near $550^{\circ} \mathrm{C}$ radiation-induced softening can be observed for Generation II FeCrAl alloys.

\subsection{Irradiated Microstructures}

The formation of Cr-rich $\alpha^{\prime}$ precipitates was characterized in Generation I FeCrAl alloys using three distinct and complementary techniques in order to provide for a more comprehensive analysis of precipitate morphology and chemistry. APT allows for an atomic-scale analysis of precipitate structure and composition but samples a very small volume of material. SANS allows for bulk measurements of precipitate structure, but is sensitive to models used in analysis and assumed composition of precipitates. Finally, STEM/EDS allows for qualitative observation of precipitate dispersion and allows for determining if there is any correlation of precipitate location with other microstructural features. Results of analyses performed using each technique are discussed below.

\subsubsection{Atom probe tomography analysis of precipitates}

An unirradiated B183Y-2 specimen was selected to serve as a representative sample of the Generation I FeCrAl alloys in their as-received state to ensure that precipitates were not present in these materials prior to irradiation. No evidence of statistically significant clustering indicative of precipitation was observed in the generated atom maps, nearest neighbor distribution analyses, concentration isosurfaces, nor $\chi^{2}$ statistical analyses $[43,46]$ generated from this data set.

Indications of $\mathrm{Cr}$ clustering were observed in all irradiated Generation I FeCrAl specimens, regardless of dose or composition. A summary of the atom probe analysis results that includes final matrix and precipitate composition and cluster morphology data is given in Table 4 . Representative atom probe reconstruction data illustrating cluster morphologies for each composition irradiated to $7 \mathrm{dpa}$ and for the various dose conditions of B183Y-2 are shown in Figure 16 and Figure 17, respectively. Precipitates are represented using indexed cluster maps generated by the maximum separation method cluster finding algorithm $[47,48]$.

Atom probe results demonstrate that, as is expected, an increased alloy $\mathrm{Cr}$ content results in a more severe precipitation response, with higher precipitate number densities and volume fractions observed in the more Cr-rich FeCrAl model alloys, accompanied by a shift in precipitate size distribution to higher radii. Perhaps more interesting is that Al additions seem to destabilize the $\alpha^{\prime}$ phase, with more Al-rich alloys containing precipitates that are less enriched in Cr when compared to the $85+$ at.\% Cr precipitates typically seen in binary Fe-Cr systems [49]. 
This difference in composition may have implications on the contribution of the precipitates to the hardening response [18].

Table 4: Summary of results for APT analysis of precipitation in Generation I FeCrAl alloys. Compositions are given in at.\%.

\begin{tabular}{|c|c|c|c|c|c|c|c|c|c|c|c|}
\hline \multirow{2}{*}{ Alloy } & \multirow{2}{*}{$\begin{array}{c}\text { Irrad. } \\
\text { Dose } \\
\text { (dpa) }\end{array}$} & \multirow{2}{*}{$\begin{array}{c}\text { Irrad. } \\
\text { Temp } \\
\left({ }^{\circ} \mathrm{C}\right)\end{array}$} & \multicolumn{3}{|c|}{ Matrix Composition } & \multicolumn{3}{|c|}{$\begin{array}{c}\text { Mean Cluster } \\
\text { Composition }\end{array}$} & \multirow{2}{*}{$\begin{array}{c}\mathrm{N}_{\alpha^{\prime}} \\
\left(\times 10^{24}\right. \\
\left.\mathbf{m}^{-3}\right) \\
\end{array}$} & \multirow{2}{*}{$\frac{f_{\alpha^{\prime}}}{(\%)}$} & \multirow{2}{*}{$\frac{\mathbf{R}_{\mathbf{u}^{\prime}}}{(\mathbf{n m})}$} \\
\hline & & & $\mathbf{F e}$ & $\mathrm{Cr}$ & Al & $\mathbf{F e}$ & $\mathrm{Cr}$ & Al & & & \\
\hline $\mathrm{Fe}(10) \mathrm{CrAl}$ & 7.0 & $\begin{array}{r}319.9 \\
\pm 12.7\end{array}$ & 80.99 & 9.26 & 9.54 & $\begin{array}{c}30.59 \\
\pm 8.50\end{array}$ & $\begin{array}{r}65.55 \\
\pm 9.67\end{array}$ & $\begin{array}{c}3.73 \\
\pm 2.50\end{array}$ & $\begin{array}{c}0.51 \\
\pm 0.11\end{array}$ & $\begin{array}{c}1.75 \\
\pm 0.42\end{array}$ & $\begin{array}{c}1.48 \\
\pm 0.89 \\
\end{array}$ \\
\hline $\mathrm{Fe}(12) \mathrm{CrAl}$ & 7.0 & $\begin{array}{r}319.9 \\
\pm 12.7 \\
\end{array}$ & 80.69 & 10.61 & 8.57 & $\begin{array}{r}32.85 \\
\pm 6.85 \\
\end{array}$ & $\begin{array}{r}62.86 \\
\pm 7.30 \\
\end{array}$ & $\begin{array}{c}4.13 \\
\pm 1.60 \\
\end{array}$ & $\begin{array}{c}0.69 \\
\pm 0.01 \\
\end{array}$ & $\begin{array}{r}2.93 \\
\pm 0.15 \\
\end{array}$ & $\begin{array}{c}1.77 \\
\pm 0.81 \\
\end{array}$ \\
\hline $\mathrm{Fe}(15) \mathrm{CrAl}$ & 7.0 & $\begin{array}{r}319.9 \\
\pm 12.7\end{array}$ & 90.30 & 11.91 & 7.60 & $\begin{array}{l}20.64 \\
\pm 7.90 \\
\end{array}$ & $\begin{array}{l}75.93 \\
\pm 8.36 \\
\end{array}$ & $\begin{array}{c}3.30 \\
\pm 1.66 \\
\end{array}$ & $\begin{array}{c}2.2 \\
\pm 0.11\end{array}$ & $\begin{aligned} 5.46 \\
\pm 0.25\end{aligned}$ & $\begin{array}{r}1.55 \\
\pm 0.61 \\
\end{array}$ \\
\hline \multirow[t]{3}{*}{$\mathrm{Fe}(18) \mathrm{CrAl}$} & 0.8 & $\begin{array}{l}355.1 \\
\pm 3.4\end{array}$ & 79.11 & 14.90 & 5.90 & $\begin{array}{l}25.02 \\
\pm 6.38\end{array}$ & $\begin{array}{r}72.62 \\
\pm 6.65\end{array}$ & $\begin{array}{c}2.29 \\
\pm 1.06\end{array}$ & $\begin{array}{c}3.1 \\
\pm 0.03\end{array}$ & $\begin{array}{c}5.29 \\
\pm 0.82\end{array}$ & $\begin{array}{c}1.47 \\
\pm 0.40\end{array}$ \\
\hline & 1.8 & $\begin{array}{r}381.9 \\
\pm 5.4 \\
\end{array}$ & 80.61 & 13.21 & 6.07 & $\begin{array}{r}16.51 \\
\pm 7.00 \\
\end{array}$ & $\begin{array}{r}81.37 \\
\pm 7.37 \\
\end{array}$ & $\begin{array}{c}2.06 \\
\pm 1.08 \\
\end{array}$ & $\begin{array}{c}2.9 \\
\pm 0.31 \\
\end{array}$ & $\begin{array}{c}6.99 \\
\pm 0.65 \\
\end{array}$ & $\begin{array}{r}1.62 \\
\pm 0.52 \\
\end{array}$ \\
\hline & 7.0 & $\begin{array}{r}319.9 \\
\pm 12.7 \\
\end{array}$ & 80.61 & 13.13 & 6.02 & $\begin{array}{c}9.46 \\
\pm 6.93\end{array}$ & $\begin{array}{r}88.20 \\
\pm 7.31\end{array}$ & $\begin{array}{c}2.23 \\
\pm 1.28 \\
\end{array}$ & $\begin{aligned} & 1.9 \\
& \pm 0.06 \\
&\end{aligned}$ & $\begin{array}{c}6.56 \\
\pm 0.20 \\
\end{array}$ & $\begin{array}{r}1.79 \\
\pm 0.67 \\
\end{array}$ \\
\hline
\end{tabular}

Precipitates were observed to form as early at $0.8 \mathrm{dpa}$, the lowest dose studied by APT. These precipitates were small and seemingly immature (as indicated by composition). With continued irradiation, precipitation is seen to saturate by $1.8 \mathrm{dpa}$, with no appreciable change in volume fraction with continued irradiation to $7 \mathrm{dpa}$. In this regime, precipitates coarsen with number density decreasing and average radius increasing as larger precipitates grow at the expense of smaller precipitates.

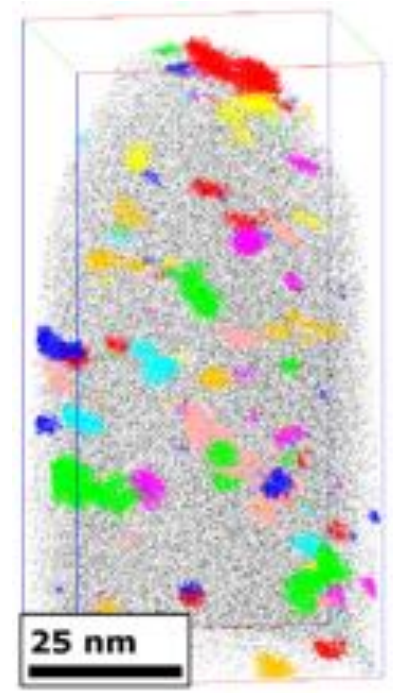

(a) $\mathrm{Fe}(10) \mathrm{CrAl}$

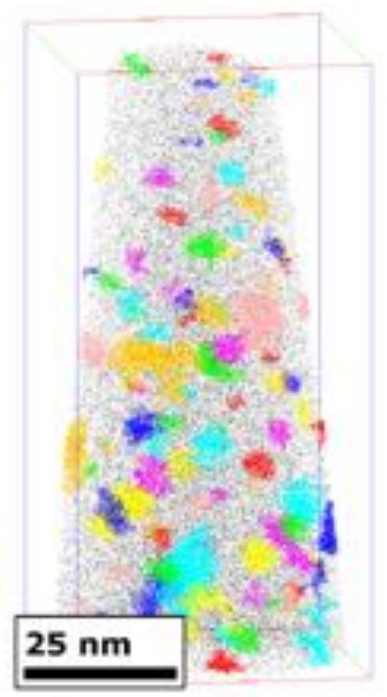

(b) $\mathrm{Fe}(12) \mathrm{CrAl}$

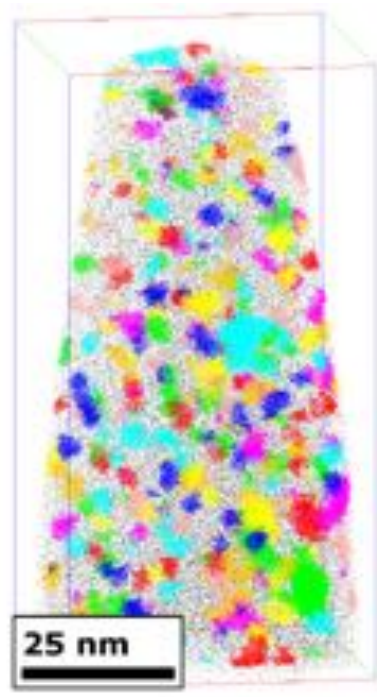

(c) $\mathrm{Fe}(15) \mathrm{CrAl}$

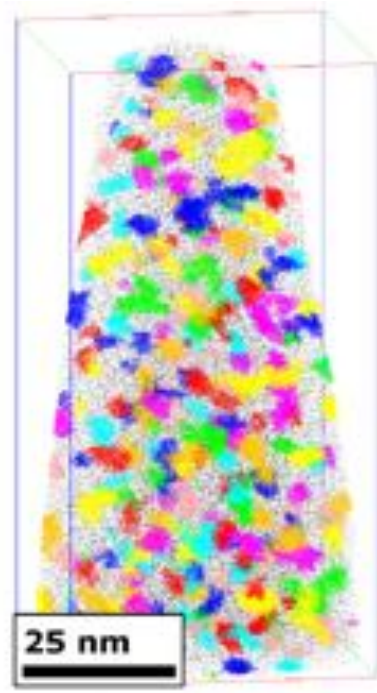

(d) $\mathrm{Fe}(18) \mathrm{CrAl}$

Figure 16: Representative atom probe reconstructions demonstrating precipitate morphology dependence on FeCrAl alloy composition. Precipitates as identified by the maximum separation method $[47,48]$ are individually colored. Black atoms represent 2 at.\% of detected matrix Fe atoms. 


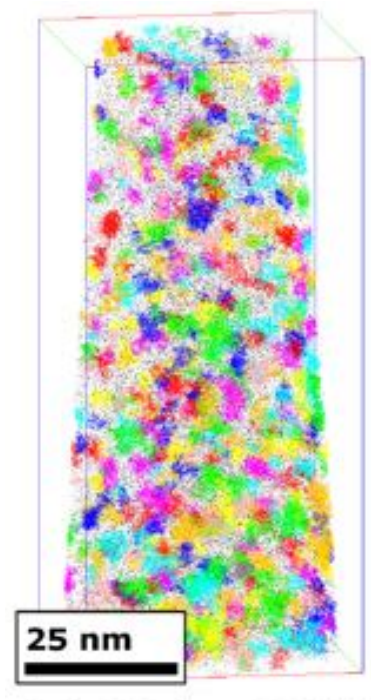

(a) $0.8 \mathrm{dpa}, 355^{\circ} \mathrm{C}$

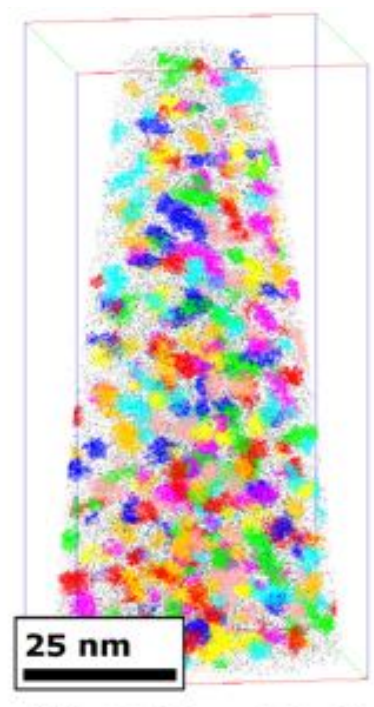

(b) $1.8 \mathrm{dpa}, 382^{\circ} \mathrm{C}$

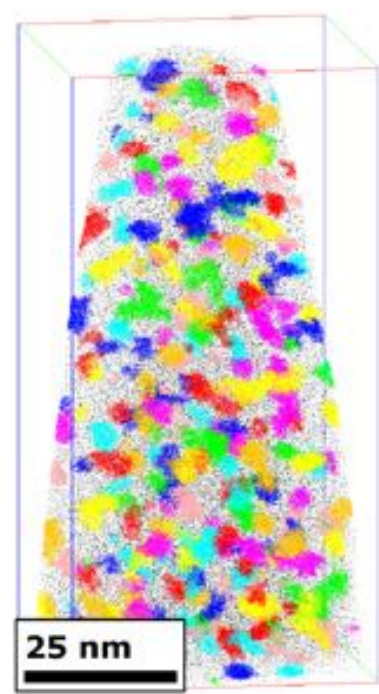

(c) $7 \mathrm{dpa}, 320^{\circ} \mathrm{C}$

Figure 17: Representative atom probe reconstructions demonstrating precipitate morphology dependence on irradiation dose for B183Y-2. Precipitates as identified by the maximum separation method $[47,48]$ are individually colored. Black atoms represent 2 at.\% of detected.

\subsubsection{Small angle neutron scattering analysis of precipitates}

Plots of SANS scattering intensities for $\mathrm{Q} \geq 0.5 \mathrm{~nm}^{-1}$ are shown in Figure 18. Figure 18a and Figure 18b compare scattering intensity for the different Generation I FeCrAl alloys for the 7 dpa dose condition and the different dose conditions for the B183Y-2 alloy, respectively. Clear differences in the intensity curves can be observed, with higher dose alloys and higher Cr alloys exhibiting more intense and sharper profiles. These qualitative trends agree with SANS observations made in other studies of $\alpha^{\prime}$ precipitation in aged and irradiated FeCrAl by several authors [50-52]. This agreement, in addition to good fits to our data in the range of $0.5<\mathrm{Q}<2.0$ $\mathrm{nm}^{-1}$, validates our use of the spherical exclusion model to analyze the SANS data.

(a)

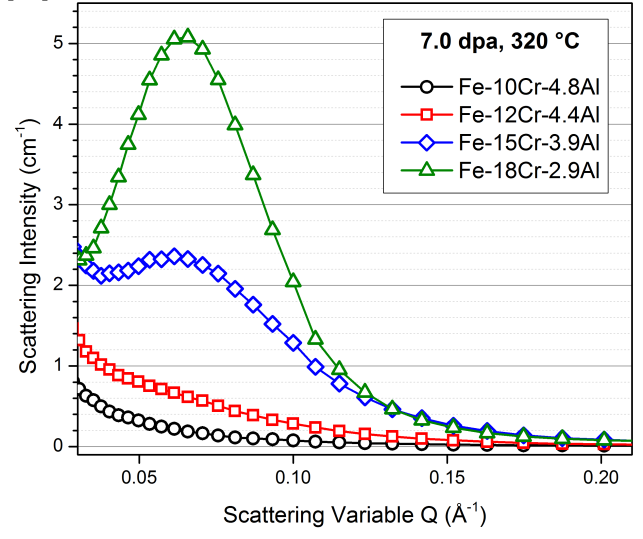

(b)

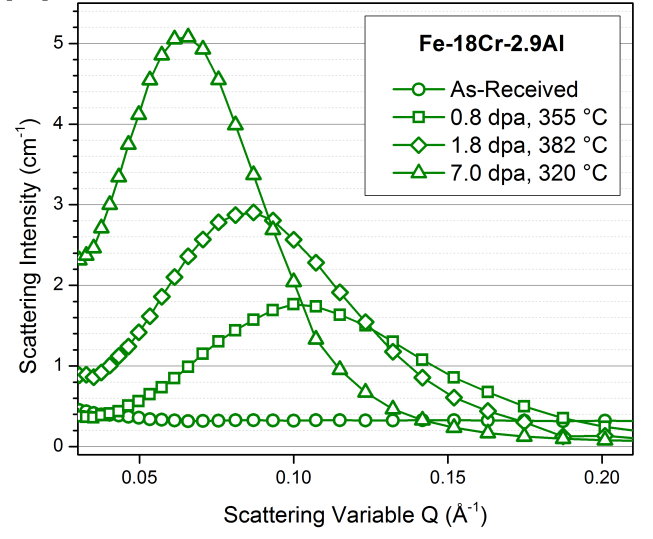

Figure 18: Plots of SANS scattering intensities for (a) the Generation I FeCrAl alloys irradiated to 7 dpa at $320^{\circ} \mathrm{C}$, and (b) the different irradiation conditions of B183Y-2. 
Table 5 summarizes the calculated $\alpha^{\prime}$ precipitate morphologies for the Generation I FeCrAl alloys considered. As discussed in Section 3.9, the SANS scattering contrast used to calculate this values is based on APT results. Number density and size trends are indicative of classical precipitate coarsening/Ostwald ripening behavior [53], which is further corroborated by excellent agreement with behavior predicted by the Lifshitz, Slyozov and Wagner (LSW) model for diffusion limited coarsening $[54,55]$. This model states that precipitate coarsening can be described by a series of temporal power laws in which average precipitate radius scales with time at temperature (and equivalently dose for a constant dose rate) to the one-third power and that number density is inversely proportional to exposure time. This agreement is depicted graphically in Figure 19, and suggests that the mechanism for coarsening in the irradiated system is similar to that of the thermally aged system.

It should be noted that volume fraction trends with increasing dose as determined by SANS suggest that precipitate volume fraction is highest at low doses and decreases with increasing fluence, which is not in agreement with APT data or expected behavior which predicts an initially non-existent volume fraction increases with fluence and eventually saturates. This discrepancy may be a result of an inadequacy in the current model being used, particularly in that a monodisperse size distribution is assumed. Determining the root cause for this discrepancy and correcting for it in the model is currently underway.

Table 5: Summary of results of SANS analysis for precipitation in Generation I FeCrAl alloys for all dose and composition conditions studied.

\begin{tabular}{|c|c|c|c|c|c|}
\hline Alloy & $\begin{array}{l}\text { Irradiation } \\
\text { Dose (dpa) }\end{array}$ & $\begin{array}{l}\text { Irradiation } \\
\text { Temp }\left({ }^{\circ} \mathrm{C}\right)\end{array}$ & $\begin{array}{c}\mathbf{N}_{\alpha^{\prime}} \\
\left(\times 10^{24} \mathbf{m}^{-3}\right)\end{array}$ & $\begin{array}{c}f_{\alpha^{\prime}} \\
(\%)\end{array}$ & $\begin{array}{c}\mathbf{R}_{\boldsymbol{\alpha}^{\prime}} \\
(\mathbf{n m})\end{array}$ \\
\hline \multirow{3}{*}{$\mathrm{Fe}(10) \mathrm{CrAl}$} & 0.8 & $355.1 \pm 3.4$ & 0.99 & 3.46 & 2.03 \\
\hline & 1.8 & $381.9 \pm 5.4$ & 0.66 & 2.88 & 2.18 \\
\hline & 7.0 & $319.9 \pm 12.7$ & 0.19 & 1.06 & 2.40 \\
\hline \multirow{3}{*}{$\mathrm{Fe}(12) \mathrm{CrAl}$} & 0.3 & $334.5 \pm 0.6$ & 6.36 & 6.86 & 1.37 \\
\hline & 1.8 & $381.9 \pm 5.4$ & 3.74 & 9.60 & 1.83 \\
\hline & 7.0 & $319.9 \pm 12.7$ & 0.78 & 3.17 & 2.13 \\
\hline \multirow{3}{*}{$\mathrm{Fe}(15) \mathrm{CrAl}$} & 0.3 & $334.5 \pm 0.6$ & 31.9 & 20.9 & 1.16 \\
\hline & 1.8 & $381.9 \pm 5.4$ & 5.45 & 13.5 & 1.81 \\
\hline & 7.0 & $319.9 \pm 12.7$ & 2.11 & 8.74 & 2.15 \\
\hline \multirow{3}{*}{$\mathrm{Fe}(18) \mathrm{CrAl}$} & 0.8 & $355.1 \pm 3.4$ & 17.0 & 25.0 & 1.52 \\
\hline & 1.8 & $381.9 \pm 5.4$ & 6.30 & 16.7 & 1.85 \\
\hline & 7.0 & $319.9 \pm 12.7$ & 1.65 & 11.1 & 2.53 \\
\hline
\end{tabular}



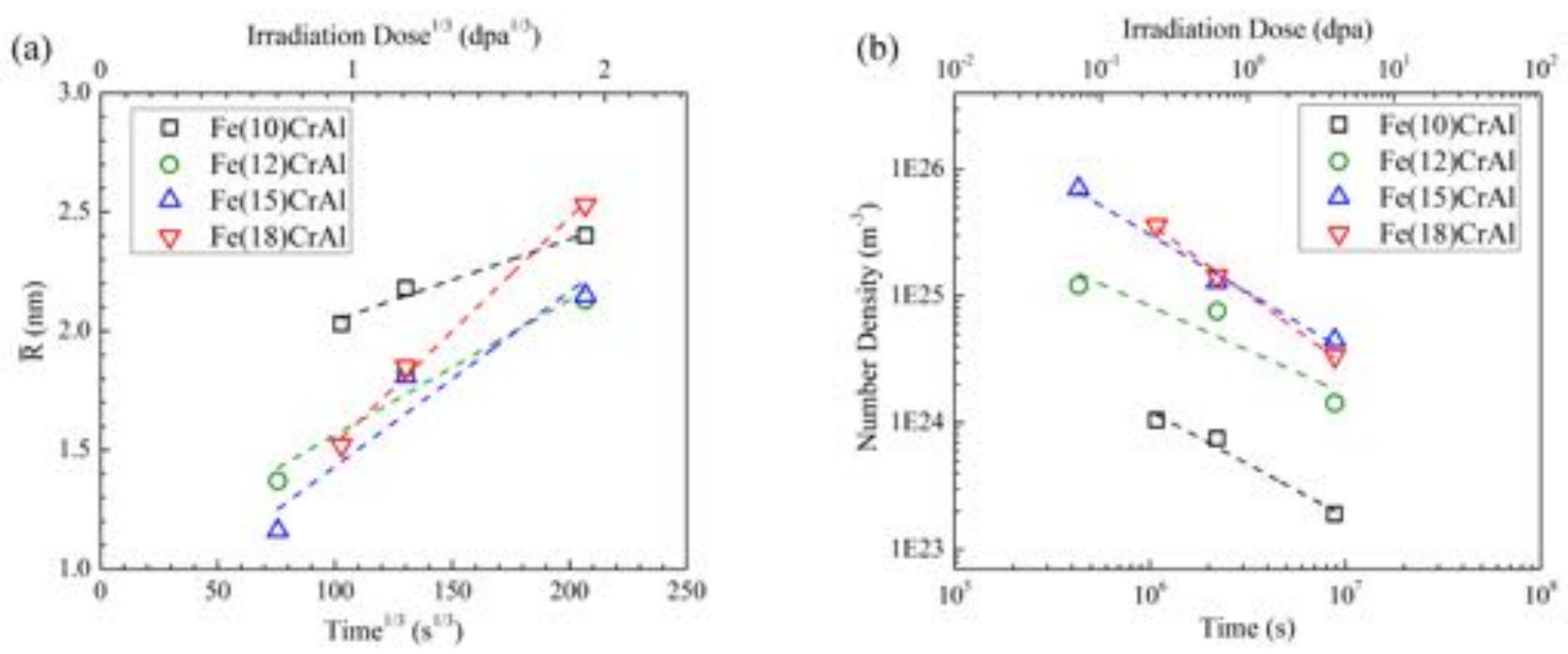

Figure 19: Comparison of observed coarsening trends with those predicted by the LSW model. Reasonable fits to the SANS data is achieved, with the plot shown in (a) demonstrating $R \propto t 1 / 3$ and (b) demonstrating $N \alpha^{\prime} \propto$ t-1.

\subsubsection{Scanning transmission electron microscopy analysis of precipitates}

Correlation of $\alpha^{\prime}$ precipitate nucleation with dislocation loops was performed by acquiring STEM/EDS maps on the [100] zone axis with simultaneous STEM imaging. Compositing the two images allows for a visual determination of any relationship between precipitate and loop structures. Such a composite image is shown in Figure 20. From these images it is apparent that precipitate nucleation is homogeneous and not at all correlated with dislocation loops.
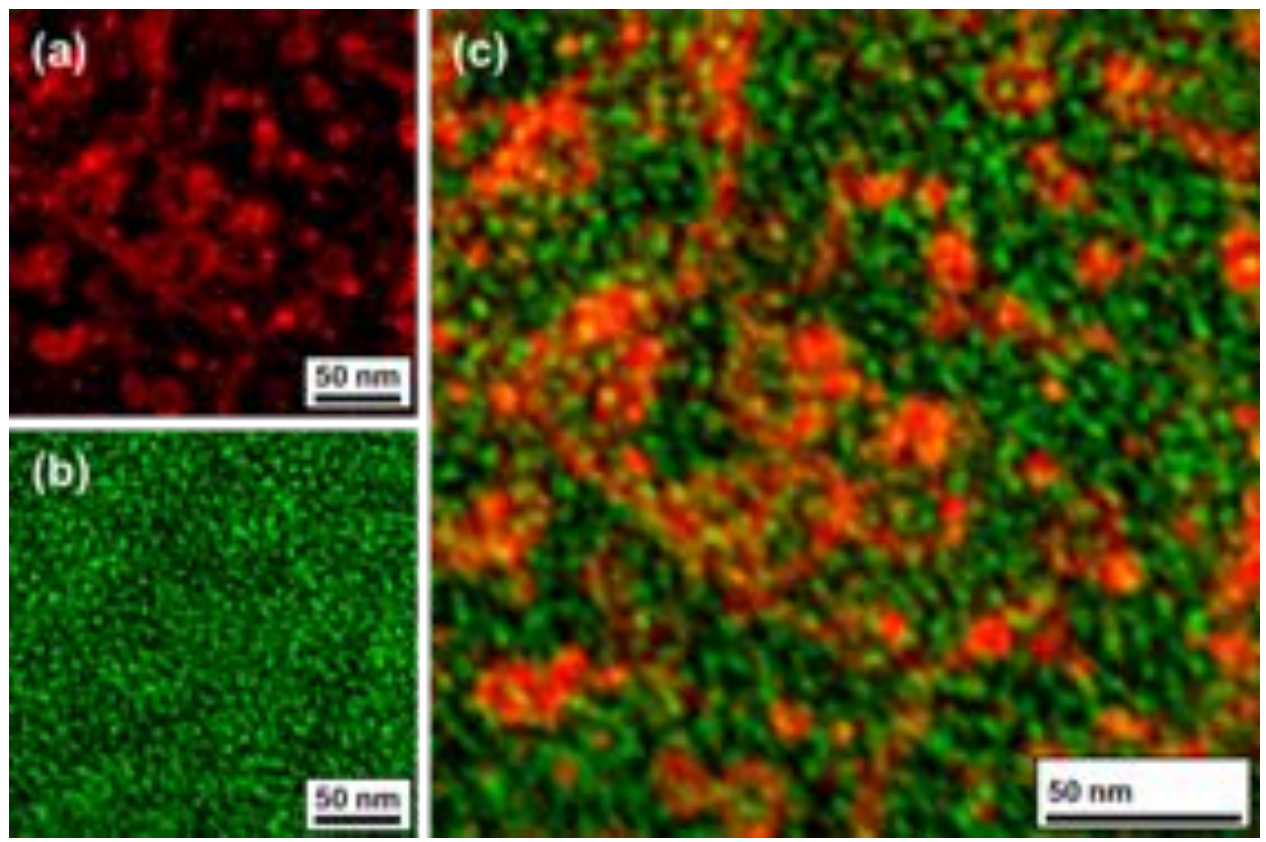

Figure 20: (a) STEM-ADF image, [110] on-zone. (b) STEM/EDS map for Cr-Ka x-rays. (c) Color overlay of ADF and EDS maps. All images from B183Y-2, $7.0 \mathrm{dpa}, 320{ }^{\circ} \mathrm{C}$. 


\subsubsection{Conclusions of correlative microscopy analysis of $\alpha^{\prime}$ precipitation}

The combined APT, SANS and STEM/EDS investigations allow for a comprehensive analysis of precipitate microstructure and chemistry. Exact quantitative agreement between APT and SANS results should not be expected due to assumptions and uncertainties inherent in each of these techniques [56]. Regardless, observed trends are generally preserved between the two analyses, allowing us to conclude that the behavior observed in the small volume of material analyzed via APT is representative of bulk behavior.

Based on the presented analysis, the following conclusions can be made:

- Precipitate response severity scales with alloy $\mathrm{Cr}$ content, while Al additions appear to partially destabilize the phase boundary, reducing the Cr content of the $\alpha^{\prime}$ phase (63-88 at.\% $\mathrm{Cr}$ ) when compared to compositions observed in similar studies performed on the binary $\mathrm{Fe}-\mathrm{Cr}$ system $(85+$ at.\% $\mathrm{Cr}$ ). These composition differences may impact embrittlement response.

- Precipitate nucleation proceeds rapidly, with the materials entering a precipitate coarsening regime by $1.8 \mathrm{dpa}$. Coarsening behavior is similar to LSW model predictions for diffusion-limited coarsening, which suggests that the coarsening mechanisms are the same for both irradiated and thermally aged materials.

- The $\alpha^{\prime}$ precipitates nucleate homogeneously, with no bias for the locations/strain fields produced by dislocation loops or other microstructural defects.

\subsubsection{Dislocation loops in irradiated Generation I FeCrAl}

General dislocation loop structures in the irradiated Generation I and commercial APMT alloy were characterized using on-zone STEM imaging as outlined by Parish et al. [31] while determination of dislocation loop nature (i.e. interstitial or vacancy type) was determined using kinematical bright-field imaging. On-zone imaging is finding popularity for characterizing dislocation loops as the on-zone technique enables all g-vectors on the [100] zone axis to be excited simultaneously. As the [100] zone contains all necessary g-vectors to image loops of both of $a / 2\langle 111\rangle$ and $a\langle 100\rangle$ Burgers vectors, and their general morphology appears differently [35], rapid determination of the size and number density of both loop populations can be determined.

\subsubsection{Dislocation loop morphology in irradiated FeCrAl}

All samples investigated, regardless of composition or irradiation condition, showed both $a / 2\langle 111\rangle$ dislocation loops, $a\langle 100\rangle$ dislocation loops, and small defect clusters determined to be "black spot" defects. To date, the low dose ( $<2$ dpa $)$ FCAY program specimens have been investigated. Figure 21 shows the dislocation loop structures in the Generation I FeCrAl alloys irradiated to $0.3-0.8 \mathrm{dpa}$ at $334-355^{\circ} \mathrm{C}$. The STEM bright field image shows edge-on loops, near perfect circles, ellipses, and line defects. The edge-on and near perfect circle (some faceting can be observed) are indicative of dislocation loops with an $a\langle 100\rangle$ Burgers vector, while the ellipses with an aspect ratio near 1:2 on the short to long axis are indicative of dislocation loops with an 
$a / 2\langle 111\rangle$ Burgers vector. The black dots in the images that are near $10 \mathrm{~nm}$ and below are the defects deemed black dot damage while the line defects are the remaining line dislocations after irradiation. It should be noted the data was removed from analysis when samples exhibited outlier number densities of black dots. This is due to black dot formation known to be a possible artifact produced during high-energy FIB sample preparation [24]. The observed morphologies are those to be expected for irradiation of Cr-rich Fe-based ferritic alloys.

a)

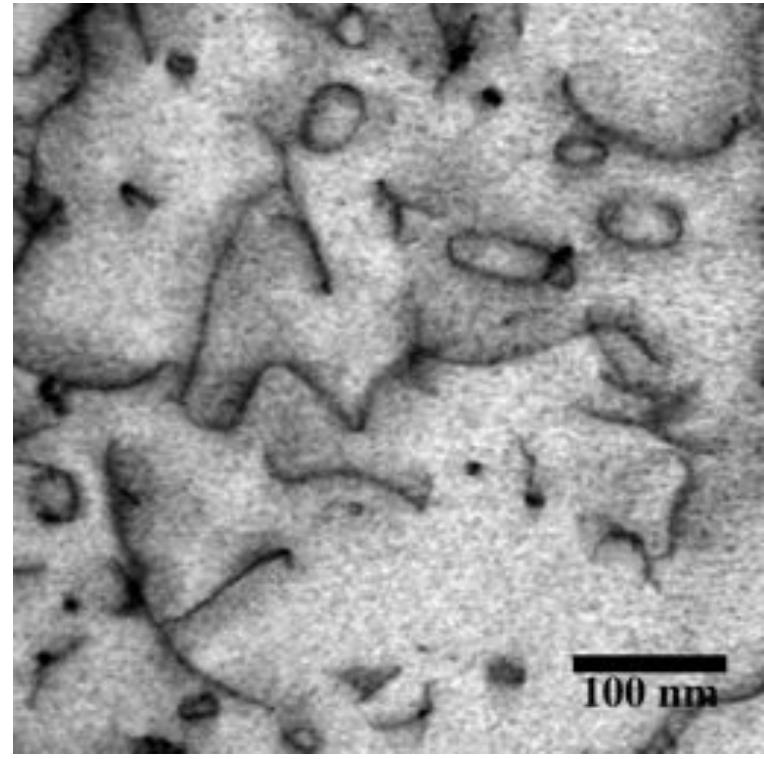

c)

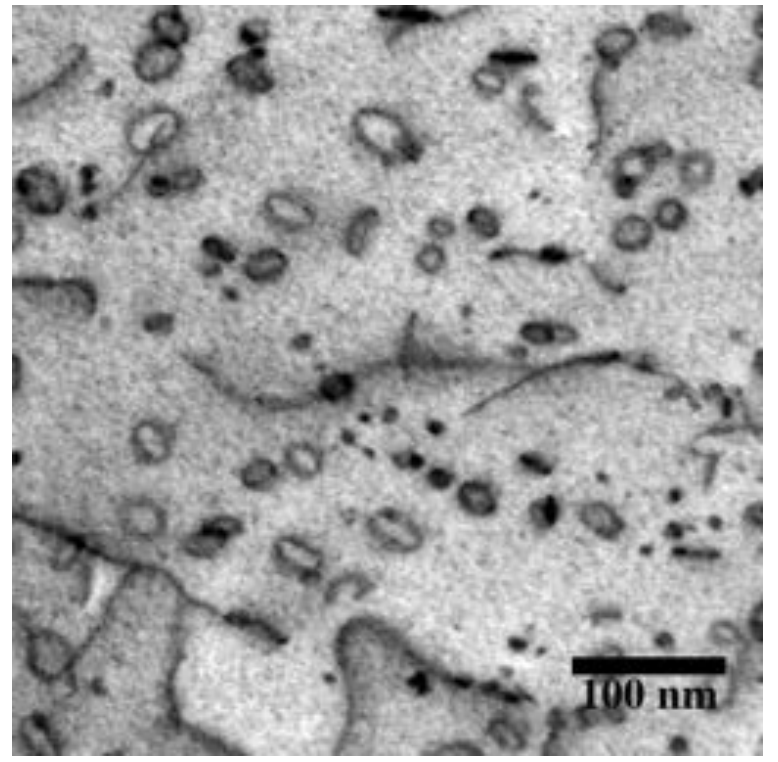

b)

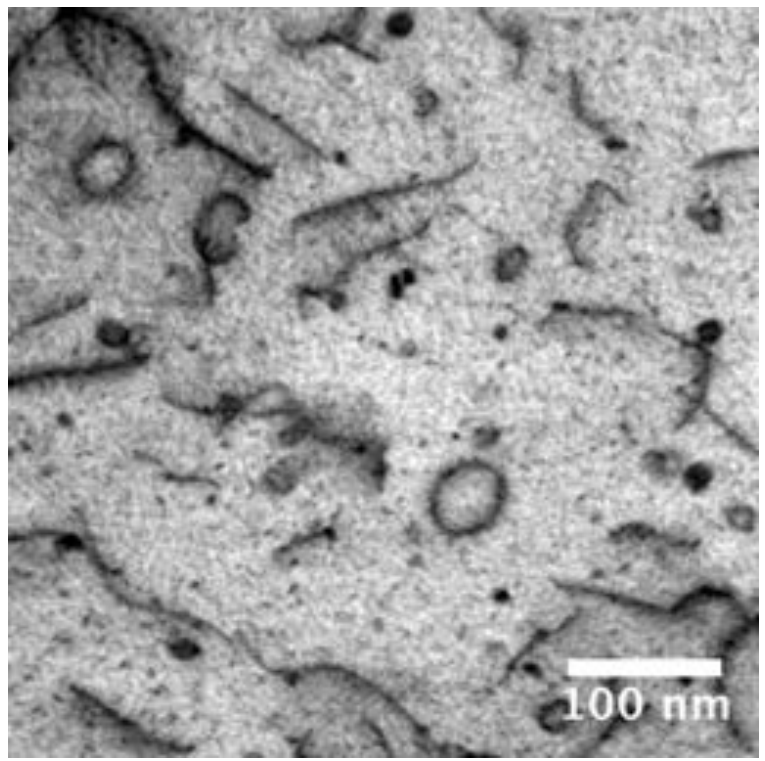

d)

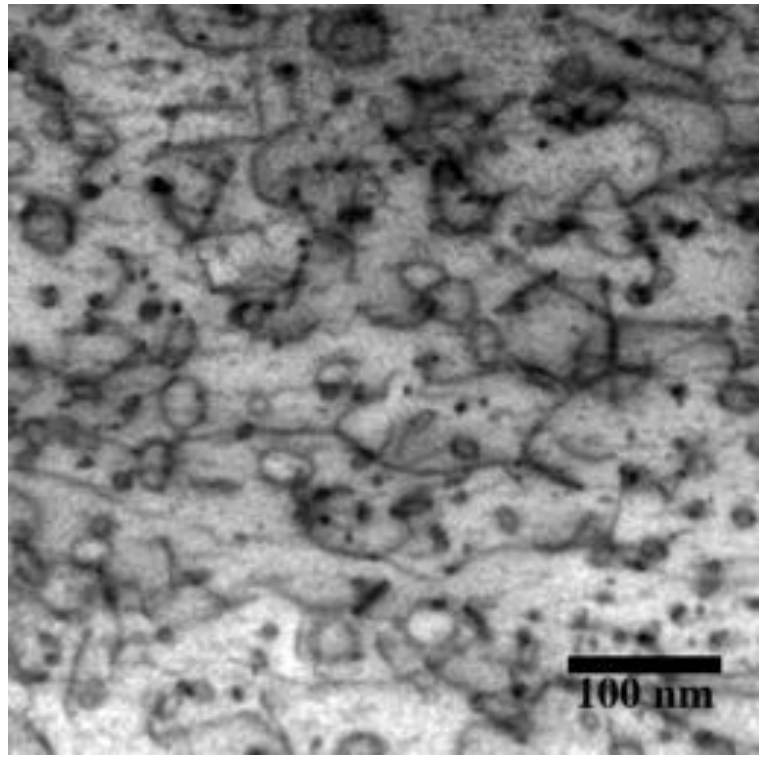

Figure 21: Dislocation structure in irradiated (a) Fe-10Cr-4.8Al, (b) Fe-12Cr-4.4Al, (c) Fe-15Cr-

3.9Al, and (d) Fe-18Cr-2.9Al alloys. STEM-ABF tilted to the [100] zone axis used to image dislocation structures. $a / 2\langle 111\rangle$ dislocation loops appear as ellipses and $a\langle 100\rangle$ dislocation loops appear edge-on. 
Similar morphologies, Figure 22, were also observed after irradiation to $1.8 \mathrm{dpa}$ at $382^{\circ} \mathrm{C}$ as previously reported by Field et al. [17] in the Generation I FeCrAl alloys. Although scales vary between Figure 21 and Figure 22, qualitatively it appears that with increasing dose the line dislocation networking has decreased while the size of edge-on $a\langle 100\rangle$ loop size increases but the other defect sizes appear relatively unchanged. To establish the quantitative number density of the defects, a plot of areal density versus specimen thickness was used while size was also measured. It should be noted that the areal density versus thickness plots for the $a / 2\langle 111\rangle$ dislocation loops, which was used for density quantification, did not intercept at zero. This indicates that a population of the $a / 2\langle 111\rangle$ loops in all samples were lost to the foil surface sometime before STEM analysis, an artifact which is unavoidable for this technique.

a)

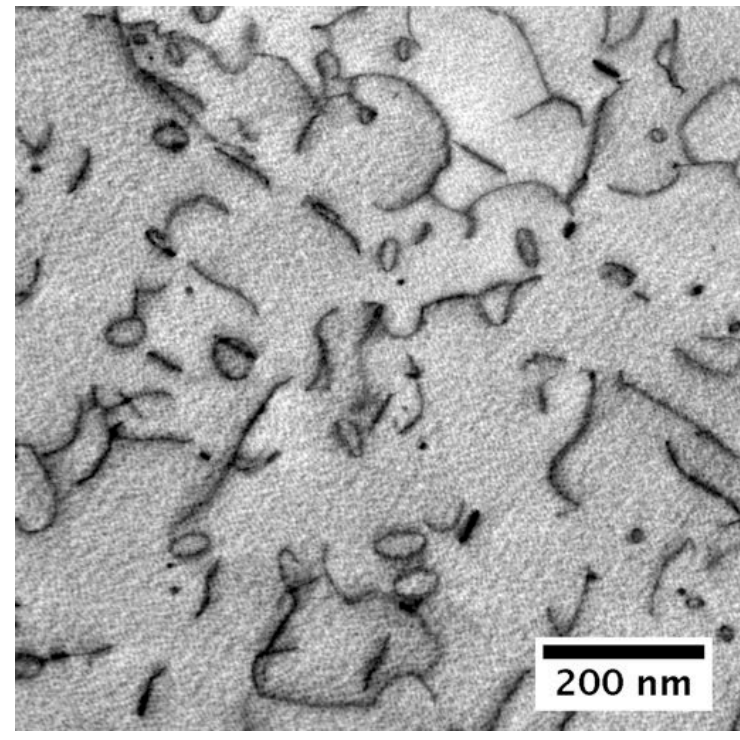

c)

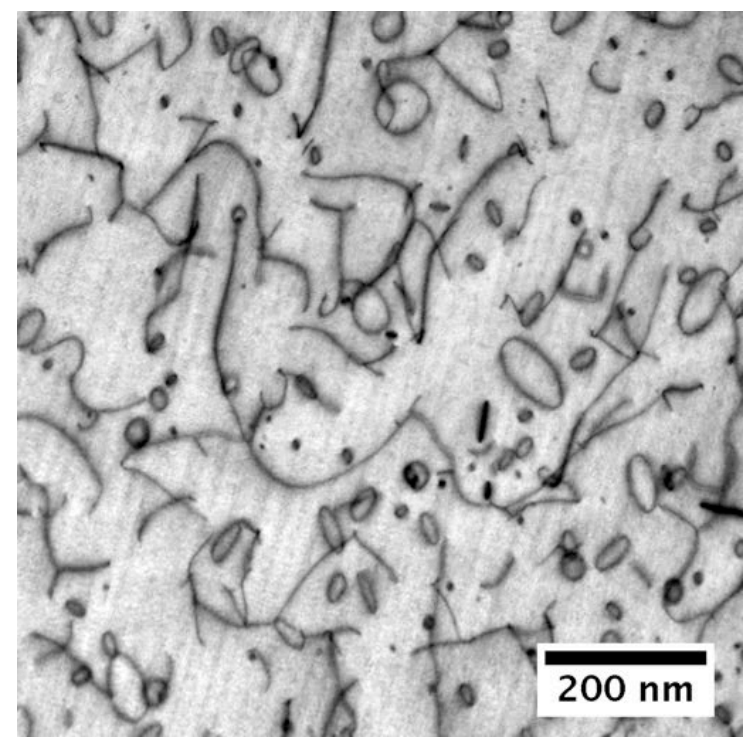

b)

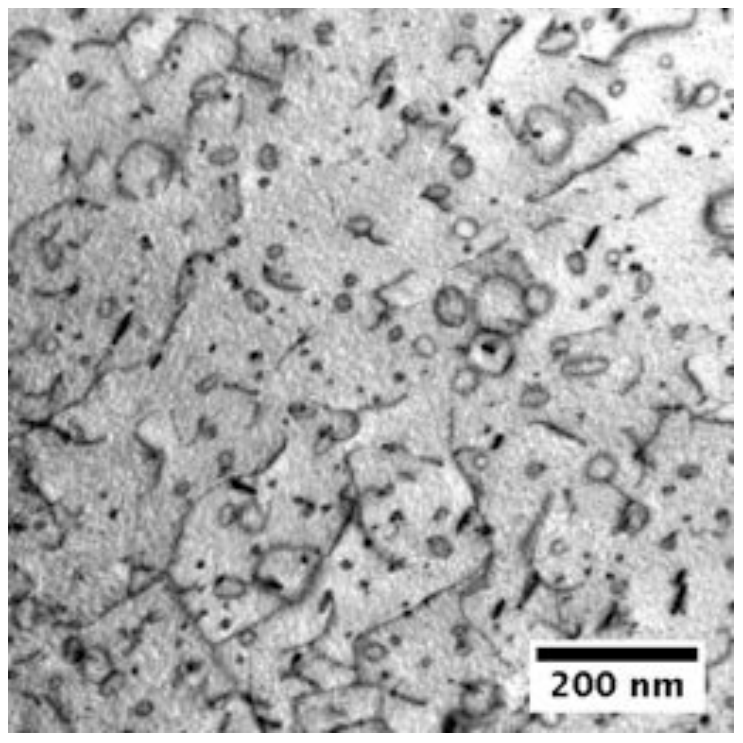

d)

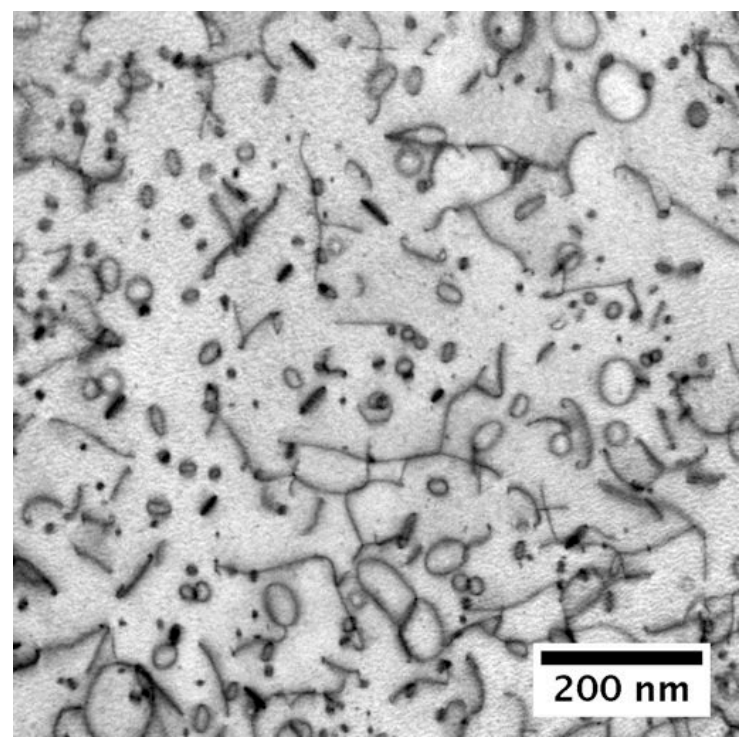

Figure 22: Dislocation structure in irradiated (a) Fe-10Cr-4.8Al, (b) Fe-12Cr-4.4Al, (c) Fe-15Cr-

3.9Al, and (d) Fe-18Cr-2.9Al alloys. STEM-ABF tilted to the [100] zone axis used to image dislocation structures. $a / 2\langle\mathbf{1 1 1}\rangle$ dislocation loops appear as ellipses and $a\langle\mathbf{1 0 0}\rangle$ dislocation loops appear edge-on. Reproduced from Ref. [17]. 


\section{A summary of the dislocation loop number density and size are provided in}

Table 6 and Figure 23. The quantitative assessments show a total reduction on the line dislocation density and black damage with increasing radiation dose. The line dislocation loss is indicative of cold work recovery in these alloys. The reduction in black dot damage could indicate that with increasing dose the loops coarsen leading to the ability for the on-zone STEM technique to distinguish the loop morphology.

Table 6: Summary of results of STEM-BF analysis for dislocation loops in Generation I FeCrAl alloys for all dose and composition conditions studied.

\begin{tabular}{|c|c|c|c|c|c|c|c|c|c|}
\hline Alloy & $\begin{array}{l}\text { Dose } \\
\text { (dpa) }\end{array}$ & $\begin{array}{c}\text { Temp } \\
\left({ }^{\circ} \mathrm{C}\right)\end{array}$ & $\underset{\left(\mathbf{m}^{-3}\right)}{\rho_{\text {bd }}}$ & $\underset{(\mathbf{n m})}{\mathbf{d}_{\mathbf{b d}}}$ & $\begin{array}{c}\rho_{<100>} \\
\left(\mathrm{m}^{-3}\right)\end{array}$ & $\begin{array}{c}d_{<100>} \\
(\mathrm{nm})\end{array}$ & $\begin{array}{l}\rho_{<111>} \\
\left(m^{-3}\right)\end{array}$ & $\begin{array}{c}d_{<111>} \\
(\mathrm{nm})\end{array}$ & $\underset{\left(m^{-2}\right)}{\rho_{\text {LD }}}$ \\
\hline $\mathrm{Fe}(10) \mathrm{CrAl}$ & 0 & $\mathrm{~N} / \mathrm{A}$ & - & - & - & - & - & - & $6.3 \pm 1.0 \times 10^{13}$ \\
\hline $\mathrm{Fe}(12) \mathrm{CrAl}$ & 0 & N/A & - & - & - & - & - & - & $1.5 \pm 0.7 \times 10^{14}$ \\
\hline $\mathrm{Fe}(15) \mathrm{CrAl}$ & 0 & N/A & - & - & - & - & - & - & $1.5 \pm 0.6 \times 10^{14}$ \\
\hline $\mathrm{Fe}(18) \mathrm{CrAl}$ & 0 & N/A & - & - & - & - & - & - & $1.0 \pm 0.5 \times 10^{14}$ \\
\hline $\mathrm{Fe}(10) \mathrm{CrAl}$ & 0.8 & $\begin{array}{l}355.1 \\
\pm 3.4\end{array}$ & $2.0 \pm 0.2 \times 10^{20}$ & $\begin{array}{c}9.1 \\
\pm 6.5\end{array}$ & $1.3 \pm 0.2 \times 10^{20}$ & $\begin{array}{c}38.0 \\
\pm 23.4\end{array}$ & $2.7 \pm 0.2 \times 10^{20}$ & $\begin{array}{l}28.3 \\
\pm 6.5\end{array}$ & $7.2 \pm 0.4 \times 10^{13}$ \\
\hline $\mathrm{Fe}(12) \mathrm{CrAl}$ & 0.3 & $\begin{array}{r}334.5 \\
\pm 0.6\end{array}$ & $7.8 \pm 0.8 \times 10^{20}$ & $\begin{array}{c}8.5 \\
\pm 3.0 \\
\end{array}$ & $2.0 \pm 0.4 \times 10^{20}$ & $\begin{array}{l}21.9 \\
\pm 13 \\
\end{array}$ & $7.1 \pm 0.6 \times 10^{20}$ & $\begin{array}{r}19.7 \\
\pm 3.0 \\
\end{array}$ & $8.5 \pm 1.0 \times 10^{13}$ \\
\hline $\mathrm{Fe}(15) \mathrm{CrAl}$ & 0.3 & $\begin{array}{l}334.5 \\
\pm 0.6\end{array}$ & $1.4 \pm 0.1 \times 10^{21}$ & $\begin{array}{c}10 \\
\pm 3.9\end{array}$ & $3.1 \pm 0.2 \times 10^{20}$ & $\begin{array}{l}22.7 \\
\pm 9.8\end{array}$ & $1.3 \pm 0.1 \times 10^{21}$ & $\begin{array}{r}23.3 \\
\pm 3.9\end{array}$ & $3.8 \pm 0.2 \times 10^{13}$ \\
\hline $\mathrm{Fe}(18) \mathrm{CrAl}$ & 0.8 & $\begin{array}{l}355.1 \\
\pm 3.4\end{array}$ & $3.5 \pm 0.2 \times 10^{21}$ & $\begin{array}{c}9.9 \\
\pm 3.1\end{array}$ & $5.1 \pm 0.5 \times 10^{20}$ & $\begin{array}{c}20.3 \\
\pm 10.5\end{array}$ & $1.4 \pm 0.1 \times 10^{21}$ & $\begin{array}{l}24.0 \\
\pm 3.1\end{array}$ & $1.7 \pm 0.2 \times 10^{14}$ \\
\hline $\mathrm{Fe}(10) \mathrm{CrAl}$ & 1.8 & $\begin{array}{r}381.9 \\
\pm 5.4\end{array}$ & $1.0 \pm 0.1 \times 10^{20}$ & $\begin{array}{c}9.1 \\
\pm 3.2\end{array}$ & $3.4 \pm 0.5 \times 10^{19}$ & $\begin{array}{c}52.5 \\
\pm 23.8\end{array}$ & $2.6 \pm 0.6 \times 10^{20}$ & $\begin{array}{c}31.9 \\
\pm 18.7\end{array}$ & $2.7 \pm 0.9 \times 10^{13}$ \\
\hline $\mathrm{Fe}(12) \mathrm{CrAl}$ & 1.8 & $\begin{array}{r}381.9 \\
\pm 5.4 \\
\end{array}$ & $1.6 \pm 0.1 \times 10^{21}$ & $\begin{array}{c}8.2 \\
\pm 4.3 \\
\end{array}$ & $2.3 \pm 0.2 \times 10^{20}$ & $\begin{array}{c}29.7 \\
\pm 13.7 \\
\end{array}$ & $1.5 \pm 0.3 \times 10^{21}$ & $\begin{array}{c}19.8 \\
\pm 11.7\end{array}$ & $4.7 \pm 1.3 \times 10^{13}$ \\
\hline $\mathrm{Fe}(15) \mathrm{CrAl}$ & 1.8 & $\begin{array}{c}381.9 \\
\pm 5.4\end{array}$ & $3.2 \pm 1.2 \times 10^{20}$ & $\begin{array}{c}9.8 \\
\pm 3.8\end{array}$ & $1.0 \pm 0.6 \times 10^{20}$ & $\begin{array}{c}41.1 \\
\pm 24.8\end{array}$ & $7.9 \pm 1.2 \times 10^{20}$ & $\begin{array}{c}30.4 \\
\pm 16.8\end{array}$ & $2.9 \pm 1.2 \times 10^{13}$ \\
\hline $\mathrm{Fe}(18) \mathrm{CrAl}$ & 1.8 & $\begin{array}{r}381.9 \\
\pm 5.4 \\
\end{array}$ & $8.8 \pm 1.1 \times 10^{20}$ & $\begin{array}{c}8.4 \\
\pm 3.4 \\
\end{array}$ & $2.0 \pm 0.3 \times 10^{20}$ & $\begin{array}{c}32.0 \\
\pm 15.6 \\
\end{array}$ & $7.2 \pm 1.0 \times 10^{20}$ & $\begin{array}{c}25.5 \\
\pm 15.4 \\
\end{array}$ & $6.0 \pm 0.9 \times 10^{13}$ \\
\hline
\end{tabular}

$\rho$ : number density, d: diameter

bd: black dot damage, $<100>$ : $a\langle 100\rangle$ dislocation loops, $<111>: a / 2\langle 111\rangle$ dislocation loops, LD: line dislocations

In the lower dose conditions $(<1 \mathrm{dpa})$, the Fe-10Cr-2.9Al alloy showed the largest loops and lowest accumulated dislocation loop density. These effects could be representative of the lower $\mathrm{Cr}$ content reducing the nucleation stage of dislocation loop formation resulting in the loops progressing towards a coarsening stage at lower doses compared to the high $\mathrm{Cr}$ content $\mathrm{FeCrAl}$ alloys. Investigations into effect are currently on going using in-situ ion beam irradiations, but were not completed at the time of this report. Above 1 dpa the composition trends for number density are less distinct. The average loop size increases for the $a\langle 100\rangle$ dislocation loops while the $a / 2\langle 111\rangle$ and black dot loop size remains relatively unchanged between the varying irradiation conditions. The increasing size of $a\langle 100\rangle$ dislocation loops with increasing dose could indicate that the $a\langle 100\rangle$ dislocation loops are growing as the result of the absorption of freely migrating defects including black dot damage and small $a / 2\langle 111\rangle$ loops $[57,58]$. The presence of $a / 2\langle 111\rangle$ dislocation loops indicates that although the loops are mobile at the investigated irradiation temperature [57] they are not fully lost to defect sinks such as grain 
boundaries under irradiation. For the cold worked Generation I FeCrAl alloys, no grain boundary effect was observed.

a)

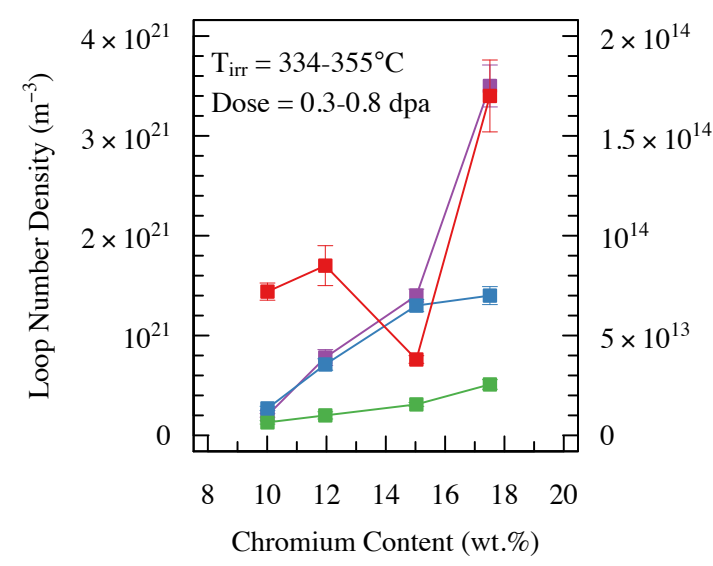

c)

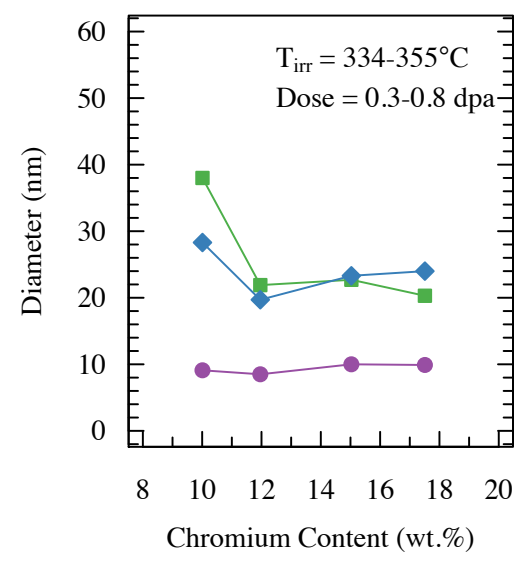

b)

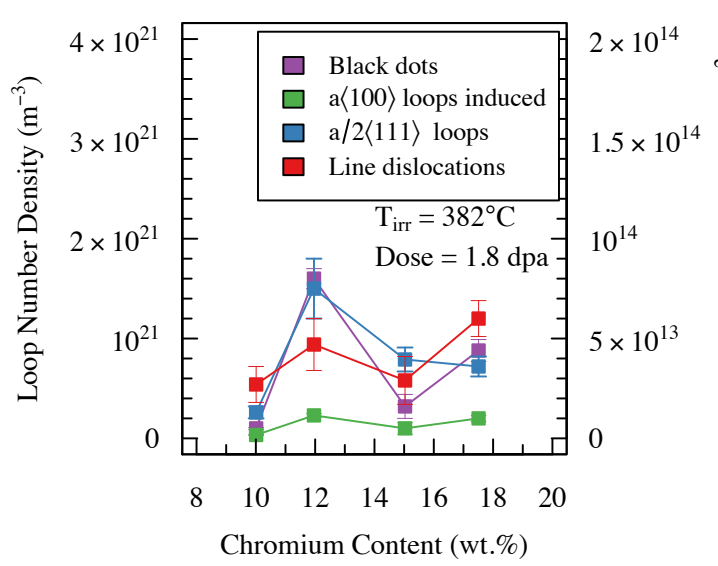

d)

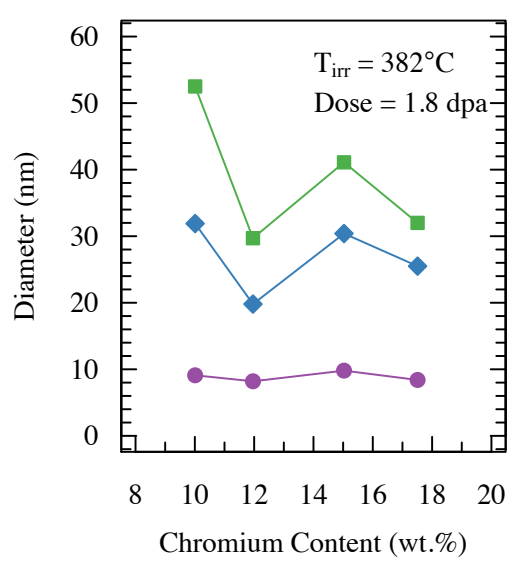

Figure 23: Summary of Generation I FeCrAl dislocation loop populations as a function of $\mathrm{Cr}$ content (in wt.\%) after irradiation to a\&c) 0.3-0.8 dpa between the temperatures of $334-355^{\circ} \mathrm{C}$ and b\&d) $1.8 \mathrm{dpa}$ at $382^{\circ} \mathrm{C}$. Number densities are shown in $a \& b$ while diameter is shown in c\&d.

A grain boundary effect was observed in the $\mathrm{K} 720$ alloy irradiated to $1.8 \mathrm{dpa}$ at $382^{\circ} \mathrm{C}$. A total of six grain boundaries were analyzed for heterogeneous dislocation loop formation. All grain boundaries were indexed to be random HAGBs. Random HAGBs have been shown through RIS studies to act in the perfect sink criteria [59-64] and hence it is anticipated all grain boundaries have the same or very similar defect sink strength and interactions. Figure $24 \mathrm{a}-\mathrm{b}$ shows representative micrographs of the dislocation loop populations near one of these random HAGBs. The dislocation loops and defect clusters were determined as $a\langle 100\rangle$ dislocation loops, $a / 2\langle 111\rangle$ dislocation loops, and black dot damage. The indexed loop types and their respective spatial distributions and morphologies can be seen in Figure 24c. Note, images in Figure 24 are a cropped FOV, total FOVs for each grain boundary were significantly larger.

Near the grain boundary in the irradiation K720 sample, the $a / 2\langle 111\rangle$ dislocation loops are the dominant feature with an increased number density compared with the grain interior and loop 
sizes of 40-60 nm. The $a\langle 100\rangle$ dislocation loops do not appear to have such a pronounced change in number density as a function of distance away from the grain boundary although the size changes as a function of distance from the grain boundary generally match those of $a / 2\langle 111\rangle$ dislocation loops. On-going quantitative measurements of size and number density of defects near grain boundaries in the irradiated K720 sample show a peak number density near $100-120 \mathrm{~nm}$ from the grain boundary. Peak cavity density has been measured in other materials and has been related to $\sim 10 \times$ the areal cavity spacing [65]. Here, the average areal defect spacing was approximated near $20 \mathrm{~nm}$ for the six investigated grain boundaries resulting in a peak density distance to defect spacing ratio of $\sim 7.0$, a value lower than that reported for cavities in neutron irradiated $\mathrm{Al}$ or $\mathrm{Ni}$. Although not identical, the ratio value seems within the reasonable range when taking into account the different material systems, defect type(s), and the fact that the defect spacing is a two-dimensional value derived from the projection of defects in a three dimensional distribution in the FIB foil specimen.

(a)

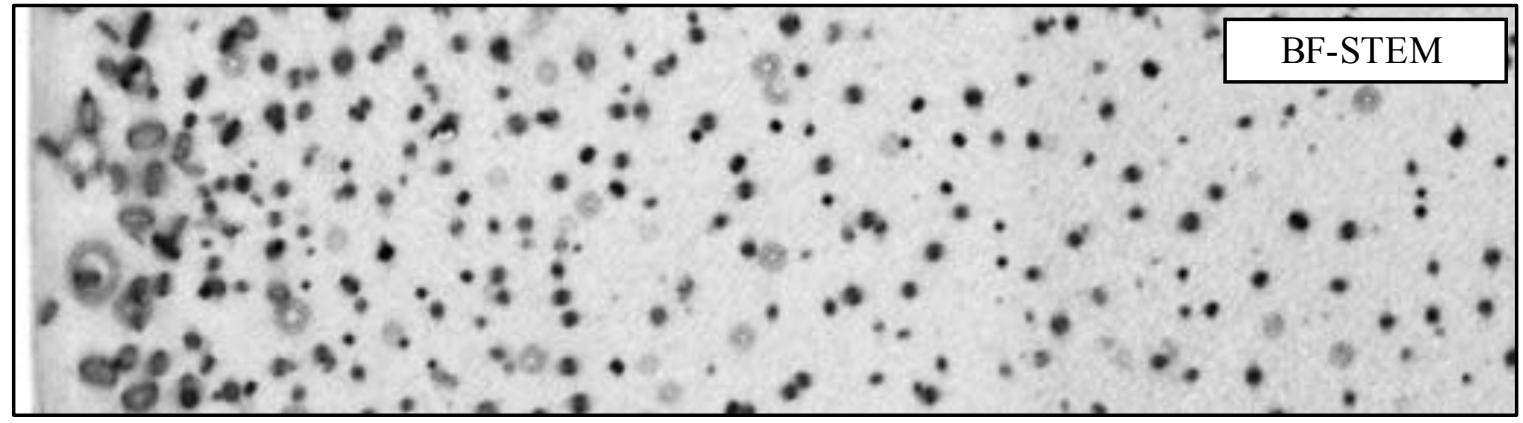

(b)

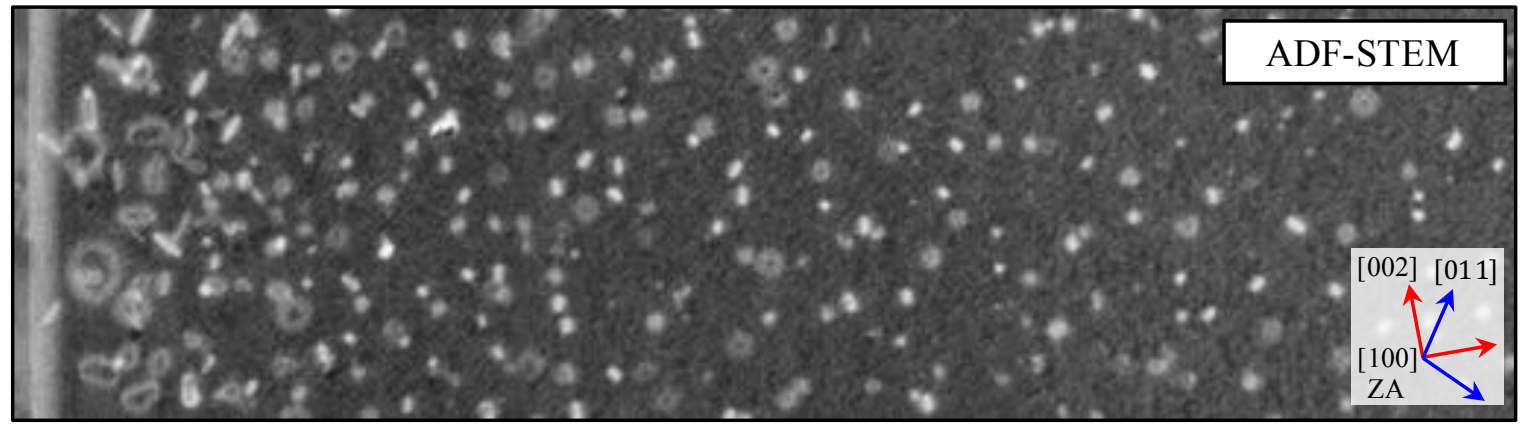

(c)

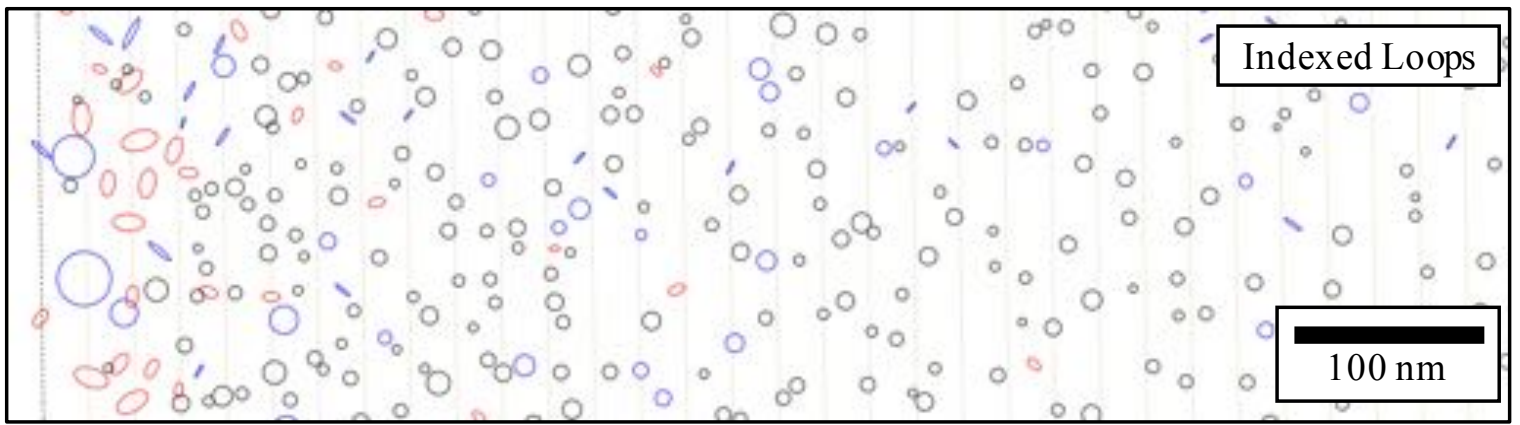

Figure 24: Dislocation loop distribution as of function of distance from a grain boundary in the K720 sample irradiated to $1.8 \mathrm{dpa}$ at $382^{\circ} \mathrm{C}$. (a) BF-STEM image, (b) ADF-STEM image, (c) indexed loop map showing different loop types; black circles are black dot damage, red ellipses are $a / 2\langle\mathbf{1 1 1}\rangle$ loops, blue circles are in-plane $a\langle\mathbf{1 0 0}\rangle$ loops, and blue ellipses are edge-on $a\langle\mathbf{1 0 0}\rangle$ loops. Thickness of sample is $74.5 \pm 5.2 \mathrm{~nm}$. 
The grain boundary effect observed in the K720 has a practical application. At simplest interpretation, this effect would mean if the average sink spacing approached $\sim 2 \mathrm{x}$ the peak number density distance from the grain boundary (i.e. $\sim 200-240 \mathrm{~nm}$ ), then the average size of dislocation loops should be increased while the dislocation loop number densities should also be increased. In the Generation I FeCrAl alloys, the dislocation cell wall spacing approached these values as shown in Figure 2. A comparison of the size and number density of the defects in the Generation I $12 \mathrm{wt} . \%$ Cr alloy to the near high angle grain boundary and grain interior is shown in Figure 25. Similarities in the dislocation loop sizes can be observed in Figure 25a between the bulk values for the cold-shaped Generation I alloy and the near grain boundary values for the K720 alloy irradiated to the same conditions. Such similarities and effect indicates the possibility for tailoring the dislocation loop populations based on grain size and initial cold working/shaping prior to irradiation.
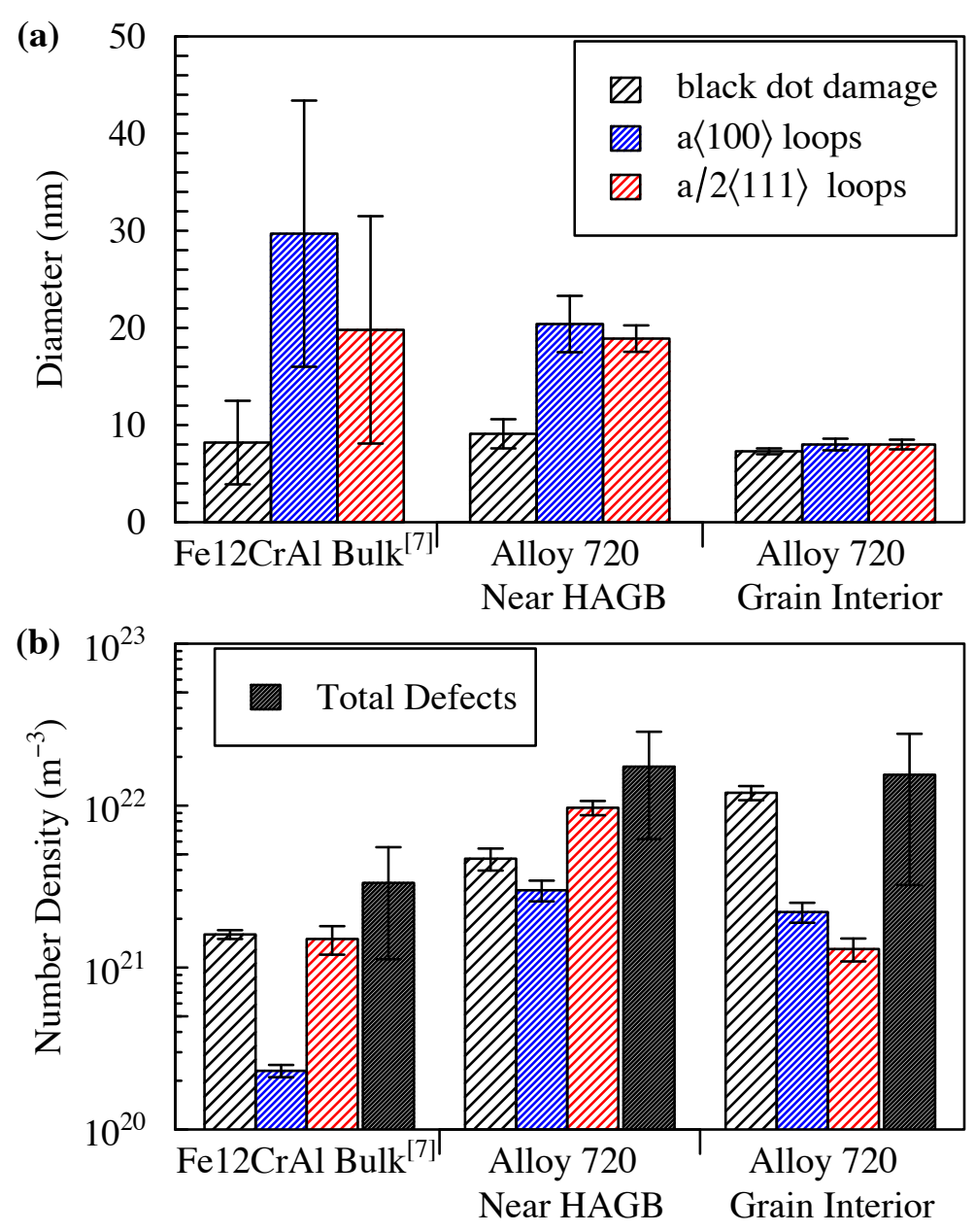

Figure 25: Comparison of size and number density of imaged defects in the cold-shaped B125Y-2 model alloy to the defects observed in the annealed K720 sample irradiated to the same condition. 


\subsubsection{Nature of dislocation loops}

Dislocation loop nature analysis was completed using a series of tilted foil images in kinematical two-beam imaging conditions for the B183Y-2 sample irradiated to $1.8 \mathrm{dpa}$ at $382^{\circ} \mathrm{C}$. Due to the time intensive nature of the analysis technique, this sample and condition and only the nature of the $a / 2\langle 111\rangle$ dislocation loops have been investigated to date. The tilt series included imaging the foil at $\pm 011, \pm 01-1, \pm 020$ and \pm 002 close to the [100]. Determination of the exact Burgers vector, i.e. not just the family of either $a\langle 100\rangle$ dislocation loops or $a / 2\langle 111\rangle$ dislocation loops but the polarity of vector, is often difficult to achieve due to the limited tilting available. An example of the method is shown in Figure 26.

a)

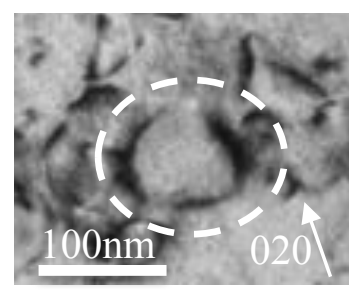

d)

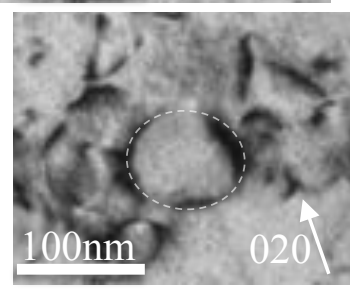

b)

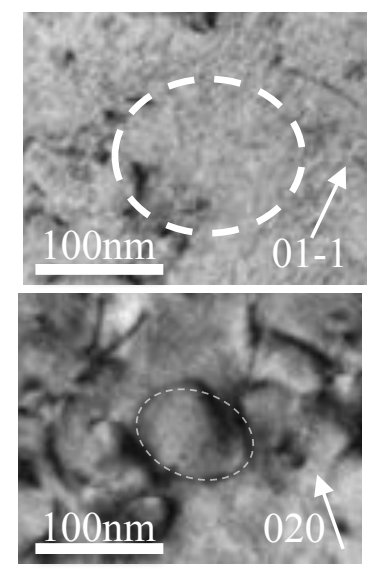

c)

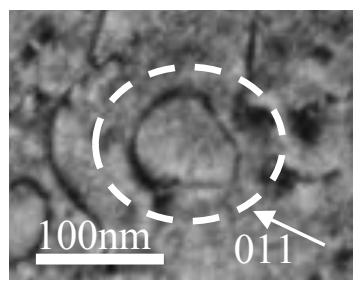

f)

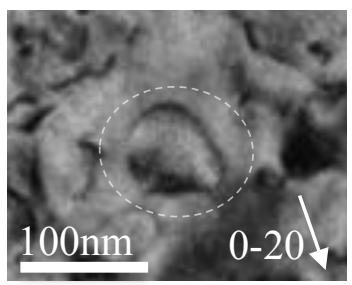

Figure 26: Kinematical two-beam bright field images of an $a / 2\langle 111\rangle$ dislocation loop imaged in varying foil tilts to determine the defect nature: a) titled to $+020, b)$ tilted to the $01-1$, and c) titled to the 011 to determine the loops Burgers vector. $d$ ) titled to the 020 near the $[100]$ zone axis and to e)

the 020 near the [30-1] zone axis confirms the loop's Burgers vector. e) tilted to the 0-20 to determine inside-outside contrast formation.

Based upon the invisibility criterion $\mathbf{g . b}=0$ and Figure $26 \mathrm{a}-\mathrm{c}$, it can be said that this loop has a Burgers vector of either $\pm 1 / 2[-111]$ or $\pm 1 / 2[111]$, but by seeing the projected width of the loop widen when titled close to the [100] pole, Figure 26d, compared to when the loop is titled at the same condition near the [30-1] indicates the exact Burgers vector is $\pm 1 / 2$ [111]. Inside-outside contrast [66] can then be used to determine the nautre of the dislocation loop. Outside contrast is seen when $\mathbf{g}=020$ and inside contrast when $\mathbf{g}=0-20$, Figure 26e and Figure $26 \mathrm{f}$ respectively.

Outside contrast occurs when (g.b) $\mathrm{s}_{\mathrm{g}}>0$, where $\mathrm{s}_{\mathrm{g}}$ is the deviation parameter and positive. For this to be true, the Burgers vector must be $+1 / 2[111]$. The electron beam is directed along [-100], and the Burgers vector therefore points against the direction of the beam which means it must be interstitial.

All loops investigated so far have been identified as interstitial. Analysis is still on-going, therefore it is too soon to be conclusive on the nature of loops in the alloys. The $<100>$ loops require more comprehensive analysis as the sense of inclination with respect to the beam must also be known in addition to the inside outside contrast. 


\subsubsection{Conclusions of electron microscopy analysis of dislocation loop behavior}

On-zone STEM imaging and traditional bright-field two beam imaging has allowed for comprehensive analysis of the dislocation loop density and morphology for the low dose $(<2$ dpa) irradiated Generation I and commercial FeCrAl alloys. Several distinct observations have been made including dose and composition effects as well as grain boundary effects.

Based on the presented analysis, the following conclusions can be made:

- Dislocation behavior in irradiated FeCrAl alloys can be characterized as having $a / 2\langle 111\rangle$ dislocation loops, $a\langle 100\rangle$ dislocation loops, black spot defects, and line dislocations. The size and number density are dependent on the irradiation condition, composition, and starting microstructure.

- Generally, $a\langle 100\rangle$ dislocation loops size increased with increasing dose while other defect sizes remained fairly unchanged at least in the low dose regime. Number densities of black dots decreased with increasing dose while in cold worked material, pre-existing line dislocation density decreased with increasing dose.

- Compositions effects based on Cr content were more pronounced below $1 \mathrm{dpa}$ than at higher doses.

- Increased defect sink density such as random high angle grain boundaries and line dislocations can affect the dislocation loop size and number.

- Initial results indicate that $a\langle 100\rangle$ dislocation loops are predominantly interstitial in nature.

\section{CONCLUSIONS}

A database of $\mathrm{FeCrAl}$ radiation tolerance has been built using an extensive series of irradiations within the HFIR at ORNL followed by advanced PIE on Generation I, Generation II, and commercial FeCrAl alloys. Both mechanical performance and microstructural analysis have been completed on these irradiated specimens. From this, it has been determined that irradiated microstructures include a combination of $\mathrm{Cr}$-rich $\alpha$, dislocation loops, black dot damage, and pre-existing line dislocation. The balance of number density and size of these defects is dependent on many factors, including irradiation temperature, irradiation dose, starting microstructure, and alloy composition. These changes in microstructure have been determined to be the overwhelming controlling factor on the mechanical response and hence the changes in mechanical properties after irradiation are also dependent on these factors. Of primary interest is that the database continues to point towards FeCrAl alloys with reduced $\mathrm{Cr}$ content $(<15$ wt. $\%$ $\mathrm{Cr}$ ) have the best performance within a radiation environment. Given this, the radiation response of the FeCrAl alloy class is inherently complex and further investigations are needed to develop a fully optimized alloy for accident tolerant fuel cladding applications. 


\section{REFERENCES}

[1] K.A. Terrani, S.J. Zinkle, L.L. Snead, Advanced oxidation-resistant iron-based alloys for LWR fuel cladding, J. Nucl. Mater. 448 (2013) 420-435. doi:10.1016/j.jnucmat.2013.06.041.

[2] S.J. Zinkle, K.A. Terrani, J.C. Gehin, L.J. Ott, L.L. Snead, Accident tolerant fuels for LWRs: A perspective, J. Nucl. Mater. 448 (2014) 374-379. doi:10.1016/j.jnucmat.2013.12.005.

[3] Y. Yamamoto, B.A. Pint, K.A. Terrani, K.G. Field, L.L. Snead, Development and property evaluation of nuclear grade wrought FeCrAl fuel cladding for light water reactors, Accept. - J. Nucl. Mater. (2015).

[4] B.A. Pint, K.A. Terrani, M.P. Brady, T. Cheng, J.R. Keiser, High temperature oxidation of fuel cladding candidate materials in steam-hydrogen environments, J. Nucl. Mater. 440 (2013) 420 427. doi:10.1016/j.jnucmat.2013.05.047.

[5] Y. Yamamoto, B.A. Pint, K.A. Terrani, K.G. Field, L.L. Snead, M3FT-13OR0202291:

Development of improved ATF engineering alloy - CALPHAD calculations and initial billet production, Oak Ridge National Laboratory, Oak Ridge, TN, 2013.

[6] Y. Yamamoto, M.N. Gussev, B.K. Kim, T.S. Byun, Optimized properties on base metal and thinwalled tube of Generation II ATF FeCrAl, Oak Ridge National Laboratory, 2015.

[7] Y. Yamamoto, Y. Yang, K.G. Field, K.A. Terrani, B.A. Pint, L.L. Snead, M3FT-14OR0202232: Letter Report Documenting Progress of Second Generation ATF FeCrAl Alloy Fabrication, Oak Ridge National Laboration, Oak Ridge, TN, 2014.

[8] K.G. Field, X. Hu, K. Littrell, Y. Yamamoto, R.H. Howard, L.L. Snead, Stability of Model Fe-CrAl Alloys Under The Presence of Neutron Radiation, Oak Ridge National Laboratory, Oak Ridge, TN, 2014.

[9] B.A. Pint, K.A. Terrani, Y. Yamamoto, L.L. Snead, Material Selection for Accident Tolerant Fuel Cladding, Accept. - Metall. Mateirals Trans. E. (2015).

[10] M. Snead, L.L. Snead, K.A. Terrani, K.G. Field, A. Worrall, K.R. Robb, et al., Technology Implementation Plan ATF FeCrAl Cladding for LWR Application, Oak Ridge National Laboratory, Oak Ridge, TN, 2014.

[11] K.G. Field, S.A. Briggs, P.D. Edmondson, X. Hu, K.C. Littrell, R.H. Howard, et al., Evaluation of the Effect of Composition on Radiation Hardening and Embrittlement in Model FeCrAl Alloys, Oak Ridge National Laboratory, Oak Ridge, TN, 2015.

[12] Y. Yamamoto, Y. Yang, K.G. Field, K.A. Terrani, B.A. Pint, L.L. Snead, Report on the development of 2nd generation ATF FeCrAl alloys, Oak Ridge National Laboratory, Oak Ridge, TN, 2014.

[13] K.G. Field, Y. Yamamoto, B.A. Pint, R.H. Howard, L.L. Snead, K.A. Terrani, Current Status of FeCrAl Alloys as an Accident Tolerant Cladding Alloy Class for Commercial Light Water Reactors, in: 2015: pp. 551-552.

[14] K.G. Field, R.H. Howard, Y. Yamamoto, Design of Experiment for Irradiation of Welded Candidate Fe-Cr-Al Alloys, ORNL/TM-2015/375. (2015).

[15] K.G. Field, R.H. Howard, Y. Yamamoto, Experimental Plan and Irradiation Target Design for FeCrAl Embrittlement Screening Tests Conducted Using the High Flux Isotope Reactor, Oak Ridge National Laboratory, n.d.

[16] Y. Yamamoto, K.G. Field, L.L. Snead, Optimization of Nuclear Grade FeCrAl Fuel Cladding for 
Light Water Reactors, Tech. Meet. Accid. Toelrant Fuel Concepts Light Water React. (2015).

[17] K.G. Field, X. Hu, K.C. Littrell, Y. Yamamoto, L.L. Snead, Radiation tolerance of neutronirradiated model Fe-Cr-Al alloys, J. Nucl. Mater. 465 (2015) 746-755. doi:10.1016/j.jnucmat.2015.06.023.

[18] P.D. Edmondson, S.A. Briggs, Y.Yamamoto, R.H. Howard, K. Sridharan, K.A. Terrani, et al., Irradiation-enhanced $\alpha^{\prime}$ precipitation in model FeCrAl alloys, Scr. Mater. 116 (2016) 112-116. doi:10.1016/j.scriptamat.2016.02.002.

[19] S. Kobayashi, T. Takasugi, Mapping of $475^{\circ} \mathrm{C}$ embrittlement in ferritic $\mathrm{Fe}-\mathrm{Cr}-\mathrm{Al}$ alloys, Scr. Mater. 63 (2010) 1104-1107. doi:10.1016/j.scriptamat.2010.08.015.

[20] Y. Yamamoto, K.A. Terrani, Optimized Gen-II FeCrAl cladding production in large quantity for campaign testing, 2016.

[21] K.G. Field, M.N. Gussev, Y. Yamamoto, L.L. Snead, Deformation behavior of laser welds in high temperature oxidation resistant $\mathrm{Fe}-\mathrm{Cr}-\mathrm{Al}$ alloys for fuel cladding applications, J. Nucl. Mater. 454 (2014) 352-358. doi:10.1016/j.jnucmat.2014.08.013.

[22] B.A. Pint, K.A. Unocic, K.A. Terrani, The effect of steam on the high temperature oxidation behavior of alumina-forming alloys, Mater. High Temp. 32 (2014) 28-35.

[23] C.P. Massey, K.A. Terrani, S.N. Dryepondt, B.A. Pint, Cladding burst behavior of Fe-based alloys under LOCA, J. Nucl. Mater. 470 (2016) 128-138. doi:10.1016/j.jnucmat.2015.12.018.

[24] K.A. Terrani, B.A. Pint, Y.-J. Kim, K.A. Unocic, Y. Yang, C.M. Silva, et al., Uniform corrosion of FeCrAl alloys in LWR coolant environments, J. Nucl. Mater. 479 (2016) 36-47. doi:10.1016/j.jnucmat.2016.06.047.

[25] S. Dryepondt, K.A. Unocic, D.T. Hoelzer, B.A. Pint, Oak Ridge National Laboratory Development of ODS FeCrAl Alloys For Accident-Tolerant Fuel Cladding, Oak Ridge, 2015. http://info.ornl.gov/sites/publications/files/Pub59171.pdf (accessed July 24, 2016).

[26] M. Gussev, R.H. Howard, C.R. Daily, K.A. Terrani, K.G. Field, Sub-size specimen design for inreactor irradiation and post-irradiation testing, Submitt. to Nucl. Eng. Des. (2016).

[27] T. Byun, J. Kim, S. Chi, J. Hong, Effect of Specimen Thickness on the Tensile Deformation Properties of SA508 Cl.3 Reactor Pressure Vessel Steel, in: Small Specim. Test Tech., ASTM International, 100 Barr Harbor Drive, PO Box C700, West Conshohocken, PA 19428-2959, 1998: pp. 575-575-13. doi:10.1520/STP38013S.

[28] A.A. Campbell, W.D. Porter, Y. Katoh, L.L. Snead, Method for Analyzing Passive SiC Thermometry with a Continuous Dilatometer to Determine Irradiation Temperature, Submitt. to J. Nucl. Mater. (2015).

[29] A. Hishinuma, A. Kohyama, R. Klueh, D. Gelles, W. Dietz, K. Ehrlich, Current status and future R\&D for reduced-activation ferritic/martensitic steels, J. Nucl. Mater. 258-263 (1998) 193-204.

[30] L.L. Snead, A.M. Williams, A.L. Qualls, Revisiting the use of SiC as a Post Irradiation Temperature Monitor, in: M. Grossbeck (Ed.), ASTM STP 1447, 2003.

[31] C.M. Parish, K.G. Field, A.G. Certain, J.P. Wharry, Application of STEM characterization for investigating radiation effects in BCC Fe-based alloys, J. Mater. Res. 30 (2015) 1246-1274.

[32] J.J. Hren, J.I. Goldstein, D.C. Joy, eds., Introduction to Analytical Electron Microscopy, Springer US, Boston, MA, 1979. doi:10.1007/978-1-4757-5581-7.

[33] M.D. Abramoff, P.J. Magalhães, S.J. Ram, Image processing with ImageJ, Biophotonics Int. 11 (2004) 36-42. http://dspace.library.uu.nl/handle/1874/204900 (accessed May 13, 2016). 
[34] C.A. Schneider, W.S. Rasband, K.W. Eliceiri, NIH Image to ImageJ: 25 years of image analysis, Nat. Methods. 9 (2012) 671-675. doi:10.1038/nmeth.2089.

[35] B. Yao, D.J. Edwards, R.J. Kurtz, TEM characterization of dislocation loops in irradiated bec Febased steels, J. Nucl. Mater. 434 (2013) 402-410. doi:10.1016/j.jnucmat.2012.12.002.

[36] J. Ribis, S. Lozano-Perez, Orientation relationships and interface structure of $\alpha$-Cr nanoclusters embedded in $\alpha$-Fe matrix after $\alpha$ - $\alpha$ ' demixing in neutron irradiated Oxide Dispersion Strengthened material, Mater. Lett. 74 (2012) 143-146. doi:10.1016/j.matlet.2012.01.115.

[37] S.J. Zinkle, Y. Matsukawa, Observation and analysis of defect cluster production and interactions with dislocations, J. Nucl. Mater. 329-333 (2004) 88-96. doi:10.1016/j.jnucmat.2004.04.298.

[38] N. Yoshida, M. Kiritani, F.E. Fujita, Electron radiation damage of iron in high voltage electron microscope, J. Phys. Soc. Japan. 39 (1975) 170-179.

[39] S. Kojima, S. Zinkle, Radiation hardening in neutron-irradiated polycrystalline copper: Barrier strength of defect clusters, J. Nucl. Mater. 179-181 (1991) 982-985.

[40] S.A. Briggs, P.D. Edmondson, Y. Yamamoto, C. Littrell, R.H. Howard, C.R. Daily, et al., A combined APT and SANS investigation of alpha prime phase precipitation in neutron-irradiated model FeCrAl alloys, Submitt. to Acta Mater. (2016).

[41] M. Bachhav, G. Robert Odette, E.A. Marquis, Microstructural changes in a neutron-irradiated Fe15at.\%Cr alloy, J. Nucl. Mater. 454 (2014) 381-386. doi:10.1016/j.jnucmat.2014.08.026.

[42] R. Prakash Kolli, D.N. Seidman, Comparison of Compositional and Morphological Atom-Probe Tomography Analyses for a Multicomponent Fe-Cu Steel, (n.d.). doi:10.1017/S1431927607070675.

[43] B. Gault, M.P. Moody, J.M. Cairney, S.P. Ringer, Atom Probe Microscopy, Springer, 2012.

[44] G.D. Wignall, K.C. Littrell, W.T. Heller, Y.B. Melnichenko, K.M. Bailey, G.W. Lynn, et al., The $40 \mathrm{~m}$ general purpose small-angle neutron scattering instrument at Oak Ridge National Laboratory, J. Appl. Crystallogr. 45 (2012) 990-998. doi:10.1107/s0021889812027057.

[45] J.-C. Brachet, X. Averty, P. Lamagnère, A. Alamo, F. Rozenblum, O. Raquet, et al., Behavior of Different Austenitic Stainless Steels, Conventional, Reduced Activation (RA) and ODS Chromium-Rich Ferritic-Martensitic Steels Under Neutron Irradiation at $325^{\circ} \mathrm{C}$ in PWR Environment, in: Eff. Radiat. Mater. 20th Int. Symp., ASTM International, 100 Barr Harbor Drive, PO Box C700, West Conshohocken, PA 19428-2959, 2001: pp. 500-500-21. doi:10.1520/STP10553S.

[46] C. Capdevila, M.K. Miller, G. Pimentel, J. Chao, Influence of recrystallization on phase separation kinetics of oxide dispersion strengthened Fe-Cr-Al alloy, Scr. Mater. 66 (2012) 254-257. doi:10.1016/j.scriptamat.2011.11.003.

[47] D. Vaumousse, A. Cerezo, P.J. Warren, A procedure for quantification of precipitate microstructures from three-dimensional atom probe data, Ultramicroscopy. 95 (2003) 215-221. doi:10.1016/S0304-3991(02)00319-4.

[48] E.A. Marquis, J.M. Hyde, Applications of atom-probe tomography to the characterisation of solute behaviours, Mater. Sci. Eng. R Reports. 69 (2010) 37-62. doi:10.1016/j.mser.2010.05.001.

[49] M. Bachhav, G.R. Odette, E.A. Marquis, $\alpha^{\prime}$ precipitation in neutron-irradiated Fe-Cr alloys, Scr. Mater. 74 (2014) 48-51. doi:10.1016/j.scriptamat.2013.10.001.

[50] K.G. Field, X. Hu, K.C. Littrell, Y. Yamamoto, L.L. Snead, Radiation tolerance of neutronirradiated model Fe-Cr-Al alloys, J. Nucl. Mater. 465 (2015) 746-755. 
doi:10.1016/j.jnucmat.2015.06.023.

[51] M.H. Mathon, Y. de Carlan, G. Geoffroy, X. Averty, A. Alamo, C.H. de Novion, A SANS investigation of the irradiation-enhanced $\alpha-\alpha^{\prime}$ phases separation in 7-12 $\mathrm{Cr}$ martensitic steels, J. Nucl. Mater. 312 (2003) 236-248. doi:10.1016/s0022-3115(02)01630-6.

[52] S. Messoloras, B.C. Pike, R.J. Stewart, C.G. Windsor, Precipitation in iron-chromium-aluminum alloys, Met. Sci. 18 (1984).

[53] A. Umantsev, G.B. Olson, Ostwald ripening in multicomponent alloys, Scr. Metall. Mater. 29 (1993) 1135-1140.

[54] I.M. Lifshitz, V.V. Slyozov, The kinetics of precipitation from supersaturated solid solutions, J. Phys. Chem. Solids1. 19 (1961) 35-50.

[55] C. Wagner, Theorie der alterung von niederschlägen durch umlösen, Zeitschrift Für Elektrochemie. 65 (1961) 581.

[56] J.M. Hyde, M.G. Burke, G.D.W. Smith, P. Styman, H. Swan, K. Wilford, Uncertainties and assumptions associated with APT and SANS characterisation of irradiation damage in RPV steels, J. Nucl. Mater. 449 (2014) 308-314. doi:10.1016/j.jnucmat.2013.07.029.

[57] Z. Yao, M. Hernández-Mayoral, M.L. Jenkins, M.A. Kirk, Heavy-ion irradiations of Fe and Fe-Cr model alloys Part 1: Damage evolution in thin-foils at lower doses, Philos. Mag. 88 (2008) 28512880. doi:10.1080/14786430802380469.

[58] N. Baluc, R. Schäublin, P. Spätig, M. Victoria, Hardening mechanisms in ferritic/martensitic steels, in: M. Grossbeck, T. Allen, R.G. Lott, A.S. Kumar (Eds.), Eff. Radiat. Mater. 21st Int. Symp., ASTM International, West Conshohocken, PA, 2004.

[59] K.G. Field, Y. Yang, T.R. Allen, J.T. Busby, Defect sink characteristics of specific grain boundary types in 304 stainless steels under high dose neutron environments, Acta Mater. 89 (2015) 438449. doi:10.1016/j.actamat.2015.01.064.

[60] R. Hu, G.D.W. Smith, E.A. Marquis, Effect of grain boundary orientation on radiation-induced segregation in a Fe-15.2at.\% Cr alloy, Acta Mater. (2013). doi:10.1016/j.actamat.2013.02.043.

[61] K.G. Field, L.M. Barnard, C.M. Parish, J.T. Busby, D. Morgan, T.R. Allen, Dependence on grain boundary structure of radiation induced segregation in a $9 \mathrm{wt} \% \mathrm{Cr}$ model ferritic/martensitic steel, J. Nucl. Mater. 435 (2013) 172-180. doi:10.1016/j.jnucmat.2012.12.026.

[62] T.S. Duh, J.J. Kai, F.R. Chen, L.H. Wang, Numerical simulation modeling on the effects of grain boundary misorientation on radiation-induced solute segregation in 304 austenitic stainless steels, J. Nucl. Mater. 294 (2001) 267-273.

[63] W.Z. Han, M.J. Demkowicz, E.G. Fu, Y.Q. Wang, A. Misra, Effect of grain boundary character on sink efficiency, Acta Mater. 60 (2012) 6341-6351. doi:10.1016/j.actamat.2012.08.009.

[64] T.S. Duh, J.J. Kai, F.R. Chen, Effects of grain boundary misorientation on solute segregation in thermally sensitized and proton-irradiated 304 stainless steel, J. Nucl. Mater. 283-287 (2000) 198204.

[65] B.N. Singh, S.J. Zinkle, Defect accumulation in pure fcc metals in the transient regime: a review, J. Nucl. Mater. 206 (1993) 212-229. doi:10.1016/0022-3115(93)90125-I.

[66] M.L. Jenkins, Kirk, Characterization of Radiation Damage by Transmission Electron Microscopy, Taylor \& Francis, 2000. 
APPENDIX A

\begin{tabular}{|c|c|c|c|c|c|c|c|c|c|}
\hline Alloy & Specimen ID(s) & $\begin{array}{c}\text { Rabbit } \\
\text { ID }\end{array}$ & $\begin{array}{l}\text { Dose } \\
\text { (dpa) }\end{array}$ & $\begin{array}{l}\mathbf{T}_{\text {irr }} \\
\left({ }^{\circ} \mathbf{C}\right)\end{array}$ & $\begin{array}{l}\mathbf{T}_{\text {test }} \\
\left({ }^{\circ} \mathbf{C}\right)\end{array}$ & YS (Mpa) & UTS (Mpa) & $\begin{array}{c}\mathbf{U E} \\
(\mathbf{m m} / \mathbf{m m})\end{array}$ & $\begin{array}{c}\text { TE } \\
(\mathbf{m m} / \mathbf{m m})\end{array}$ \\
\hline F1C5AY & 0531,0533 & N/A & 0 & 0 & 24 & $556 \pm 7.1$ & $574 \pm 5.7$ & $0.021 \pm 0.003$ & $0.137 \pm 0.013$ \\
\hline F1C5AY & 0532 & N/A & 0 & 0 & 320 & 462 & 486 & 0.009 & 0.102 \\
\hline F1C5AY & 0501 & FCAY02 & 0.8 & 355 & 24 & 587 & 620 & 0.033 & 0.129 \\
\hline F1C5AY & 0513,0515 & FCAY03 & 1.8 & 382 & 24 & $558 \pm 83.4$ & $605 \pm 52.3$ & $0.048 \pm 0.031$ & $0.141 \pm 0.045$ \\
\hline F1C5AY & 0514 & FCAY03 & 1.8 & 382 & 320 & 417 & 477 & 0.04 & 0.116 \\
\hline F1C5AY & 0520 & FCAY04 & 7 & 320 & 24 & 770 & 771 & 0 & 0.095 \\
\hline F1C5AY & 0521 & FCAY04 & 7 & 320 & 320 & 598 & 605 & 0.004 & 0.08 \\
\hline F1C5AY & 0525 & FCAY05 & 13.8 & 320 & 24 & 826 & 827 & 0 & 0.074 \\
\hline F1C5AY & 0526 & FCAY05 & 13.8 & 320 & 320 & 607 & 612 & 0.002 & 0.06 \\
\hline $\mathrm{B} 125 \mathrm{Y}$ & 2531 & $\mathrm{~N} / \mathrm{A}$ & 0 & 0 & 24 & 593 & 602 & 0.007 & 0.121 \\
\hline $\mathrm{B} 125 \mathrm{Y}$ & 2532 & N/A & 0 & 0 & 320 & 489 & 507 & 0.005 & 0.106 \\
\hline $\mathrm{B} 125 \mathrm{Y}$ & 2501 & FCAY01 & 0.3 & 334 & 24 & 676 & 696 & 0.031 & 0.111 \\
\hline $\mathrm{B} 125 \mathrm{Y}$ & 2513 & FCAY03 & 1.8 & 382 & 24 & 695 & 719 & 0.029 & 0.104 \\
\hline $\mathrm{B} 125 \mathrm{Y}$ & 2514 & FCAY03 & 1.8 & 382 & 320 & 475 & 530 & 0.039 & 0.118 \\
\hline $\mathrm{B} 125 \mathrm{Y}$ & 2520 & FCAY04 & 7 & 320 & 24 & 781 & 783 & 0 & 0.08 \\
\hline $\mathrm{B} 125 \mathrm{Y}$ & 2521 & FCAY04 & 7 & 320 & 320 & 607 & 609 & 0 & 0.093 \\
\hline $\mathrm{B} 125 \mathrm{Y}$ & 2525 & FCAY05 & 13.8 & 320 & 24 & 792 & 793 & 0 & 0.084 \\
\hline $\mathrm{B} 125 \mathrm{Y}$ & 2526 & FCAY05 & 13.8 & 320 & 320 & 603 & 604 & 0 & 0.095 \\
\hline B154Y-2 & 5431 & $\mathrm{~N} / \mathrm{A}$ & 0 & 0 & 24 & 592 & 615 & 0.007 & 0.107 \\
\hline B154Y-2 & 5432 & N/A & 0 & 0 & 320 & 490 & 504 & 0.006 & 0.087 \\
\hline B154Y-2 & 5401 & FCAY01 & 0.3 & 334 & 24 & 808 & 817 & 0.006 & 0.087 \\
\hline B154Y-2 & $\begin{array}{c}5413,5415 \\
5416\end{array}$ & FCAY03 & 1.8 & 382 & 24 & $743.7 \pm 51$ & $783.3 \pm 31.6$ & $0.043 \pm 0.014$ & $0.131 \pm 0.021$ \\
\hline
\end{tabular}




\begin{tabular}{|c|c|c|c|c|c|c|c|c|c|}
\hline B154Y -2 & 5414 & FCAY03 & 1.8 & 382 & 320 & 545 & 606 & 0.05 & 0.113 \\
\hline B154Y -2 & 5420 & FCAY04 & 7 & 320 & 24 & 841 & 843 & 0.002 & 0.075 \\
\hline B154Y -2 & 5421 & FCAY04 & 7 & 320 & 320 & 680 & 683 & 0 & 0.095 \\
\hline B154Y-2 & 5425 & FCAY05 & 13.8 & 320 & 24 & 831 & 832 & 0 & 0.068 \\
\hline B154Y-2 & 5426 & FCAY05 & 13.8 & 320 & 320 & 637 & 639 & 0 & 0.069 \\
\hline B183Y-2 & 8331,8333 & $\mathrm{~N} / \mathrm{A}$ & 0 & 0 & 24 & $530.5 \pm 0.7$ & $537.0 \pm 2.8$ & $0.008 \pm 0.002$ & $0.122 \pm .011$ \\
\hline B183Y-2 & 8332 & $\mathrm{~N} / \mathrm{A}$ & 0 & 0 & 320 & 373 & 374 & 0.002 & 0.097 \\
\hline B183Y-2 & 8301 & FCAY02 & 0.8 & 355 & 24 & 864 & 870 & 0.003 & 0.08 \\
\hline B183Y-2 & 8313 & FCAY03 & 1.8 & 382 & 24 & $688.3 \pm 136.4$ & $712.5 \pm 140$ & $0.029 \pm 0.021$ & $0.106 \pm 0.018$ \\
\hline B183Y-2 & 8316 & FCAY03 & 1.8 & 382 & 320 & 645 & 653 & 0.004 & 0.08 \\
\hline B183Y-2 & 8320 & FCAY04 & 7 & 320 & 24 & 855 & 857 & 0 & 0.083 \\
\hline B183Y-2 & 8323 & FCAY04 & 7 & 320 & 320 & 678 & 681 & 0 & 0.062 \\
\hline B183Y-2 & 8325 & FCAY05 & 13.8 & 320 & 24 & 666 & 666 & 0 & 0 \\
\hline B183Y-2 & 8326 & FCAY05 & 13.8 & 320 & 320 & 669 & 673 & 0 & 0.089 \\
\hline K720 & K731 & $\mathrm{N} / \mathrm{A}$ & 0 & 0 & 24 & 415 & 557 & 0.191 & 0.351 \\
\hline K720 & K701 & FCAY02 & 0.8 & 355 & 24 & 844 & 895 & 0.068 & 0.164 \\
\hline K720 & K713 & FCAY03 & 1.8 & 382 & 24 & 777 & 847 & 0.064 & 0.159 \\
\hline K720 & K720 & FCAY04 & 7 & 320 & 24 & 1035 & 1035 & 0 & 0.069 \\
\hline K720 & K725 & FCAY05 & 13.8 & 320 & 24 & 1006 & 1006 & 0 & 0.001 \\
\hline APMT & AP31, AP33 & $\mathrm{N} / \mathrm{A}$ & 0 & 0 & 24 & $504 \pm 12.7$ & $575.5 \pm 14.9$ & $0.022 \pm 0.007$ & $0.0225 \pm 0.008$ \\
\hline APMT & AP34 & N/A & 0 & 0 & 320 & 362 & 653 & 0.19 & 0.265 \\
\hline APMT & AP01 & FCAY01 & 0.3 & 334 & 24 & $785^{*}$ & $785^{*}$ & 0 & 0 \\
\hline APMT & AP13 & FCAY03 & 1.8 & 382 & 24 & 816 & 825 & 0.004 & 0.004 \\
\hline APMT & AP14 & FCAY03 & 1.8 & 382 & 320 & 614 & 762 & 0.101 & 0.171 \\
\hline APMT & AP20, AP23 & FCAY04 & 7 & 320 & 24 & $\begin{array}{c}666.0 \pm 116.0 \\
*\end{array}$ & $\begin{array}{c}666.0 \pm 116.0 \\
*\end{array}$ & 0 & 0 \\
\hline APMT & AP21 & FCAY04 & 7 & 320 & 320 & 926 & 964 & 0.035 & 0.085 \\
\hline
\end{tabular}




\begin{tabular}{|c|c|c|c|c|c|c|c|c|c|}
\hline APMT & AP25, AP28 & FCAY05 & 13.8 & 320 & 24 & $\begin{array}{c}470.0 \pm 101.8 \\
*\end{array}$ & $\begin{array}{c}470.0 \pm 101.8 \\
*\end{array}$ & 0 & 0 \\
\hline APMT & AP26 & FCAY05 & 13.8 & 320 & 320 & 834 & 898 & 0.056 & 0.102 \\
\hline $\mathrm{C06M}$ & ZM01 & FCAT01 & 1.9 & 200 & 24 & 1194 & 1196 & 0 & 0.017 \\
\hline $\mathrm{C} 06 \mathrm{M}$ & ZM04 & FCAT02 & 1.8 & 330 & 24 & 938 & 964 & 0.021 & 0.076 \\
\hline $\mathrm{C} 06 \mathrm{M}$ & ZM07 & FCAT03 & 1.9 & 550 & 24 & 471 & 602 & 0.117 & 0.21 \\
\hline $\mathrm{C} 35 \mathrm{M}$ & MF01 & FCAT01 & 1.9 & 200 & 24 & 1316 & 1316 & 0 & 0.026 \\
\hline $\mathrm{C} 35 \mathrm{M}$ & MF04 & FCAT02 & 1.8 & 330 & 24 & 903 & 944 & 0.042 & 0.115 \\
\hline $\mathrm{C} 35 \mathrm{M}$ & MF07 & FCAT03 & 1.9 & 550 & 24 & 585 & 725 & 0.126 & 0.204 \\
\hline $\mathrm{C} 35 \mathrm{MN}$ & N501 & FCAT01 & 1.9 & 200 & 24 & 1276 & 1282 & 0.003 & 0.045 \\
\hline $\mathrm{C} 35 \mathrm{MN}$ & N503 & FCAT02 & 1.8 & 330 & 24 & 982 & 1059 & 0.035 & 0.079 \\
\hline $\mathrm{C} 35 \mathrm{MN}$ & N505 & FCAT03 & 1.9 & 550 & 24 & 722 & 821 & 0.099 & 0.154 \\
\hline C36M & MV01-6 & FCAT01 & 1.9 & 200 & 24 & 1167 & 1167 & 0 & 0.026 \\
\hline $\mathrm{C} 36 \mathrm{M}$ & MV04-6 & FCAT02 & 1.8 & 330 & 24 & 997 & 1003 & 0.005 & 0.063 \\
\hline $\mathrm{C} 36 \mathrm{M}$ & MV07-6 & FCAT03 & 1.9 & 550 & 24 & 574 & 689 & 0.11 & 0.201 \\
\hline $\mathrm{C} 37 \mathrm{M}$ & MV01 & FCAT01 & 1.9 & 200 & 24 & 1083 & 1089 & 0.004 & 0.061 \\
\hline $\mathrm{C} 37 \mathrm{M}$ & MV04 & FCAT02 & 1.8 & 330 & 24 & 949 & 983 & 0.019 & 0.096 \\
\hline $\mathrm{C} 37 \mathrm{M}$ & MV07 & FCAT03 & 1.9 & 550 & 24 & 553 & 711 & 0.134 & 0.24 \\
\hline $\begin{array}{c}125 \mathrm{YF}- \\
\mathrm{ODS}\end{array}$ & OD01 & FCAT01 & 1.9 & 200 & 24 & 1108 & 1130 & 0.008 & 0.05 \\
\hline $\begin{array}{c}125 \mathrm{YF}- \\
\mathrm{ODS}\end{array}$ & OD03 & FCAT02 & 1.8 & 330 & 24 & 1037 & 1074 & 0.05 & 0.097 \\
\hline $\begin{array}{c}125 \mathrm{YF}- \\
\mathrm{ODS}\end{array}$ & OD06 & FCAT03 & 1.9 & 550 & 24 & 1104 & 1160 & 0.062 & 0.114 \\
\hline
\end{tabular}

*Indicates fracture stress

YS: Yield Strength, UTS: Ultimate Tensile Strength, UE: Uniform Elongation, TE: Total Elongation 